Alexandre Morais de Souza

\title{
Critérios de Seleção de Sistemas de Gerenciamento de Banco de Dados Não Relacionais em Organizações Privadas
}

\author{
Dissertação apresentada como parte dos \\ requisitos para obtenção do título de Mestre \\ em Ciências pelo programa de Pós-graduação \\ em Sistemas de Informação EACH - Escola de \\ Artes, Ciências e Humanidades.
}

Orientador: Prof. Dr. Edmir Parada Vasques Prado

São Paulo

Novembro de 2013 
Autorizo a reprodução e divulgação total ou parcial deste trabalho, por qualquer meio convencional ou eletrônico, para fins de estudo e pesquisa, desde que citada à fonte.

\section{CATALOGAÇÃO-NA-PUBLICAÇÃO \\ Biblioteca}

Escola de Artes, Ciências e Humanidades da Universidade de São Paulo

Souza, Alexandre Morais de

Critérios de seleção de sistemas de gerenciamento de banco de dados não relacionais em organizações privadas / Alexandre

Morais de Souza ; orientador Edmir Parada Vasques Prado - São

Paulo, 2013.

$137 \mathrm{f}$.

Dissertação (Mestrado em Ciências) - Programa de Pós-

Graduação em Sistemas de Informação, Escola de Artes, Ciências

e Humanidades, Universidade de São Paulo, em 2013.

Versão corrigida.

1. Banco de dados. 2. Banco de dados - Administração. 3.

Gerenciadores de banco de dados. 4. Empresas privadas. I.

Prado, Edmir Parada Vasques, orient. II. Título. 
Dissertação de mestrado sob o título "Critérios de Seleção de Sistemas de Gerenciamento de Banco de Dados Não Relacionais em Organizações Privadas", defendido por Alexandre Morais de Souza em São Paulo, Estado de São Paulo, pela banca examinadora constituída pelos doutores:

Prof. Dr. Edmir Parada Vasques Prado Orientador

Prof. Dr. Luciano Vieira Araújo Universidade de São Paulo

Prof. Dr. César Alexandre de Souza Universidade de São Paulo 


\section{Dedicatória}

Para Deus, Vanda, José, cuja ajuda e apoio foram decisivos na realização deste trabalho. 


\section{Agradecimentos}

Meus agradecimentos sinceros ao meu orientador Prof. Dr. Edmir Parada Vasques Prado, pela paciência e conhecimento passado durante a realização deste trabalho, pelo incentivo, pelas sugestões decisivas e ajuda indispensáveis para a conclusão do trabalho e principalmente para meu crescimento pessoal e profissional. Agradeço muito pela dedicação, por ter investido no meu potencial e incentivado a trilhar caminho na vida acadêmica e ter acreditado nesta pesquisa.

Ao Prof. Dr. Luciano Araújo e Prof. Dr. João Porto pelas valiosas recomendações quando da participação na banca do exame de qualificação, que contribuíram de forma decisiva para o direcionamento correto do trabalho e grande melhoria na qualidade da pesquisa.

Meus agradecimentos, ainda, aos demais professores das disciplinas que cursei ao longo do Programa de Mestrado, cujos ensinamentos em muito contribuíram para que esta etapa da minha vida acadêmica fosse concluída.

Aos meus colegas do curso de PPgSI, em especial ao Neílson Ramalho, que me ajudou com conselhos e recomendações que foram de valia para pesquisa e apoio e ajuda do Ricardo Wandré, que fez parte dos trabalhos de disciplina em que participei e se mostrou um excelente parceiro neste sentido.

Agradecimentos sinceros a todos que responderam ao extenso Painel de especialistas Delphi, que sem sua paciência e boa vontade em participar da pesquisa não seria possível concluir este trabalho com um resultado satisfatório. Aos executivos, gestores e Demais Profissionais de TI, que por compromisso, devo manter em anonimato.

A todos os funcionários da EACH e à Universidade de São Paulo.

Aos meus pais, especialmente à minha mãe, por sempre me ensinar que o caminho da educação e do conhecimento é a forma mais acertada de se atingir a dignidade plena de um homem e de poder ir mais longe.

O meu sincero e carinhoso agradecimento à minha noiva Mariana, pela compreensão, apoio, paciência e por ter suportado bem minha ausência e pouca atenção enquanto estive envolvido com este estudo. 
SOUZA, A. M. Critérios de seleção de sistemas de gerenciamento de banco de dados não relacionais em organizações privadas. 2003. 137 f. Dissertação (Mestrado) - Escola de Artes, Ciências e Humanidades, Universidade de São Paulo, São Paulo, 2013.

\section{Resumo}

Sistemas de Gerenciamento de Banco de Dados Não Relacionais (SGBDs NoSQL) são pacotes de software para gerenciamento de dados utilizando um modelo não relacional. Dado o atual contexto de crescimento no volume de dados e a necessidade que as organizações possuem em coletar grande quantidade de informações de clientes, pesquisas científicas, vendas e outras informações para análises futuras, é importante repensar a forma de se escolher um SGBD adequado levando em consideração fatores econômicos, técnicos e estratégicos da organização. Esta é uma pesquisa relacionada com o estudo do novo conceito de gerenciamento de banco de dados, conhecido como NoSQL e traz como contribuição apresentar critérios de seleção para auxiliar consumidores de serviços de banco de dados, em organizações privadas, a selecionar um SGBD NoSQL. Para atender a este objetivo foi realizada revisão da literatura com levantamento bibliográfico sobre processo de seleção de software e de SGBDs, levantando critérios utilizados para este fim. Feito o levantamento bibliográfico, definiu-se o método de pesquisa como sendo a aplicação de um Painel Delphi, na modalidade ranking form. Por meio do painel foi possível determinar, após a realização de duas rodadas e participando um grupo de especialistas misto formado por gerentes, fornecedores de SGBD, acadêmicos, desenvolvedores e DBAs e DAs, os critérios mais relevantes para a escolha de um SGBD NoSQL, ordenados conforme pontuação obtida para cada critério. Os dados foram coletados por meio de questionário. A partir dos critérios identificados, foram feitas análises sobre os principais critérios de seleção de SGBDs NoSQL. Posteriormente, as conclusões e considerações finais contemplaram a análise dos resultados obtidos com o Painel Delphi. Como principal resultado alcançado, este estudo oferece uma visão realística acerca do modelo não relacional para gerenciamento de dados e apresenta os critérios mais importantes que indicam plausível a adoção de SGBDs NoSQL.

Palavras-chave: SGBDs NoSQL. Tecnologia da Informação. Técnica Delphi. Banco de Dados. Big Data. 
SOUZA, A. M. Selection criteria of non-relational database management systems data in private organizations. 2003. 137 f. Dissertação (Mestrado) - Escola de Artes, Ciências e Humanidades, Universidade de São Paulo, São Paulo, 2013.

\section{Abstract}

Database Management Systems Not Relational (NoSQL DBMSs) are software packages for data management using a non-relational model. Given the current context of growth in data generation and the need that organizations have to collect vast amount of customer information, scientific research, sales and other information for further analysis, it is important to rethink how to define a suitable DBMS considering economic, technical and strategic organization. This research is concerned with the study of the new management model database, known as NoSQL, and brings the present contribution selection criteria to assist service consumers Database, private organizations, to select a NoSQL DBMS. To satisfy this objective was reviewed the literature with bibliographic on software selection process and DBMSs, identifying criteria used for this purpose. After completion of the literature, was defined the search method with application of a Delphi panel, by the ranking form mode. Through the panel could be determined, after the completion of two rounds and attending a mixed group of experts formed by managers, DBMS vendors, academics, developers, DBAs and DAs, the most relevant criteria for choosing a NoSQL DBMS, ordered according score for each criteria. Data were collected through a survey. From the identified criteria, analyzes were made on the main selection criteria of NoSQL DBMSs. Subsequently, the conclusions and final considerations were made with analysis of the results obtained with the Delphi panel. The main result achieved, this study offers a realistic view about the nonrelational model for managing data and presents the most important criteria that indicate plausible the adoption of NoSQL DBMSs.

Keywords: NoSQL DBMSs. Information Technology. Delphi Technique. Database. Big Data. 


\section{Sumário}

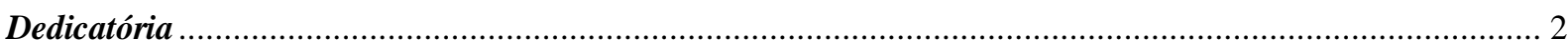

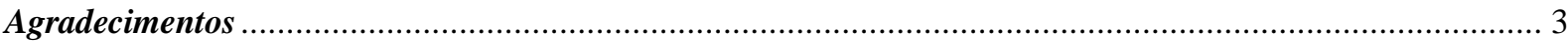

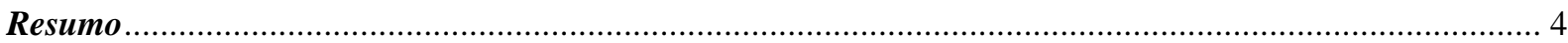

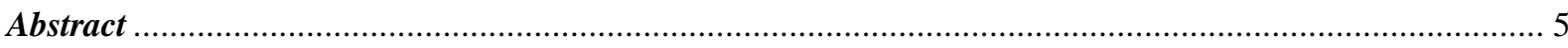

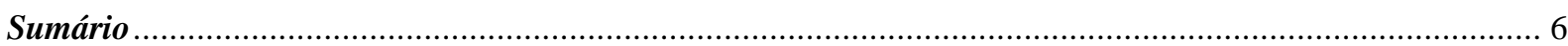

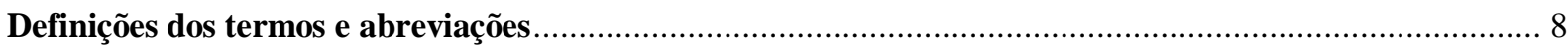

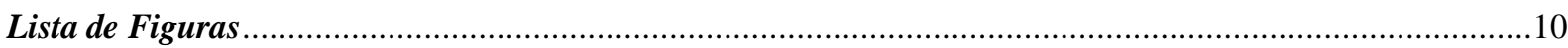



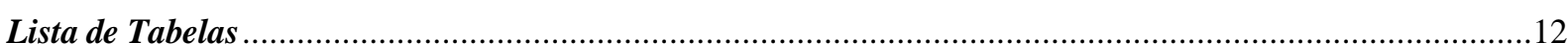

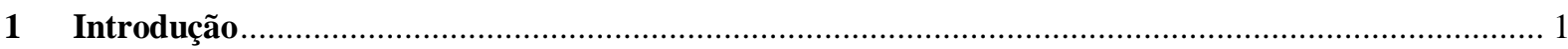

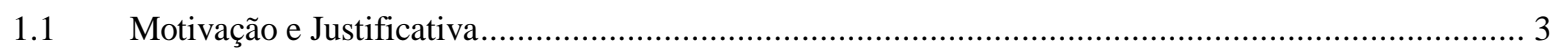

Formulação da Situação-Problema ................................................................................. 4

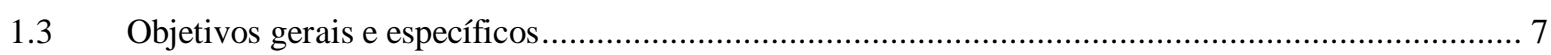

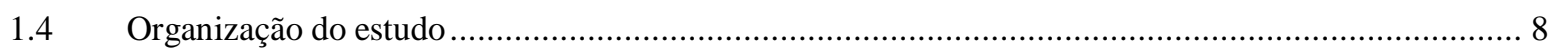



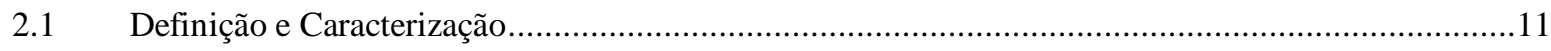

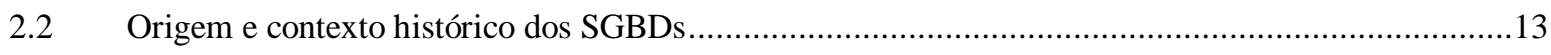

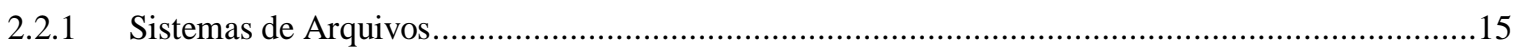

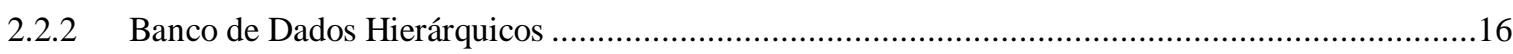

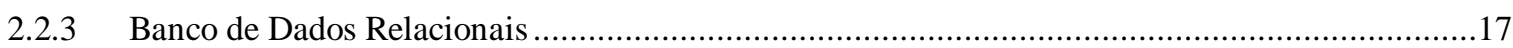

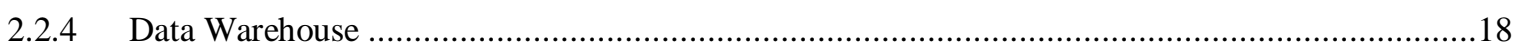

2.2.5. Diferenças entre Data Warehouse e NoSQL .......................................................................21

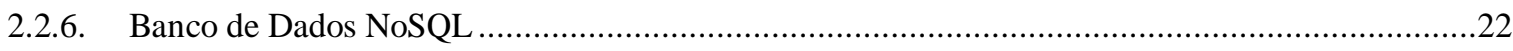

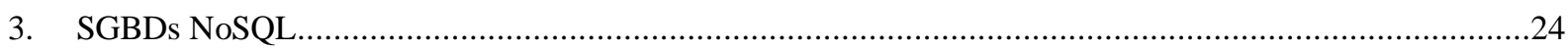

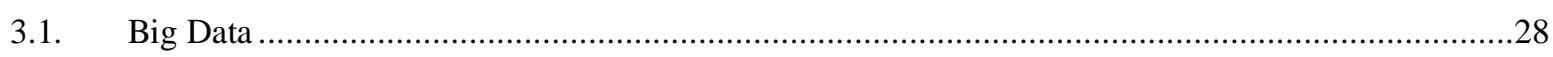

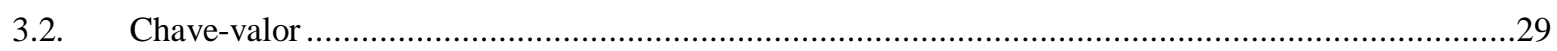

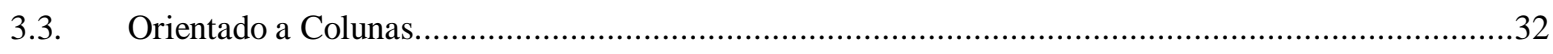

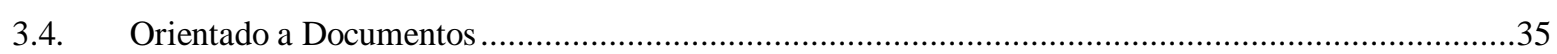

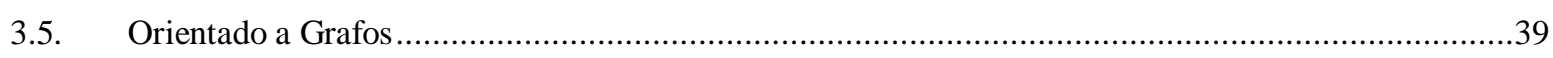

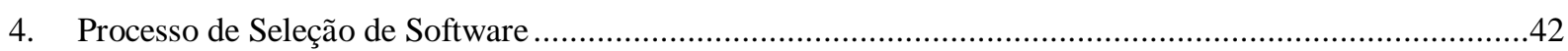

4.1. Análise geral das normas de qualidade e avaliação de software .................................................42

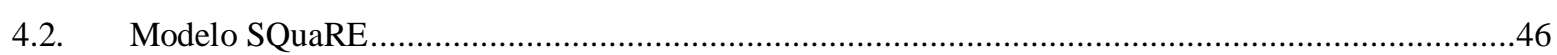

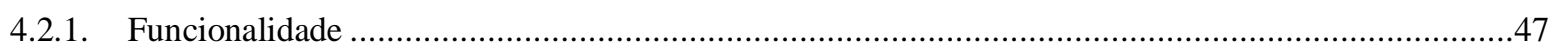

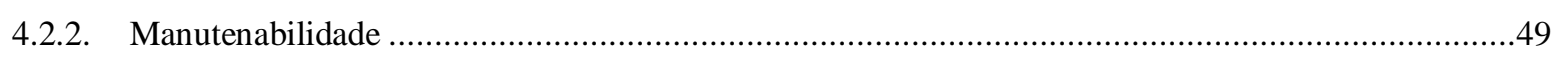

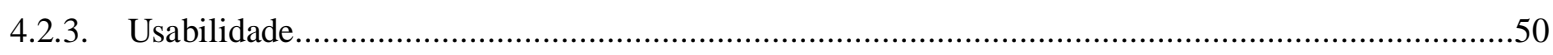

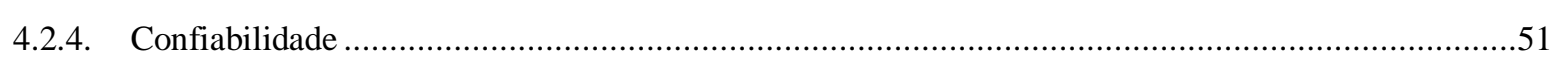

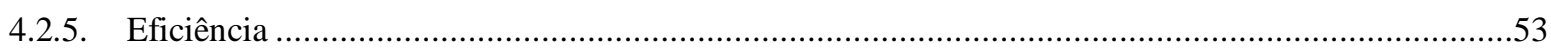

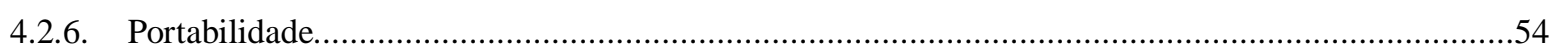




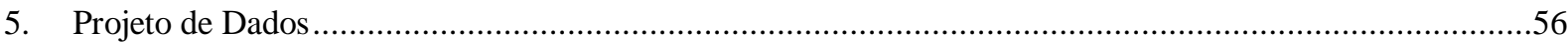

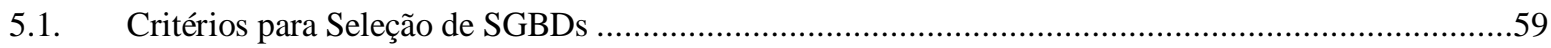

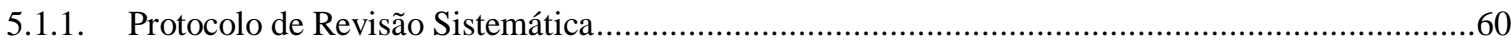

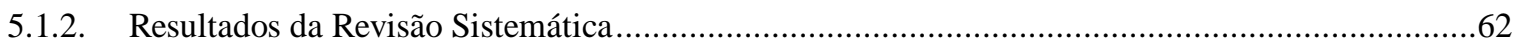

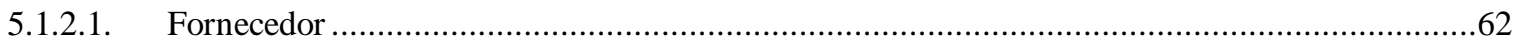

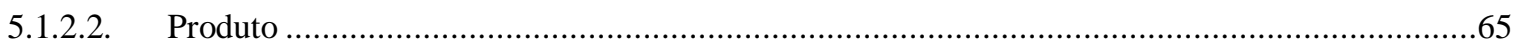

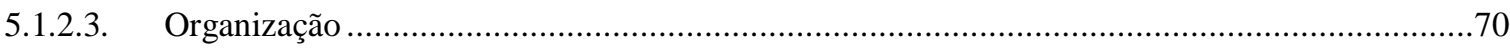

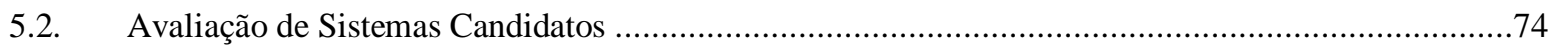

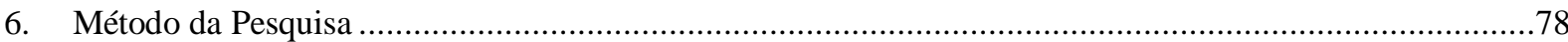

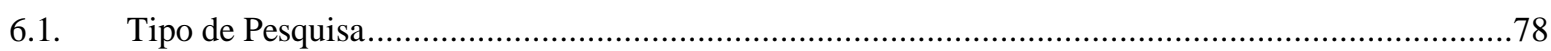

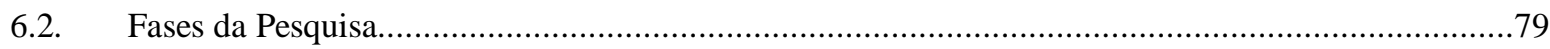

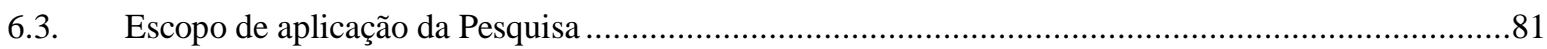

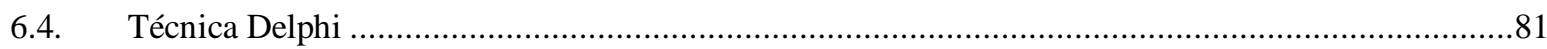

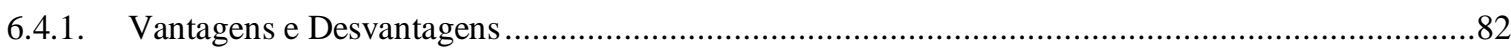

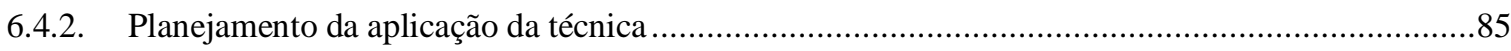

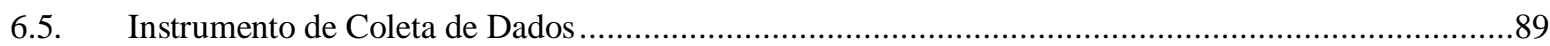

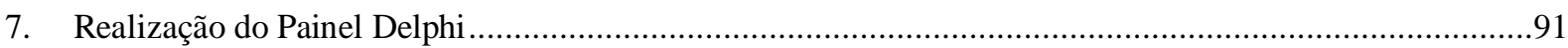

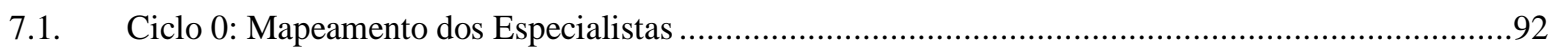

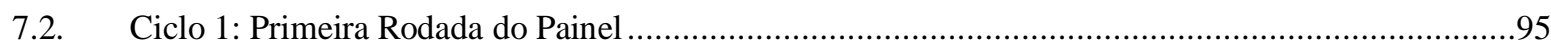

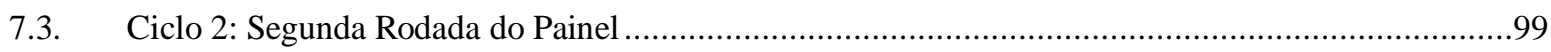

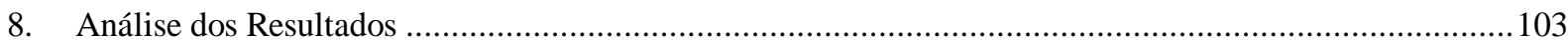

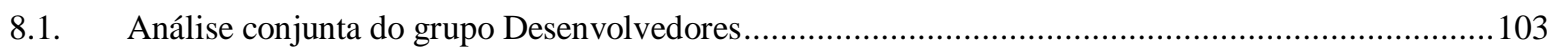

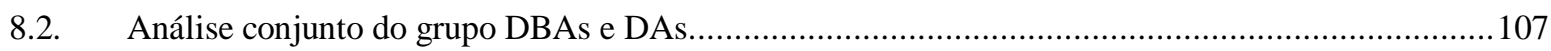

8.3. Análise conjunta do grupo Demais Profissionais de TI........................................................109

8.4. Comparação dos resultados entre os grupos de especialistas e tipos de critérios............................112

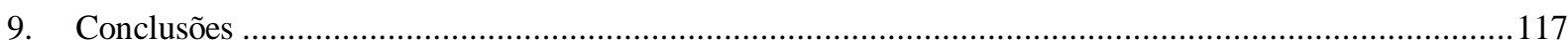

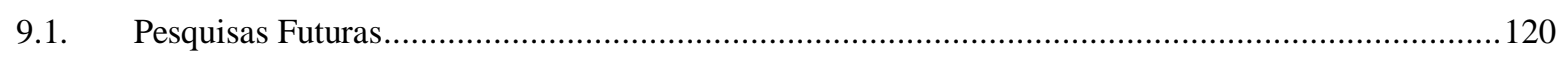

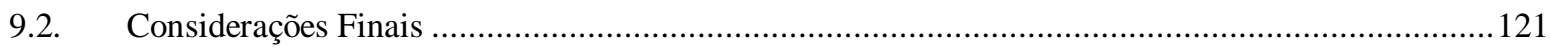

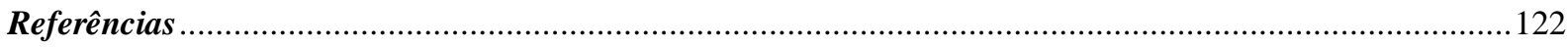

APÊNDICE

APÊNDICE A

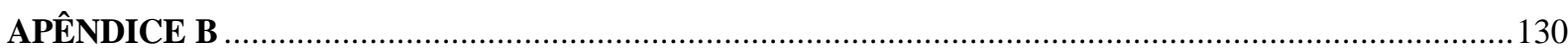

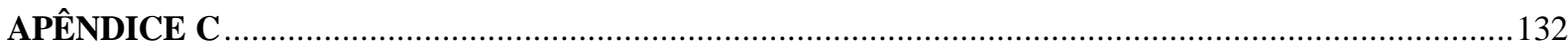

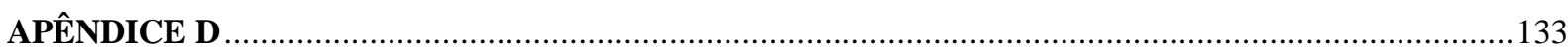

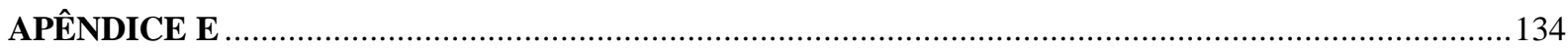

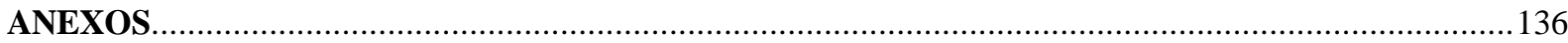

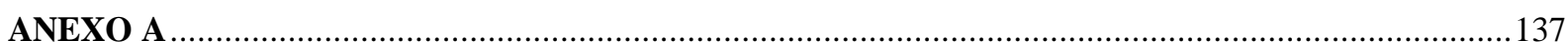




\section{Definições dos termos e abreviações}

$\mathrm{Na}$ área de sistemas de informação utilizam-se muitos termos que não fazem parte do jargão de outras disciplinas e normalmente podem ser ambíguos. Por este fato, segue abaixo a lista de abreviações e termos utilizados neste trabalho para melhor entendimento:

NOSQL - Not Only SQL (Não apenas relacional).

SGBD - Sistemas de Gerenciamento de Banco de Dados.

SGBDR - Sistemas de Gerenciamento de Banco de Dados Relacional.

ACID - Sigla utilizada em banco de dados definida que resumem as principais características de um SGBDR tradicional.

Backup - Mecanismo de recuperação de dados, especialmente em SGBDs.

CPU - sigla de central processing unit. Unidade Central de Processamento: grupo de circuitos que executam as funções básicas de um computador composto de três partes: a unidade de controle, a unidade lógica e aritmética e a unidade de entrada/saída. Termo utilizado nesta pesquisa para relacionar desempenho com os SGBDs.

DA - Data Administrator, em português Administrador de Dados, profissional especializado para analisar a modelagem de dados do sistema e implementar suas regras e como os dados são armazenados no SGBD.

Data Centers - também chamado de CPD (Centro de Processamento de Dados), é o local onde são concentrados os computadores e sistemas confiáveis (software) responsáveis pelo processamento de dados de uma empresa ou organização.

$\boldsymbol{D B A}$ - Database Administrator, ou Administrador de Banco de Dados, é profissional responsável pelo bom funcionamento do banco de dados, definição do esquema, execuções no SGBD, concessão e autorização de acesso aos dados, melhoria de desempenho, estratégia de backup etc.

Cache - Na área da computação, cache é um dispositivo de acesso rápido, interno a um sistema, que serve de intermediário entre um operador de um processo e o dispositivo de armazenamento ao qual esse operador acessa.

Buffer - Em ciência da computação, buffer (retentor) é uma região de memória temporária utilizada para escrita e leitura de dados. Os dados podem ser originados de dispositivos (ou processos) externos ou internos ao sistema. Os buffers podem ser implementados em software (mais usado) ou hardware. 
Clustering - Processo de sistema de computação distribuído, geralmente dentro de organizações, que utiliza a capacidade de máquinas ociosas para processar grandes quantidades de informação.

SQL - Structured Consulta Language, também pode ser definido como Linguagem de Consulta Estruturada ou SQL, é uma linguagem de pesquisa declarativa para banco de dados relacional.

Open Source - Código aberto, distribuição livre. A licença não deve restringir de nenhuma maneira a venda ou distribuição do programa gratuitamente, como componente de outro programa ou não, incluindo o código fonte do programa.

XML - (Extensible Markup Language) é uma linguagem que permite a construção de documentos legíveis para seres humanos e que podem ser facilmente tratados por máquinas, ou seja, a XML possui um conjunto de marcadores que é mais expressivo e flexível do que a HTML, uma vez que estes marcadores podem ser definidos de acordo com as necessidades do usuário.

Map/reduce - é um modelo de programação para processamento de grandes volumes de dados, projetado pelo Google@ . O map/reduce é tipicamente utilizado em computação distribuída em computadores em cluster. 


\section{Lista de Figuras}

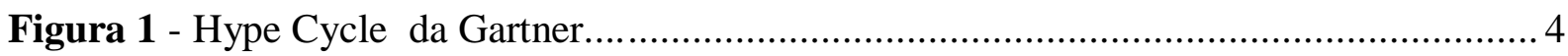

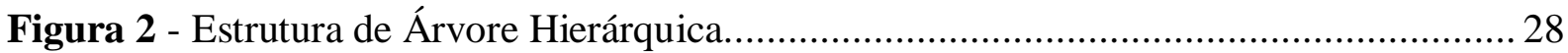

Figura 3 - Banco de Dados NoSQL - Uma abordagem com Chave-Valor ........................ 42

Figura 4 - Modelo Família de Coluna........................................................................... 45

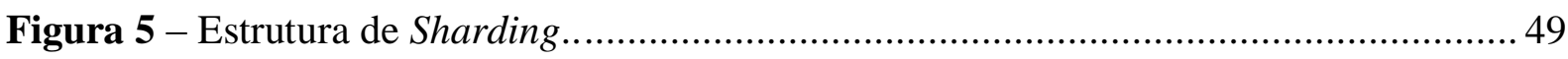

Figura 6 - NoSQL - Banco de Dados em Grafos.. ........................................................ 52

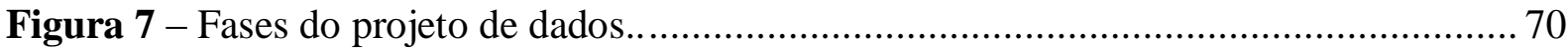

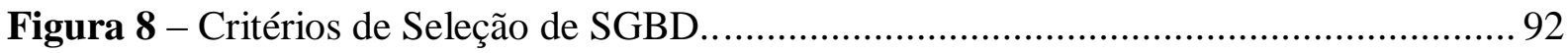

Figura 9 - Fluxo de um questionário Delphi........................................................ 97

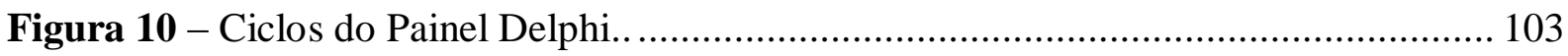




\section{Lista de Quadros}

Quadro 1 - Dados no Data Warehouse e Dados Operacionais............................................ 33

Quadro 2 - Vantagens e Desvantagens do uso de SGBDs NoSQL..................................... 39

Quadro 3 - Comparativo modelo relacional X orientado a colunas.................................. 45

Quadro 4 - Comparativo modelo relacional X orientado a documentos.. ........................... 48

Quadro 5 - Condução das buscas da Revisão Sistemática............................................... 72

Quadro 6 - Lista de artigos utilizados por meio de levantamento da revisão sistemática. ..... 73

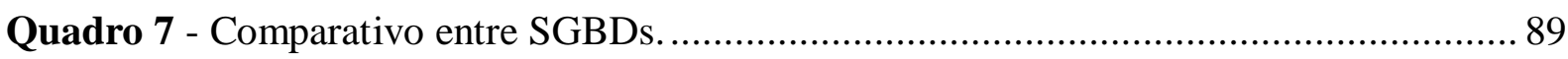

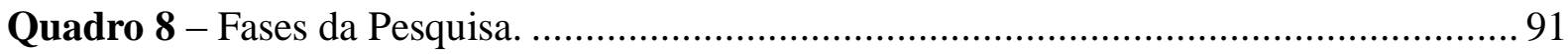

Quadro 9 - Significado para o grau de concordância W................................................... 100

Quadro 10 - Significância Estatística Conforme valor de p........................................... 101

Quadro 11 - Comparativo Ranking Critérios de Seleção SGBD NoSQL........................... 125 


\section{Lista de Tabelas}

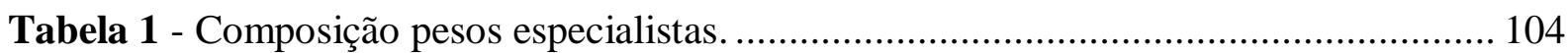

Tabela 2 - Características do Grupo de Painelistas.................................................... 107

Tabela 3 - Classificação das respostas dos especialistas $-1^{\text {a }}$ Rodada............................. 109

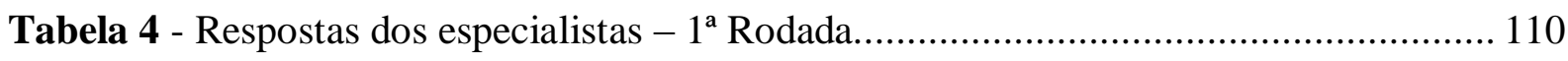

Tabela 5 - Classificação das respostas dos especialistas - 2a Rodada.. ............................. 111

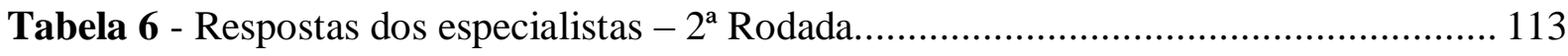

Tabela 7 - Respostas dos especialistas na $2^{\mathrm{a}}$ Rodada - Desenvolvedores. ........................... 116

Tabela 8 - Respostas dos especialistas na 2a Rodada - DBAs e DAs.................................. 119

Tabela 9 - Respostas dos especialistas na $2^{\text {a }}$ Rodada- Demais Profissionais de TI............ 122 


\section{Introdução}

Atualmente a maioria das organizações coleta grande quantidade de dados de clientes, pesquisas científicas, vendas e outras informações para análises futuras. Tradicionalmente, a maior parte dessas organizações tem armazenado seus dados de forma estruturada em bases de dados relacionais para posterior acesso e análise.

O grande volume de dados gerado por aplicações $W e b$, juntamente com os requisitos diferenciados como a escalabilidade e o elevado grau de disponibilidade tem contribuído para o surgimento de novos modelos e tecnologias com relação aos SGBDs que as suportam. As redes sociais, por exemplo, requerem o gerenciamento de grandes quantidades de dados não estruturados que são gerados diariamente por milhões de usuários em busca de compartilhamento de informações, conhecimentos e interesses. Além disso, em conjunto com a crescente demanda por informação, têm-se também os dispositivos móveis que permitem às pessoas gerarem informações em qualquer lugar e em qualquer momento, demandando assim maior poder de processamento e armazenamento às aplicações Web atuais.

Neste ambiente de crescente demanda por volume de dados e desempenho, surge um novo conceito de SGBD, chamado NoSQL (Not Only $S Q L$ ), ou seja, não apenas SQL (Linguagem de Consulta Estruturada). Este novo conceito foi proposto com o objetivo de atender aos requisitos de gerenciamento de grandes volumes de dados semiestruturados ou não estruturados, que necessitam de alta disponibilidade e escalabilidade (LÓSCIO et al., 2011). A necessidade de um novo conceito em banco de dados surgiu como consequência da ineficiência, em determinados casos, dos SGBDRs em lidar com o atual volume de informações das aplicações Web. Os SGBDRs foram propostos na década de 70, quando as aplicações lidavam com dados estruturados, ou seja, dados que possuem uma estrutura fixa e bem definida. Além disso, o volume de dados gerado por aplicações Web, como as redes sociais, traz a necessidade de repensar sobre os SGBDs.

Surgem então diferentes tipos de SGBDs NoSQL, com diferentes abordagens, mas possuindo a semelhança de serem não relacionais. Os SGBD NoSQL possuem esta denominação pois armazenam os dados de forma não estruturada e não exigem esquemas fixos como os SGBD relacionais, onde em muitos casos não oferecem apoio a operações de junção como no modelo relacional (LEAVITT, 2010).

NoSQL é, literalmente, uma combinação de duas palavras: "Não" e "SQL". Para Tiwari (2011) a implicação é que NoSQL não é uma tecnologia ou produto sobre SQL. Os 
criadores e pioneiros do termo NoSQL provavelmente quiseram dizer "Não SGBDR" ou "Não Relacional", mas foram tomados pela sonoridade do termo "NoSQL" e ficaram presos a ele. No devido tempo, alguns propuseram "NonRel" como uma alternativa ao NoSQL. Alguns outros tentaram salvar o termo original, propondo que NoSQL é realmente uma sigla que se expande para "não só SQL." Qualquer que seja o significado literal, NoSQL é usado hoje como um termo para todos os bancos de dados e armazenamento de dados que não seguem os princípios dos estabelecidos SGBDRs e muitas vezes se relacionam com grandes conjuntos de dados acessados e manipulados em escala Web. O significado de NoSQL não está relacionado a um único produto ou até mesmo a uma única tecnologia. Representa uma classe de produtos e uma coleção de diversos conceitos sobre dados, armazenamento e manipulação (TIWARI, 2011).

A grande contribuição que os SGBDs NoSQL vêm trazer é garantir escalabilidade para as aplicações e desempenho no acesso a dados, o que não se consegue em todas as situações com banco de dados relacionais. Segundo Vijaykumar (2010), os SGBDs NoSQL foram criados como meio de oferecer alto desempenho e alta disponibilidade, no entanto com o preço de perder as propriedades ACID (Atomic, Consistence, Isolated, Durable), que no português quer dizer atomicidade, consistência, isolamento e durabilidade. Os SGBDs NoSQL normalmente processam mais rápido que os relacionais em determinados contextos. Todavia não são adequados para aplicações que exigem precisão e consistência, como por exemplos sistemas bancários ou altamente transacionais. No entanto, quando a aplicação necessita de alto desempenho, muitos desenvolvedores optam por SGBDs NoSQL e o problema de precisão e consistência passa a ficar a cargo da aplicação (LEAVITT, 2010).

Os desafios dos SGBDRs quanto ao processamento de dados em escala Web não são especificamente para um produto, mas dizem respeito a toda a classe de bancos de dados. Os SGBDRs assumem uma estrutura de dados bem definida, onde os dados são densos e uniformes. Basicamente para esta família de SGBDs há o pré-requisito de que as propriedades dos dados podem ser bem definidas e que as suas inter-relações estão estabelecidas e sistematicamente referenciadas, de forma que é possível definir índices que podem ser consistentemente definidos em conjuntos de dados e que tais índices podem ser aproveitados para uma consulta mais rápida. Com massivos volumes de dados, a definição de típicos mecanismos de armazenamento e métodos de acesso também se estendeu. Desnormalizar tabelas, retirar restrições e relaxar a garantia transacional são ações que podem ajudar um SGBDR escalar, mas após essas modificações um SGBDR começa a possuir características de um produto NoSQL (TIWARI, 2011). 
O conceito NoSQL reduz os problemas que normalmente ocorrem nos SGBDRs e torna mais fácil trabalhar com grandes quantidades de dados esparsos. Por outro lado, tira o poder de integridade transacional, indexação e consulta flexível. Ironicamente, uma das características mais perdidas em NoSQL é a característica SQL.

Esta pesquisa aborda o uso de SGBDs NoSQL em organizações privadas, em especial os critérios de seleção deles. Faz parte dessa abordagem considerar as limitações e vantagens do seu uso nas organizações.

\subsection{Motivação e Justificativa}

A motivação deste trabalho se deve aos poucos estudos relacionados com processos de seleção de SGBDs e com o conceito de banco de dados NoSQL. Atualmente tem-se baixa inserção dessa nova tecnologia no mercado, no entanto há casos de sucesso no uso de SGBDs NoSQL em empresas de tecnologia, especialmente em empresas Web. Neste contexto, podem-se citar alguns exemplos: o Hadoop Distributed File System usado pelo Yahoo!@; o Dynamite baseado no Dynamo da Amazon®; o Cassandra, usado pelo Facebook® e os populares MongoDB e CouchDB (LÓSCIO et al., 2011).

A Gartner (2012), consultoria conhecida mundialmente, divulga anualmente um relatório descrevendo a curva de adoção de novas tecnologias. Este relatório é uma representação gráfica da maturidade de adoção das tecnologias e aplicações que são potencialmente relevantes para resolver problemas reais de negócio e explorar novas oportunidades.

Essa representação é conhecida como Hype Cycle e está apresentada na Figura 1 com o relatório do Big Data divulgado em julho de 2012. O eixo horizontal é a linha do tempo no ciclo de vida da tecnologia e o eixo vertical representa as expectativas em relação à nova tecnologia, que traduzem no quanto a tecnologia está sendo abordada pela mídia por meio de notícias, artigos, fóruns e eventos em geral.

Os SGBDs NoSQL caminham para a fase do Pico de Expectativas, sendo caracterizado pelo processamento e gerenciamento extremo de informação A criação dos SGBDs NoSQL se apoiou principalmente no contexto do Big Data e a necessidade de gerenciamento de volumes extremos de dados. 


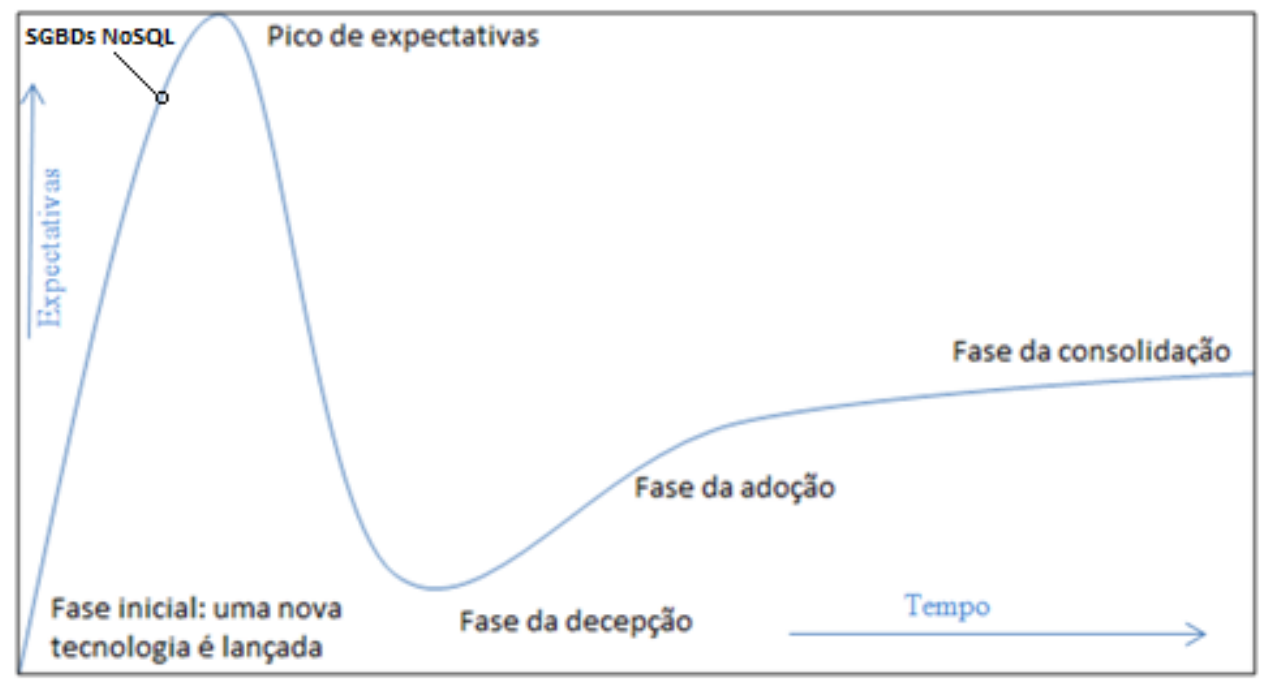

Figura 1 - Hype Cycle for Big Data da Gartner

Fonte: Adaptado de Gartner (2012)

O Hype Cycle em sua fase inicial determina quando uma nova tecnologia é lançada, após disso tem-se o pico de expectativas das novas tecnologias, logo após a fase de decepção tem-se a fase da adoção e a fase de consolidação.

Neste relatório da Gartner as tecnologias que envolvem gerenciamento e armazenamento de grande volume de dados cresceram nos últimos anos, caminhando para a fase de "Pico de Adoção". Comparando-se com o relatório 2012 com o de 2011, percebeu-se um avanço do Big Data, caminhando da fase inicial para a fase de pico de adoção.

\subsection{Formulação da Situação-Problema}

Nas últimas duas décadas o aumento contínuo do poder computacional produziu um fluxo avassalador de dados. Além disso, os recentes avanços na tecnologia Web, como por exemplo, a Web 2.0, tornaram possível para qualquer usuário fornecer e consumir conteúdo de qualquer forma e em qualquer lugar. Esta nova realidade passa a exigir uma revisão de modelo com relação aos SGBDs e dos mecanismos de processamento de dados e armazenamento. Surge então o uso de SGBDs NoSQL de diferentes tipos e abordagens, denominados NoSQL. NoSQL é o nome do conceito que promove alternativas ao conceito relacional de armazenamento de dados e propõe uma nova forma de armazenamento e define também novas arquiteturas de acesso a dados como orientado a documentos, a colunas, chavevalor e grafo. 
Segundo Stonebraker (2011), os SGBDRs como Oracle e IBM normalmente oferecem uma única solução para um problema específico, não atendendo muitas vezes a demanda que o atual fluxo de geração de dados exige. Em cada segmento de negócio pode-se encontrar pelo menos um contexto em que os SGBDRs não atendem os problemas das aplicações atuais de forma adequada e no futuro será necessário se reajustarem a essa nova realidade. A exemplo da necessidade de adequação com essa nova realidade, a Oracle, o principal fornecedor de SGBDR do mundo lançou a sua versão de SGBD NoSQL orientado a chavevalor, chamada Oracle NoSQL Database Key-Value Pairs.

As aplicações atuais, além de gerar enorme volume de dados, exigem cada vez mais disponibilidade, escalabilidade e poder de processamento. Para Stonebraker (2011), com relação ao grande volume de dados é possível elencar três problemas principais:

- Crescimento do volume de dados. Terabytes estão se transformando em pentabytes de dados, ou seja, o volume de dados tem crescido de forma contínua em praticamente todos os tipos de aplicações.

- Aumento no fluxo de dados. Imaginando a situação em que uma pessoa está tentando beber água em uma mangueira de bombeiro, a água vem em maior velocidade do que ela pode suportar. Fazendo uma analogia com a atual realidade das aplicações, é este o cenário que acontece com as aplicações em relação ao aumento no fluxo de dados e poder de processamento, ou seja, o poder de processamento não acompanha o aumento no fluxo de dados.

- Grande variedade na fonte de dados. Podem ser desde simples cliques em uma página de conteúdo Web até as informações geradas em dispositivos móveis. O problema é a tentativa de integrar uma ou duas centenas de fontes de dados separadas.

A tecnologia NoSQL está cada vez mais presente no mercado nos últimos anos. Segundo levantamento feito por Lóscio et al. (2011), tal evidência pode ser comprovada pela forte adoção de soluções NoSQL em grandes empresas de tecnologia, para o gerenciamento dos seus dados, como por exemplo, os casos abaixo:

Twitter. É uma rede social e servidor para microblogging, que permite aos usuários enviar e receber atualizações pessoais de outros contatos, por meio do site do serviço, por SMS, bem como por softwares específicos de gerenciamento. Com o crescimento exponencial do uso do Twitter ${ }^{\circledR}$, resolver o problema de armazenamento e processamento de grandes volumes de dados em tempo-real tornou-se um grande desafio. Em 2010, o número de tweets 
era 1.2 bilhões por mês. A preocupação com o problema de disponibilidade fez com que a empresa substituísse o SGBDR MySQL pelo Cassandra, uma solução NoSQL. A empresa utiliza o Cassandra para armazenar resultados de data mining realizados sobre a base dos usuários, resultados dos tópicos mais comentados e análises em tempo real em larga escala. A utilização do Cassandra trouxe vantagens tanto na implementação da modelagem dos dados relacionados aos tweets, como no desempenho com relação às buscas por usuários ou palavras-chaves, além disso, aumentou a disponibilidade dos seus serviços.

Facebook. O Facebook® possui, atualmente, cerca de 3,5 bilhões de conteúdos (links, posts, etc) compartilhados por semana. Para evitar problemas com a escalabilidade e disponibilidade dos dados, a empresa desenvolveu o Cassandra, uma solução NoSQL. Criado para otimizar o sistema de busca do Facebook®, atualmente o Cassandra é utilizado para dar suporte à replicação, detecção de falhas, armazenamento em cache dentre outras funcionalidades.

Google. O Google (C também desenvolveu sua própria solução NoSQL, chamada de BigTable, que é um sistema de armazenamento distribuído para gerenciar dados estruturados em larga escala. Mais de 60 produtos (como Gmail, Google Docs, Google Analytics, Orkut, Personalized Search, Google Earth etc) utilizam o BigTable. Esta solução permite a escalabilidade de recursos, bem como alto desempenho no processamento das consultas e disponibilidade dos serviços.

Amazon. Um dos maiores desafios enfrentados pela Amazon@ está relacionado com a confiabilidade do grande volume de dados gerenciado por suas aplicações, não apenas por questões financeiras e devido aos gastos com soluções convencionais, mas também por causa do impacto da confiança de seus clientes em seus produtos. Em 2007, com o intuito de garantir alta disponibilidade dos dados de seus serviços "always-on" (sempre disponíveis), a Amazon@ desenvolveu uma solução NoSQL, o Dynamo. Com a adoção do conceito NoSQL, diversos serviços da Amazon@ $\bigodot$ têm-se mantido disponíveis em 99,9995\% das requisições realizadas.

LinkedIn. É uma rede de negócios que tem como principal objetivo o estabelecimento de relações entre profissionais. Em março de 2011, atingiu a marca de 100 milhões de usuários. Como em outras redes de relacionamentos, o desempenho no processamento de consultas foi afetado com o crescimento na quantidade de dados. Para suprir a demanda das aplicações do Linkedin, diversas soluções relacionais foram utilizadas, mas com pouco sucesso. Diante do fracasso das soluções relacionais, a empresa desenvolveu sua própria solução NoSQL, chamada de Voldemort que trouxe melhores resultados de desempenho. O 
SGBD Voldemort suporta escalabilidade horizontal, replicação, particionamento, tolerância a falhas dentre outras funcionalidades, atendendo aos requisitos esperados pela aplicação.

Os exemplos citados mostram a importância de considerar como é desenhada a arquitetura de soluções Web no projeto de dados, mensurando o volume de dados crescente, o custo operacional de manutenção de uma plataforma robusta e flexível, e as novas necessidades do mercado como alto desempenho, escalabilidade e alta disponibilidade.

Este trabalho não tem o objetivo de comparar o conceito NoSQL com os conceitos relacionais, mas sim identificar e analisar os critérios de seleção de SGBDs NoSQL. Para tal pretende-se responder a seguinte pergunta: Quais os principais critérios usados na avaliação de SGBD NoSQL e qual o grau de importância de cada critério?

Este trabalho tem como contribuição levantar um conjunto de critérios e definir os mais importantes para avaliação e seleção de SGBDs NoSQL, possibilitando assim às organizações em ambiente Web utilizar este conjunto de critérios que foram pautados na opinião de especialistas, colaborando para uma decisão mais acertada sobre a seleção de SGBDs NoSQL.

\subsection{Objetivos gerais e específicos}

O objetivo geral deste trabalho é identificar e analisar os principais critérios que devem ser usados para avaliação de um SGBD NoSQL, com base na opinião de especialistas em SGBDs. Para consecução desse objetivo geral foram identificados quatro objetivos específicos:

a) Identificar na literatura os principais critérios de seleção de SGBDs.

b) Identificar com especialistas, a partir dos critérios encontrados na literatura, os principais critérios para seleção de SGBDs NoSQL.

c) Ordenar os critérios de seleção de SGBDs NoSQL conforme a importância atribuída pelos especialistas.

d) Analisar os principais critérios de seleção de SGBDs NoSQL no contexto das organizações brasileiras em ambiente Web, a partir da percepção de especialistas. 


\subsection{Organização do estudo}

Este trabalho está organizado nos seguintes capítulos:

Capítulo 1 - Introdução

Neste capítulo apresenta-se o tema e a sua relevância para a prática e para o meio acadêmico. Nele estão descritos a formulação da situação-problema, o objetivo geral e os objetivos específicos, o escopo da pesquisa e as definições dos principais termos e siglas usados no decorrer do trabalho.

\section{Capítulo 2 - Evolução Histórica dos SGBDs}

Neste capítulo buscam-se as definições e conceitos acerca de SGBDs, em especial a respeito do conceito NoSQL, suas categorias, sua forma de comercialização (open source e proprietário), características técnicas, os aspectos econômicos envolvidos e tentar estabelecer uma relação com outras tecnologias como Data Warehouse, sistemas distribuídos e aplicações Web.

Capítulo 3 - Banco de Dados NoSQL

Neste capítulo são apresentados com mais detalhes a definição de Big Data e o conceito dos SGBDs NoSQL. Para cada tipo de SGBD NoSQL são apresentadas as vantagens e desvantagens e situações em que o seu uso é recomendado.

Capítulo 4 - Processo de Seleção de Software

Neste capítulo são apresentados os critérios do modelo de qualidade de software das normas ISO/IEC 9126 e 14598 que contribuíram para compor os critérios de seleção de SGBDs.

Capítulo 5 - Projeto de dados

Neste capítulo são apresentadas as fases de um projeto de dados, onde é destacada a fase de definição de critérios de avaliação e seleção de SGBDs. A definição dos critérios é pautada segundo levantamento na literatura. Posteriormente os critérios foram utilizados na aplicação do Painel Delphi. 
Capítulo 6 - Método de Pesquisa

Este capítulo apresenta o método de pesquisa para este trabalho. Buscou descrever as características da pesquisa realizada e justificar a escolha do método. Em seguida, são descritas as fases da pesquisa, escopo da pesquisa, forma de utilização do método, as técnicas estatísticas utilizadas, a fonte e descrição do processo de coleta de dados.

\section{Capítulo 7 - Realização do Painel Delphi}

Este capítulo detalha os passos da realização do Painel Delphi, como foi realizado o mapeamento dos especialistas, descrição da realização dos ciclos e apresenta os dados obtidos ao final das rodadas do painel.

\section{Capítulo 8 - Resultados da Pesquisa}

Neste capítulo é realizada a análise dos dados coletados por meio do Painel Delphi. Inicialmente a amostra é descrita por meio de análises feitas do ranking de critérios de seleção de SGBDs NoSQL obtido com a finalização das rodadas do painel. Em seguida, são feitas análises por grupos de especialistas, comparando-se o grau de concordância $\mathrm{W}$ e fazendo um paralelo com o resultado obtido e o resultado esperado de acordo com a definição da literatura sobre SGBDs NoSQL.

\section{Capítulo 9 - Conclusões}

Neste capítulo são apresentadas as conclusões gerais feitas a partir dos resultados e análises feitas com a aplicação do Painel Delphi. Também são apresentados temas relevantes para possíveis pesquisas futuras e finalmente são feitas considerações finais sobre a escolha de critérios de seleção de SGBDs NoSQL em organizações privadas.

\section{Apêndice}

A: Contém o questionário utilizado na coleta de dados.

B: Contém o questionário utilizado no mapeamento de perfil dos especialistas.

C: Contém a carta convite para participação da primeira rodada do Painel Delphi.

D: Contém a carta lembrete para participação do Painel Delphi. 
E: Contém a carta convite para participação da segunda rodada do Painel Delphi e informativo do resultado da primeira rodada

\section{Anexos}

A: Contém as fórmulas e variáveis para os cálculos realizados no Painel Delphi. 


\section{Evolução Histórica dos SGBDs}

Este capítulo traz a evolução histórica dos SGBDs, desde o uso de sistemas de gerenciamento em arquivos até o novo conceito de SGBDs NoSQL, com o objetivo de contextualizar a evolução dos SGBDs, sua história, definições, caracterização e paralelos que podem ser feitos entre os SGBDs NoSQL e os demais.

\subsection{Definição e Caracterização}

Uma das primeiras aplicações dos computadores é o gerenciamento de dados. Desde então as instituições que utilizam computadores armazenam dados em grandes volumes. Avanços nas tecnologias de armazenamento de dados tais como dispositivos de armazenamento mais rápidos, maior capacidade de armazenamento com custos menores além de SGBDs mais eficientes, têm contribuído para fazer com que existam enormes volumes de dados disponíveis (DATE, 2004).

A quantidade de informações que se encontra disponível está crescendo de forma desordenada e o valor dos dados como um ativo organizacional é amplamente reconhecido. Para obter a maior parte de seus grandes e complexos conjuntos de dados, os usuários necessitam de ferramentas que simplifiquem as tarefas de gerenciamento dos dados e a extração de informações úteis assim que desejado. Um banco de dados é uma coleção de dados que, normalmente, define as atividades de uma ou mais organizações relacionadas. Já um SGBD é um software projetado para auxiliar a manutenção e utilização de vastos conjuntos de dados. A alternativa para não usar um SGBD é armazenar os dados em arquivos e escrever código específico do aplicativo para gerenciá-los (RAMAKRISHNAN; GEHRKE, 2003).

É alarmante também a distância crescente entre a geração de dados e a capacidade de analisar e compreender esses dados. Conforme o volume de dados aumenta, a proporção dos dados que é analisada e entendida pelas pessoas diminui (ELMASRI; NAVATHE, 2005).

Segundo Date (2004), um SGBD é basicamente um sistema computadorizado para guardar registros. É possível considerar a própria base de dados como uma espécie de armazém eletrônico para arquivar as informações. Os usuários de um sistema podem executar uma variedade de operações sobre banco de dados como: incluir novos registros nas bases de 
dados; recuperar dados em arquivos existentes; modificar dados existentes; eliminar dados existentes e eliminar toda uma base de dados existente.

Para Elmasri e Navathe (2005), um Banco de Dados (também chamado de Base de Dados) é uma coleção de dados relacionados, organizados e armazenados visando facilitar a manipulação dos dados, permitindo realizar alterações, inserções, remoções e consultas. Os tipos de "coleções de dados" são ilimitados, por exemplo, dados de um produto, de um estudante, mapas, dados sobre genes humanos, etc., ou seja, quaisquer aplicações do mundo real que possam ser representadas por meio de dados computáveis poderão ser armazenadas em um banco de dados. Segue abaixo outras definições:

- "Um Banco de Dados é uma coleção de dados operacionais armazenados, sendo usados pelos sistemas de aplicação de uma determinada organização" (DATE, 2004, p. 10).

- "Um Banco de Dados representa alguns aspectos do mundo real, sendo chamado, às vezes, de minimundo ou de universo de discurso. As mudanças no minimundo são refletidas em um Banco de Dados” (ELMASRI; NAVATHE, 2005, p. 4).

De fato, como definiram Elmasri e Navathe (2005), um banco de dados é um modelo de uma determinada parte da realidade, geralmente denominada de Universo de Discurso ou minimundo. Isso porque só se deve colocar no banco de dados informações do domínio que sejam relevantes para resolução de um problema real ou para obter determinadas informações.

Um banco de dados pode ser criado e mantido por um conjunto de aplicações desenvolvidas especialmente para esta tarefa ou por um Sistema Gerenciador de Banco de Dados (SGBDs ou DBMS - Database Management System). Um SGBD é um pacote de software designado para guardar e gerenciar um banco de dados. É ele que realiza a manipulação dos dados armazenados em um banco de dados. O SGBD tem uma gama de funções pré-implementadas que gerenciam as operações de inserção, remoção, atualização e consulta dos dados armazenados (ELMASRI; NAVATHE, 2005).

Antes de existirem os bancos de dados, qualquer sistema, programa ou aplicação que precisasse armazenar e manipular dados fazia uso de um sistema de arquivos. Ou seja, cada sistema, programa ou aplicação desenvolvido tinha os seus próprios arquivos de armazenamento de dados. 


\subsection{Origem e contexto histórico dos SGBDs}

Os primeiros SGBDs surgiram por volta de 1960 e foram desenvolvidos com base nos primitivos sistemas de arquivos. Dentre as principais características de um SGBD destaca-se: controle de concorrência, segurança, recuperação de falhas, gerenciamento dos mecanismos de armazenamento de dados e controle das restrições de integridade do Banco de Dados (ELMASRI; NAVATHE, 2005).

O primeiro SGBD de propósito geral, projetado por Charles Bachman, na General Electric $@$, no início da década de 1960, foi chamado de Depósito de Dados Integrados. Ele constitui a base do modelo de dados de rede e influenciou bastante os sistemas de banco de dados na década de 1960. Em 1970, Edgar Codd, do Laboratório de Pesquisa de San Jose, da IBM, propôs uma nova estrutura de representação de dados chamada modelo de dados relacional, que veio a ser um marco histórico no desenvolvimento de sistemas de banco de dados. Ele impulsionou o rápido desenvolvimento de vários SGBDs baseados no modelo relacional, juntamente com um rico conjunto de resultados teóricos que consolidaram a área. Os sistemas de banco de dados amadureceram e a popularidade dos SGBDRs alterou o cenário comercial. Seus benefícios foram amplamente reconhecidos, e o uso de SGBDs para gerenciar dados corporativos tornou-se uma prática padrão (RAMAKRISHNAN; GEHRKE, 2003).

Outra importante função de um SGBD é o gerenciamento de transações. Segundo Elmasri e Navathe (2005), uma transação pode ser definida como um conjunto de operações que possuem uma função específica para a aplicação do sistema de banco de dados, em outras palavras uma transação representa um conjunto de operações de leitura ou escrita que são realizadas no banco de dados. A execução de transações em um SGBD deve obedecer a algumas propriedades a fim de garantir o correto funcionamento do sistema e a respectiva consistência dos dados. Estas propriedades são chamadas de propriedades ACID e são definidas a seguir:

- Atomicidade. Todas as operações da transação são executadas, ou seja, a transação é executada por completo, ou nada é executado.

- Consistência. Após uma transação ter sido concluída, o banco de dados deve continuar em um estado consistente, ou seja, deve satisfazer as condições de consistência e restrições de integridade previamente assumidas. 
- Isolamento. Se duas transações estão sendo executadas concorrentemente, seus efeitos devem ser isolados uma da outra. Esta propriedade está relacionada ao controle de concorrência do SGBD;

- Durabilidade. Uma vez que uma transação ocorreu com sucesso, seu efeito não poderá mais ser desfeito, mesmo em caso de falha. Esta propriedade está relacionada à capacidade de recuperação de falhas do SGBD.

Diferentes modelos de dados foram propostos desde o surgimento dos SGBDs, os quais se diferenciam pelos conceitos adotados para representação dos dados do mundo real. Inicialmente foram propostos os modelos hierárquicos e de rede. No modelo hierárquico os dados são representados como registros, organizados em árvores e relacionados por meio de associações do tipo pai-filho. $\mathrm{O}$ modelo em rede foi proposto como uma extensão ao modelo hierárquico, onde não existe o conceito de hierarquia e um mesmo registro pode estar envolvido em várias associações (DATE, 2004).

No início dos anos 70 surgiram os SGBDRs, os quais se firmaram como solução comercial para armazenamento e gerenciamento de dados convencionais, ou seja, dados que possuem uma estrutura fixa, bem definida e com tipos de dados simples, como os dados gerados e manipulados por aplicações convencionais de bancos de dados, por exemplo, sistemas de controle de estoque e folha de pagamento. Os conceitos básicos do modelo relacional são: relação (tabela), atributo (coluna) e tupla (linha). Especificamente, uma tabela representa um conceito (ex: Pessoa, Veículo) ou uma associação entre conceitos (ex: Pessoa possui Veículo), as colunas definem as propriedades destes conceitos (ex: Nome, Endereço e Telefone, no caso de uma pessoa) e as linhas representam as instâncias propriamente ditas (ex: João, Rua A, 11-2321-2243). Dentre os motivos do grande sucesso do modelo relacional destacam-se a padronização de conceitos, sua base formal e a facilidade de uso da linguagem SQL (Structured Consulta Language), linguagem padrão para consultas e manipulação de dados relacionais (ELMASRI; NAVATHE, 2005).

Segundo Date (2004), um SGBD é basicamente um sistema computadorizado para guardar registros. É possível considerar a própria base de dados como uma espécie de armazém eletrônico para arquivar as informações. Os usuários de um sistema podem executar uma variedade de operações sobre banco de dados como: incluir novos registros nas bases de dados; recuperar dados em arquivos existentes; modificar dados existentes; eliminar dados existentes e eliminar toda uma base de dados existente. 
De uma maneira geral, a simplicidade do modelo relacional contribuiu para sua grande disseminação e adoção. Porém, à medida que as aplicações de bancos de dados foram evoluindo surgiu à necessidade de manipulação de outros formatos de dados, como imagem, som e vídeo, bem como repensar a forma de armazenar e acessar grandes volumes de dados. Posteriormente, com o surgimento da Web, outras aplicações de banco de dados começaram a ser desenvolvidas, originando, dessa forma, novos requisitos de bancos de dados. Dentre estes requisitos destaca-se a necessidade de manipulação de grandes volumes de dados não estruturados ou semiestruturados, bem como novas necessidades de disponibilidade e escalabilidade. Assim, a fim de atender aos requisitos destas aplicações, novas soluções para gerenciamento de dados começaram a serem propostas, como, por exemplo, os SGBDs NoSQL (LEAVITT, 2010).

\subsubsection{Sistemas de Arquivos}

Segundo Elmasri e Navathe (2005), os sistemas de processamento de arquivos caracterizam-se por uma série de registros guardados em diversos arquivos e uma série de programas para extrair e adicionar registros de forma apropriada. Há diversas organizações primárias de arquivo que determinam como os registros de um arquivo são posicionados fisicamente no disco e, portanto, como eles podem ser acessados. Os sistemas de arquivos basicamente resumem-se nas operações de recuperação e atualização de registros em arquivos tendo como base uma condição de seleção.

O sistema de gerenciamento por arquivos precede o modelo relacional. Podem ser citados alguns problemas com o uso de SGBDs em arquivos como:

- Redundância e inconsistência de dados. Dificuldade em manter restrições de integridade automaticamente. Seriam checagens de determinadas condições a serem feitas pelo sistema sobre os dados armazenados (por exemplo, a quantidade de produtos em estoque não pode ser inferior a um valor X).

- Dificuldade de acessar informação (programa pode não estar disponível). O acesso à informação é dificultado em sistemas em arquivos, pois depende da aplicação e de suas regras de acesso, dependendo da sua disponibilidade.

- Anomalias de acesso concorrente (multiusuários). O acesso aos dados em arquivos não é feito com controle de acesso concorrente, possibilitando a ocorrência de anomalias como dados incorretos no momento da consulta. 
- Problemas de segurança e integridade. Sistemas em arquivos não possuem política de acesso aos dados como concessão de privilégios, causando possíveis problemas de segurança.

- Isolamento de dado. Como não há controle de acesso concorrente, as transações não são isoladas e uma pode influenciar a outra.

- Problemas de atomicidade. Uma vez que não há controle de transações, elas podem ser executadas de forma não completa, possibilitando inconsistências nos dados.

\subsubsection{Banco de Dados Hierárquicos}

O modelo hierárquico representa os dados de forma semi estruturada como estruturas de árvores hierárquicas. Cada hierarquia representa um número de registros relacionados. Não há nenhuma linguagem-padrão definida especialmente para o modelo hierárquico, embora a maioria dos SGBDs hierárquicos possuam linguagens um-registro-por-vez (ELMASRI; NAVATHE, 2005). Os modelos hierárquicos e de rede precederam o modelo relacional e foram propostos na década de 60 e implementados em antigos SGBDs durante as décadas de 70 e 80. Segue na Figura 2 exemplo de uma aplicação em um banco de dados hierárquico.

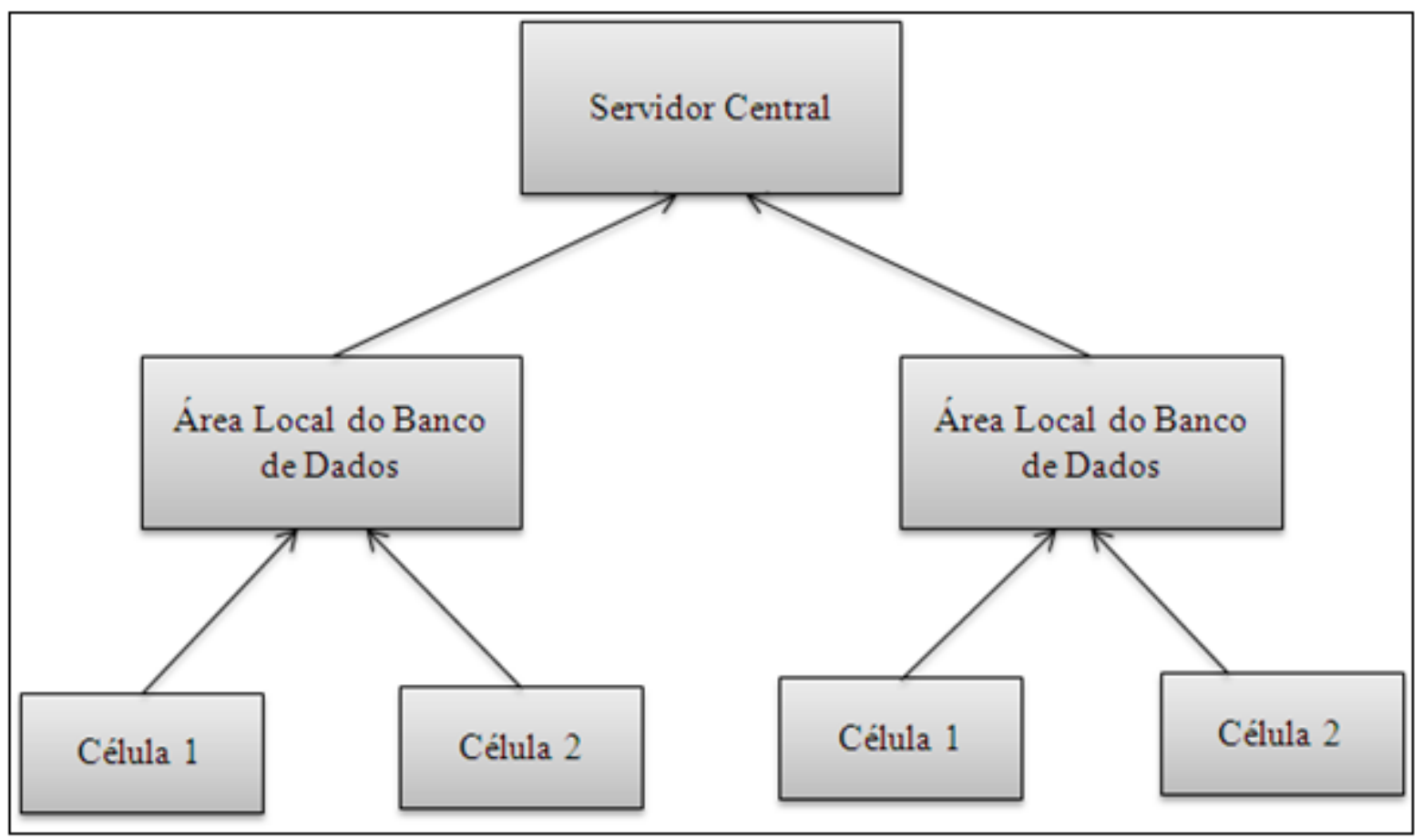

Figura 2 - Estrutura de Árvore Hierárquica

Fonte: Llyas e Vijayakumar (2010) 
Os bancos de dados relacionais se consolidaram como substituto natural do banco hierárquico em praticamente cem por cento das aplicações com o advento dos computadores pessoais no início dos anos oitenta, o que mudou radicalmente este cenário sob o ponto de vista de hardware, onde sistemas de armazenamento de dados se faziam necessários em equipamentos ditos pessoais.

\subsubsection{Banco de Dados Relacionais}

Os SGBDRs foram projetados com o objetivo de separar o armazenamento físico dos dados da sua representação conceitual e prover uma fundamentação matemática para os SGBDs. O modelo de dados relacional também introduziu as linguagens de consulta de alto nível, que são uma alternativa às interfaces para as linguagens de programação, consequentemente, ficou mais rápido escrever novas consultas. Os sistemas relacionais foram, a princípio, direcionados para as mesmas aplicações dos sistemas pioneiros, mas foi decisivo o fato de oferecerem flexibilidade para o desenvolvimento rápido de novas consultas e para reorganizar o banco de dados quando os requisitos eram alterados (ELMASRI; NAVATHE, 2005).

Os SGBDRs têm como base o modelo relacional, que é um modelo de tabelas, onde existe uma técnica matemática poderosa que faz validação, a álgebra relacional, e uma linguagem de banco de dados bastante popular, a linguagem SQL (Structured Consulta Language) (INMON, 2005).

Os bancos de dados relacionais possuem funcionalidades e recursos importantes tais como, segurança, compartilhamento, mecanismo de recuperação e integridade dos dados. Eles são compostos de relações entre entidades, denominadas tabelas. As tabelas se relacionam por meio de chaves, chamadas de estrangeiras, que podem ser simples ou compostas, dependendo se são formadas por um ou vários atributos. Atributo é a representação de um tipo de informação (INMON, 2005).

Resumidamente um modelo relacional consiste em uma coleção de variáveis no tempo e relações tabulares (como as propriedades citadas anteriormente) com regras de inserçãoalteração-deleção e álgebra relacional (CODD, 1979).

Os bancos de dados relacionais podem apresentar um alto custo nas consultas pela soma de dois fatores: o tempo da entrada e saída e o tempo de uso da CPU. Deve-se encontrar o plano de execução de consulta que leve à execução da consulta num tempo adequado. 
Normalmente, o número de planos de execução para uma consulta é determinado por dois fatores: o número de operações na consulta e o número de maneira que podem ser usadas para avaliar cada operação (O'NEIL, 1997).

Em virtude desta dificuldade, para consultas em geral, usam-se heurísticas ou um espaço de busca reduzido para obter-se um plano razoável, não necessariamente o ótimo. As duas formas de otimização mais usadas são: a otimização baseada em álgebra e a otimização baseada em custo (O`NEIL, 1997).

Neste trabalho são abordados os problemas causados pelo massivo volume de dados que ocorrem com os SGBDRs, devido principalmente à complexidade na definição de planos de execução otimizados e a álgebra relacional que está implicitamente envolvida. Os bancos NoSQL apresentam uma forma de relacionamento diferente e pode apresentar ganhos com relação à performance no processo de consulta uma vez que os dados não possuem relacionamentos pré-definidos entre entidades do modelo de dados e é eliminada a álgebra relacional.

\subsubsection{Data Warehouse}

Os Data Warehouses, em português armazém de dados, são bancos de dados com grande volume de dados, com finalidades específicas e contêm dados integrados provenientes de fontes independentes, permitindo a identificação de tendências e eventuais problemas. $\mathrm{O}$ processamento é executado com consultas que agregam, filtram e agrupam os dados de diferentes formas (O`NEIL, 1997).

Para Inmon (2005), um armazém de dados é um banco de dados centralizado, definido por assunto, integrado, não volátil e histórico, com o objetivo de dar apoio à tomada de decisão e que estrutura os dados em uma arquitetura analítica distinta da arquitetura relacional utilizada nos bancos de dados transacionais.

Os dados armazenados nos Data Warehouses tem origem nos sistemas que produzem dados operacionais, ou seja, as informações de clientes, dados de venda e operações realizadas por um sistema. Os dados operacionais são produzidos no dia a dia das operações dos sistemas de informática, no entanto não estão organizados de forma analítica, dificultando a sua análise para tomada de decisão.

Desta forma é necessário fazer uso de processos de extração, transformação e carga (ETL - Extract, Transformation and Load) a partir dos dados operacionais, para que seja possível carregar o Data Warehouse. 
De acordo com Kimball e Ross (2002), os Data Marts são segmentos dos Data Warehouses que agrupam apenas parte das informações para uma finalidade em específico. Trata-se de dados relacionados a um assunto em especial, por exemplo, venda, contabilidade, pagamentos ou diferentes níveis de agrupamento, como por exemplo, venda anual, venda mensal, venda de cinco anos, que se referem a áreas específicas. Data Marts extraem e ajustam porções de Data Warehouses aos requisitos específicos de setores ou departamentos das empresas.

O objetivo do Data Warehousing é criar e gerir repositórios de dados de diferentes origens e trazer a visão de uma parte, ou do todo, do negócio, servindo assim para o apoio a tomada de decisão de uma forma mais rápida.

Nas últimas três décadas, muitas organizações tem gerado enorme quantidade de dados interpretáveis por máquinas em arquivos e banco de dados. Para processar esses dados, existe a tecnologia de banco de dados disponível que compõe linguagens de consulta (consulta) como SQL. O problema com a linguagem SQL é que ela é estruturada e parte do princípio que o usuário conhece o esquema do banco de dados. A linguagem SQL comporta operações de álgebra relacional que permitem que o usuário selecione linhas e colunas de dados das tabelas ou informações relacionadas (join) de tabelas baseadas e campos comuns (ELMASRI; NAVATHE, 2005).

Segundo Elmasri e Navathe (2005), o Data Warehouse (armazém de dados) permite visualizar as mesmas informações em múltiplas dimensões. A proposta de um Data Warehouse é sustentar a tomada de decisão com dados. O resultado principal conseguido em um projeto de Data Warehousing é considerado uma das primeiras etapas para tornar viável a análise de grande quantidade de dados no apoio ao processo decisório. Os Data Warehouse fornecem armazenamento, funcionalidade e capacidade de responder consultas acima das capacidades de bancos de dados orientados por transação. O acompanhamento deste poder continuamente crescente traz uma grande demanda pela melhoria de desempenho do acesso a dados em bancos de dados. Os bancos de dados tradicionais equilibram a exigência de acesso de dados com a necessidade de assegurar a integridade deles. Em organizações modernas, os usuários são mantidos frequentemente afastados das fontes de dados. Muitas pessoas precisam apenas do acesso de leitura dos dados, mas ainda assim precisam de um acesso muito rápido para um volume maior de dados do que pode ser carregado convenientemente em um computador convencional desktop. Normalmente tais dados vêm de múltiplos bancos de dados. Como muitas das análises realizadas são reincidentes e previsíveis, os fabricantes de software e as equipes de suporte a sistemas começaram a projetar sistemas para dar suporte a 
essas funções. No momento há grande necessidade de proporcionar aos tomadores de decisão, da gerencia média para cima, informações no nível correto de detalhe para dar suporte à tomada de decisão. Data Warehousing, online analytical processing (OLAP - Processamento Analítico On-line) e data mining (garimpagem de dados) garantem essa funcionalidade.

Para Noaman (2000), existem várias abordagens para a arquitetura de um Data Warehouse, entre elas pode-se destacar: Data Warehouse Centralizado; Data Warehouse Virtual:

\section{a) Data Warehouse centralizado}

O Data Warehouse Centralizado é usualmente utilizado quando as organizações ou empresas têm uma definição clara das necessidade de acesso às informações que os usuários precisam.

\section{b) Data Warehouse Virtual}

O Data Warehouse Virtual permite acesso aos dados operacionais. Essa solução define regras para as buscas, uma vez que as bases também são utilizadas pelos sistemas transacionais.

Com o objetivo de facilitar o acesso são criadas camadas de software com o objetivo de definir regras para o acesso às bases compartilhadas com as duas finalidades, operacional e de informação.

Esta solução possui a vantagem do baixo custo de implementação, uma vez que não há duplicidade de armazenamento de dados. Uma desvantagem é que buscas complexas podem ser realizadas na base operacional, podendo diminuir sua disponibilidade uma vez que os dados podem não estar na forma necessária a ser utilizada pelo usuário final (NOAMAN, 2000).

\section{c) Data Mart}

Os Data Marts fornecem os dados de um contexto específico de interesse ao usuário, setor ou departamento. Isso permite controle maior por parte do usuário das requisições de dados e manipulações.

Normalmente os Data Marts são mais refinados, ou seja, de interesse específico para determinado usuário, enquanto que nos Data Warehouse os dados estão relacionados a um contexto mais geral. 
As características dos Data Marts permitem que sejam de menor tamanho, aumentando o desempenho das buscas. A desvantagem é que não há uma visão global dos dados (WHITE, 1995).

\section{d) Data Warehouse e Data Marts}

Essa arquitetura é faz uso do Data Warehouse Centralizado e dos Data Marts, utilizando-se das características das duas soluções, ou seja, a integração do Data Warehouse para um contexto genérico de visão dos dados e o acesso aos dados do Data Marts com uma visão segmentada das informações (WHITE, 1995).

\section{e) Dados Operacionais e Dados de Data Warehouse}

Os dados operacionais são provenientes de processos rotineiros. São utilizados para o armazenamento de transações comerciais, tais como, controle de estoque, pagamentos em sistemas de $e$-commerce, automação bancária etc.

Os dados de Data Warehouse são utilizados de forma que auxiliem no planejamento, gerenciamento e previsão das organizações, auxiliando na tomada de decisão gerencial. Essas informações são obtidas a partir de dados (WHITE, 1995).

O Quadro 1 traz uma comparação entre os dados de Data Warehouse e dados Operacionais.

\begin{tabular}{c|c}
\hline Dados nos Data & Dados Operacionais \\
Warehouses & \\
\hline Orientado a assunto & Orientado a aplicação \\
Integrado aos dados & Integração limitada dos dados \\
Não volátil & Atualização constante \\
Dados permanentes & Dados correntes (atuais) \\
Consultas ad hoc & Consultas previsíveis \\
\hline
\end{tabular}

Quadro 1 - Dados no Data Warehouse e Dados Operacionais

Fonte: Adaptado de Noaman (2000)

\subsubsection{Diferenças entre Data Warehouse e NoSQL}

Conforme discutido anteriormente, as tecnologias Data Warehouse e NoSQL foram desenvolvidas para resolver principalmente o problema de consultas em bases de dados relacionais com grande volume de informações. No entanto, as finalidades das duas 
abordagens são distintas e aplicadas em cenários específicos. No caso do Data Warehouse, o seu uso é voltado principalmente para auxiliar na tomada de decisão, gerando relatórios consolidados onde é agregado aos dados valor com a extração de informações gerenciais, além da disponibilização dos relatórios em tempo hábil. A função dos SGBDs NoSQL está direcionada ao processamento e consultas de um volume massivo de dados em larga escala e em tempo real, onde as aplicações e a interface com o usuário final possam responder de forma online, ou seja, a informação esteja disponível assim que o usuário final utilize a interface com a aplicação. Neste caso, o foco não é o apoio à decisão com geração de relatórios gerenciais, mas simplificar o acesso aos dados e o seu armazenamento com uma estrutura mais simples e de melhor desempenho para as aplicações.

Desta forma, pode-se verificar que o contexto do Data Warehouse e dos SGBDs NoSQL estão em cenários distintos, no entanto ambos vieram para agregar funcionalidades que os bancos relacionais não possuem como:

- Baixo valor agregado. As decisões gerenciais são tomadas com apenas a disponibilização dos dados em um modelo relacional.

- Problemas com desempenho. Modelos de dados excessivamente normalizados e relacionais normalmente encontram problemas de desempenho com o avanço no crescimento dos dados das organizações.

- Baixa escalabilidade. Com o aumento no crescimento dos dados das aplicações atuais, normalmente passam a apresentar dificuldades em escalar.

- Dificuldade nas consultas. Para obtenção de informações úteis para a tomada de decisão.

\subsubsection{Banco de Dados NoSQL}

Inicialmente as propostas de bancos de dados não relacionais foram desenvolvidas por pequenas empresas e por comunidades de software livre. Tais soluções foram então agrupadas em um termo, NoSQL (Not Only SQL), que significa "não apenas SQL". Este termo faz referência a SGBDs que não adotam o modelo relacional e são mais flexíveis quanto às propriedades ACID. Esta flexibilidade torna-se necessária devido aos requisitos de alta escalabilidade e alta disponibilidade, necessários para gerenciar grandes quantidades de dados, sendo característica fundamental para as aplicações da Web 2.0 (TIWARI, 2011).

Os SGBDs NoSQL possuem uma representação de relacionamentos diferente, ser fazer uso da álgebra relacional. Também não possui linguagem de consulta nativa SQL, o que 
torna mais complexa a atividade de desenvolvimento. Normalmente os SGBDs NoSQL possuem estrutura simplificada, sem relacionamentos entre entidades, com suporte natural a replicação. São também conhecidos como banco de dados escaláveis e direcionados para aplicações Web, devido sua característica inerente de ter bom desempenho com grande volume de dados. A escalabilidade dos SGBDs NoSQL está relacionada com a característica de que se aumentar o volume de dados não é necessário aumentar o poder de processamento da máquina, ou seja, o SGBD suporta o crescimento no volume de dados de forma linear, com a capacidade de realizar processamento distribuído dos dados. 


\section{SGBDs NoSQL}

Os SGBDs NoSQL apresentam algumas características fundamentais que os diferenciam dos tradicionais sistemas de bancos de dados relacionais, tornando-os adequados para armazenamento de grandes volumes de dados não estruturados ou semiestruturados. Segundo Lóscio et al. (2011), é possível descrever algumas destas características abaixo:

a) Escalabilidade horizontal. À medida que o volume de dados cresce, aumenta a necessidade de escalabilidade e melhoria de desempenho. Dentre as soluções para este problema, pode-se citar a escalabilidade vertical, que consiste em aumentar o poder de processamento e armazenamento das máquinas, e a escalabilidade horizontal, onde ocorre um aumento no número de máquinas disponíveis para o armazenamento e processamento de dados. Em comparação com a escalabilidade vertical, a escalabilidade horizontal tende a ser uma solução mais viável, porém requer que diversas threads/processos de uma tarefa sejam criadas e distribuídas. Neste caso, o uso de um banco de dados relacional poderia ser inviável, uma vez que diversos processos conectando simultaneamente em um mesmo conjunto de dados causaria uma alta concorrência, aumentando, consequentemente, o tempo de acesso às tabelas envolvidas. A ausência de controle de bloqueios é uma característica dos SGBDs NoSQL que permite a escalabilidade horizontal e torna esta tecnologia adequada para solucionar os problemas de gerenciamento de volumes de dados que crescem exponencialmente, como os dados da Web 2.0.

Taylor et al. (2011) argumenta que uma alternativa muito conhecida para alcançar escalabilidade horizontal é o Sharding, consistindo em dividir os dados em múltiplas tabelas a serem armazenadas ao longo de diversos nós de uma rede. A aplicação desta técnica traz o grande problema de "quebrar" a lógica de relacionamentos, que é a principal característica dos bancos relacionais. Neste caso, as aplicações têm que resolver a complexidade gerada pela partição de informações como, por exemplo, a execução de junções e outros comandos. Fazer sharding, em um contexto de SGBDRs, de forma manual não é uma tarefa simples e exige considerável esforço da equipe de desenvolvimento. Algumas soluções relacionais implementam uma técnica similar ao sharding chamada particionamento, que particiona os dados de acordo com algum critério. Desta forma os dados particionados fisicamente são acessados de forma mais rápida e eficiente. 
b) Ausência de esquema ou esquema flexível. Uma característica evidente dos SGBDs NoSQL é a ausência completa ou quase total do esquema que define a estrutura dos dados modelados. Esta ausência de esquema facilita tanto a escalabilidade quanto contribui para um maior aumento da disponibilidade. Em contrapartida, não há garantias da integridade dos dados, o que ocorre nos bancos relacionais, devido à sua estrutura rígida;

c) Permite a replicação de forma nativa. Diminui o tempo gasto para recuperar informações. Existem duas abordagens principais para replicação:

- Master-Slave (Mestre-Escravo). Cada escrita no banco resulta em N escritas no total, onde $\mathrm{N}$ é o número de nós escravos. Nesta arquitetura a escrita é feita no nó mestre, sendo a escrita refeita em cada nó escravo pelo nó mestre. A leitura tornase mais rápida, porém a capacidade de escrita torna-se um gargalo nesta abordagem. Geralmente não é recomendada quando se tem grande volume de dados.

- Multi-Master. Neste caso existe, não apenas um, mas vários nós mestres, de forma que é possível diminuir o gargalo gerado pela escrita que ocorre na abordagem mestre-escravo. Porém, a existência de diversos nós mestres pode causar um problema de conflito de dados.

- API simples para acesso aos dados. O objetivo da solução NoSQL é prover uma forma eficiente de acesso aos dados, oferecendo alta disponibilidade e escalabilidade, ou seja, primando pela recuperação eficiente dos dados. Para isto, é necessário que APIs sejam desenvolvidas para facilitar o acesso a estas informações, permitindo que qualquer aplicação possa utilizar os dados do banco de forma rápida e eficiente. API é uma interface que permite a utilização das funcionalidades do SGBD NoSQL por aplicativos sem envolver detalhes de programação utilizando-se normalmente o formato JSON ou XML.

d) Consistência eventual. É uma característica dos bancos NoSQL relacionada ao fato de que a consistência nem sempre é mantida entre os diversos pontos de distribuição de dados. Esta característica tem como princípio o teorema CAP (Consistency, Availability e Partition Tolerence), que diz que, em um dado momento, só é possível garantir duas de três propriedades entre consistência, disponibilidade e tolerância à partição. No contexto de aplicações $W e b$, por exemplo, geralmente são privilegiadas a disponibilidade e tolerância à partição. Como consequência, as propriedades ACID não podem ser obedecidas simultaneamente. Em vez disso, tem-se outro conjunto de projetos denominado BASE 
(basicamente disponível, consistência temporária em determinadas situações). Neste caso, o sistema deve ser planejado para tolerar inconsistências temporárias a fim de poder priorizar disponibilidade. Essa prática é muito comum em sistemas Web, onde a consistência e integridade dos dados muitas vezes são sacrificadas para garantir alto desempenho e disponibilidade. A maioria das aplicações em escala dos sistemas Web apresenta carga altamente assimétrica, desta forma o sistema deve distribuir entre os nós do cluster de forma uniforme a fim de melhorar a sua facilidade de utilização (YE; LI, 2011).

Segundo Xiang et al. (2010), a consistência em SGBDs NoSQL pode ser garantida por meio de algoritmos responsáveis pelo balanceamento do dado nos nós do cluster. Assim mesmo em sistemas distribuídos, com desenvolvimento de algoritmos adicionais para manter a consistência da replicação, é possível obter-se determinados níveis de consistência.

Para Leavitt (2010), os SGBDs NoSQL podem ser mais rápidos com relação ao processamento de consultas porque os seus modelos são mais simples. No entanto esse tipo de consulta normalmente é eficiente em uma estrutura de dados simples, não transacional e que não exige relacionamento. Os SGBDs NoSQL não utilizam a linguagem SQL para construção de consultas no sistema, característica que exige um manual de programação para consultas, pois as instruções de acesso ao banco de dados passam a ser feitas no nível de desenvolvimento, sendo este um aspecto ruim, pois sua complexidade para alterações e construções de consultas passa a ser maior do que nos bancos de dados relacionais.

Os SGBDs NoSQL geralmente processam dados mais rápido que os SGBDRs devido, principalmente, a sua estrutura mais simples como, por exemplo, ausência de relacionamento entre as entidades. Uma das desvantagens é que não são recomendados para aplicações que exigem alta precisão e consistência nas transações como, por exemplo, sistemas bancários e aplicações transacionais. No entanto, quando é necessário alto desempenho em processos de consulta em volumes massivos de dados, muitos desenvolvedores optam por utilizar SGBDs NoSQL onde os problemas de precisão e consistência passam a ser responsabilidade da aplicação. Segundo Leavitt (2010), os SGBDs NoSQL não trabalham com a linguagem de consulta SQL, eles demandam programação de consultas para acesso ao dado, o que pode ser ruim por tornar a atividade de programação mais complexa. Os SGBDs NoSQL não suportam de forma nativa as propriedades ACID, enquanto os SGBDRs suportam. Para suportar ACID, os SGBDs NoSQL devem implementar suas propriedades por meio de programação adicional. Há um grande número de problemas que requerem as propriedades ACID, como por exemplo, transações bancárias, mas pode ser considerada a opção de sacrificar tais 
propriedades em aplicações que exigem alto desempenho nas consultas as bases de dados, tolerância a falhas e escalabilidade em lugar de precisão e consistência.

Além do desafio de escolher entre um SGBD NoSQL e um relacional, as organizações ainda deparam-se com o problema de escolher o SGBD NoSQL mais adequado para o seu contexto e objetivo de negócio dentre as várias opções NoSQL existentes. Entre os critérios para se escolher um SGBD NoSQL, pode-se destacar: persistência, replicação, alta disponibilidade, transacional, consistência, linguagem de implementação, influências, patrocinadores, tipos de licenças e profissionais especializados (TUDORICA; BUCUR, 2011).

Com relação a vantagens e desvantagens do conceito NoSQL, os próximos itens trazem mais detalhes para cada tipo de SGBD NoSQL, mas pode-se verificar um resumo no Quadro 2:

\begin{tabular}{l|l}
\hline Vantagens & \multicolumn{2}{l}{ Desvantagens } \\
\hline $\begin{array}{l}\text { Desempenho: geralmente processam com maior velocidade } \\
\text { que bancos de dados relacionais. }\end{array}$ & $\begin{array}{l}\text { Complexidade: o que requer um manual de } \\
\text { programação de consultas. }\end{array}$ \\
\hline $\begin{array}{l}\text { Open Source: a grande maioria é open source, ou seja, não é } \\
\text { necessária a compra de licença para o seu uso comercial. }\end{array}$ & $\begin{array}{l}\text { Confiabilidade: Não suportam propriedades } \\
\text { ACID. }\end{array}$ \\
\hline $\begin{array}{l}\text { Escalabilidade: aplicações possuem maior facilidade para } \\
\text { escalar, principalmente em volume de dados, do que } \\
\text { aplicações convencionais em bancos de dados relacionais. }\end{array}$ & $\begin{array}{l}\text { Falta de familiaridade Não são capazes de manter a dos dados. } \\
\text { maioria das organizações não } \\
\text { famologia: a }\end{array}$ \\
\hline
\end{tabular}

Quadro 2 - Vantagens e Desvantagens do uso de SGBDs NoSQL

Fonte: Adaptado de Leavitt (2010)

Os bancos de dados relacionais com frequência apresentam custos elevados e normalmente não são justificados quando não se requer garantias estritas de ACID. As bases de dados não relacionais disponíveis são distribuídas e apresentam, geralmente, replicação de dados nativa, formando uma base de serviços de apoio à implementação. Com relação à integração com o desenvolvimento, tipicamente utiliza-se de API que oferece operações simples para consulta, alteração e remoção de valores e a sua implementação e funcionamento internos são transparentes ao desenvolvedor, ou seja, o próprio desenvolvedor é capaz de alterar na aplicação tais características (LÓSCIO et al., 2011). 


\subsection{Big Data}

Atualmente qualquer conjunto de dados com um tamanho da ordem de terabytes é classificado como Big Data. Isto representa um tamanho no qual o conjunto de dados é grande o suficiente para começar a abranger múltiplas unidades de armazenamento e na qual as técnicas tradicionais SGBDRs começam a mostrar os primeiros sinais de estresse.

Para Tiwari (2011), com o crescimento no tamanho e nas fontes de criação dos dados, que estão cada vez mais diversificadas, os seguintes desafios foram ampliados:

a) Eficiência no armazenamento e acesso a grandes quantidades de dados. As exigências adicionais de tolerância a falhas e backups tornam os processos ainda mais complexos.

b) Manipulação de grandes conjuntos de dados. O que envolve a imensa execução de processos em paralelo. A recuperação de qualquer falha no momento em que ocorre e fornecer resultados em um período relativamente curto de tempo tornamse atividades complexas.

c) Modelo de dados e metadados. O gerenciamento em constante evolução para dados semiestruturados e não estruturados, gerados por diversas fontes, passa a ser um problema difícil.

Embora o tamanho dos dados esteja crescendo assim como a capacidade de armazenamento, a velocidade de acesso, gravação e leitura a disco não tem acompanhado o mesmo ritmo. Soluções para problemas de dados envolvem esquemas flexíveis, armazenamento centrado em família de colunas, replicação e consistência eventual. O foco dessas soluções está em gerir grandes volumes de dados. Muitas vezes, quando se está trabalhando com grande armazenamento de dados, existem formas específicas e pré-definidas de análise e acesso aos dados. Além disso, muitas dessas soluções voltadas para grandes volumes de dados envolvem produtos que são muito novos e ainda em evolução. Tais produtos não foram testados em uma ampla gama de casos de uso e, portanto, não estão suficientemente maduros. Nos próximos itens são apresentadas soluções de dados NoSQL abordadas no contexto do Big Data. Lóscio et al. (2011) classificaram os principais tipos de modelos de dados NoSQL em: chave-valor, orientado a documentos, orientado a colunas e orientado a grafos. Nas próximas subseções são apresentadas as principais soluções de dados NoSQL. 


\subsection{Chave-valor}

O modelo chave-valor (key-value) é considerado simples e permite a visualização do banco de dados como uma grande tabela hash. Tabela hash é uma estrutura de dados especial que associa chaves de pesquisa a valores. De maneira bem simples, o banco de dados é composto por um conjunto de chaves, as quais estão associadas a um único valor, que pode ser uma string ou um binário. A chave representa um campo como, por exemplo, nome e idade, enquanto que o valor representa a instância para o campo correspondente.

O modelo chave-valor é a forma mais simples de estrutura de dados, que contém um par chave-valor. Tais estruturas de dados são extremamente populares porque proporcionam grande eficiência. Um par chave-valor é um valor único em um conjunto e pode ser facilmente utilizado para acessar os dados (TIWARI, 2011).

Este modelo é de fácil implementação, permite que os dados sejam rapidamente acessados pela chave e contribui para aumentar a capacidade de acesso aos dados principalmente em sistemas que possuem alta escalabilidade.

A seguir são apresentados os principais conceitos do modelo chave-valor:

a) Chaves. A chave é uma string indexada que permite o acesso direto ao valor ao qual está associado, permitindo ganho em desempenho nas consultas. Os pares chave-valor são de variados tipos: alguns são utilizados para manter os dados na memória e outros possuem a capacidade de manter os dados em disco. O modelo chave-valor pode ser distribuído e sua estrutura pode ser realizada em um cluster de nós (TIWARI, 2011).

Por exemplo, um aplicativo de armazenamento de perfis de usuário pode usar o nome do perfil, como um caminho da chave principal e depois ter vários menores caminhos para os diferentes componentes do perfil, tais como endereço de $e$-mail, nome, telefone, etc. Como os aplicativos tem controle total sobre a composição e interpretação de chaves, diferentes "Caminhos Principais" de chave podem ter estruturas completamente diferentes de "Caminhos Menores" de chaves. Continuando com o exemplo anterior, podem-se armazenar perfis de usuário e perfis de aplicação no mesmo local e manter diferentes "Caminhos Menores" de chaves para cada um (ORACLE KEY-VALUE PAIRS, 2011).

b) Valores. $\mathrm{O}$ campo de valor é armazenado como uma matriz de bytes arbitrária. $\mathrm{O}$ mapeamento das matrizes de bytes para estruturas de dados (serialização e desserialização) é deixado a cargo da aplicação. Aplicações com requisitos de dados muito simples podem usar valores contendo simples estruturas de dados (ORACLE KEY-VALUE PAIRS, 2011). 
$\mathrm{Na}$ Figura 3 há uma representação da estrutura chave-valor com o exemplo de aplicação para e-commerce. Este é um típico exemplo onde se pode combinar o uso do SGBD NoSQL orientado a chave-valor e o modelo relacional. Neste exemplo é demonstrada uma transação financeira em uma plataforma de e-commerce, onde se podem guardar as informações do produto do carrinho de compras e o cookie da sessão da transação, para permitir recuperação da informação de forma mais eficiente. A efetiva confirmação da transação com a ordem completada pode ser armazenada em um banco relacional tradicional, com a estrutura de relacionamento de clientes, valores da transação e movimentações financeiras internas do sistema.

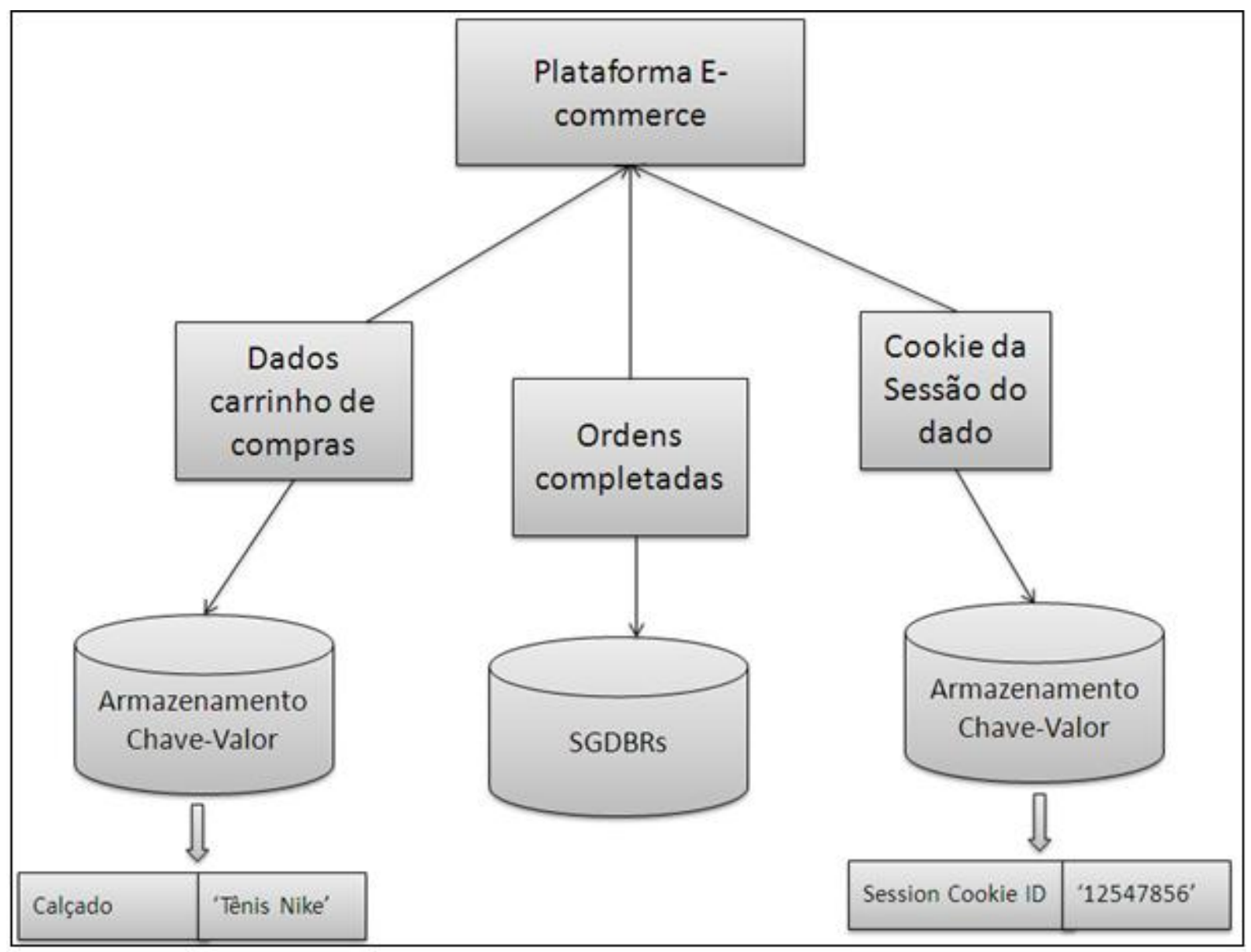

Figura 3 - Banco de Dados NoSQL - Uma abordagem com Chave-Valor Fonte: Adaptado de Sadalage et al. (2013)

Segundo Sadalage et al. (2013), o modelo chave-valor possui vantagens e desvantagens, dependendo do contexto de uso: 


\section{a) Aplicações do modelo chave-valor.}

- Armazenamento de informações de sessão. Normalmente toda sessão Web é única e definida por meio de um valor único. Aplicações que armazenam o id da sessão em disco ou em SGBDR vão obter benefícios migrando para o modelo chave-valor.

- Perfil de usuários, preferências. Quase todos os usuários possuem um único conjunto de idUsuário, nome, ou outro atributo, como preferências. Essas informações podem ser armazenadas em um objeto, buscando as preferências de um usuário por meio de uma operação get.

- Informações de comércio eletrônico. Sites de comércio eletrônico têm carrinhos de compras vinculados ao usuário. Uma vez que os carrinhos de compras devem estar disponíveis o tempo todo, em todos os navegadores, máquinas e sessões, todas as informações de compras podem ser colocadas em valor, onde a chave é a identificação do usuário.

\section{b) Desvantagens do modelo chave-valor.}

- Relacionamentos entre os dados. Não é possível fazer uso do modelo chavevalor quando é necessário relacionamentos entre diferentes conjuntos de dados ou correlacionar dados entre diferentes grupos de chaves.

- Operações transacionais. O uso do modelo chave-valor não é recomendado quando for necessário guardar múltiplas chaves e em caso de falha deseja-se reverter toda a operação.

- Consulta por dado. Este modelo não é adequado quando é necessária a busca de chaves baseadas em algum valor em específico.

- Operações por conjuntos. Desde que as operações sejam limitadas por uma chave por vez, não há um modo de operar múltiplas chaves ao mesmo tempo no modelo chave-valor. 


\subsection{Orientado a Colunas}

O modelo orientado a coluna é mais complexo que o modelo chave-valor e, neste caso, muda-se o modelo de orientação a registros ou tuplas, como no modelo relacional, para orientação a atributos ou colunas, conceito NoSQL (POKORNY, 2011). Neste modelo os dados são indexados por uma tripla (linha, coluna e timestamp), onde linhas e colunas são identificadas por chaves e o timestamp permite diferenciar múltiplas versões de um mesmo dado. Vale ressaltar que operações de leitura e escrita são atômicas, ou seja, todos os valores associados a uma linha são considerados na execução destas operações, independentemente das colunas que estão sendo lidas ou escritas. Outro conceito associado ao modelo é o de família de colunas (column family), que é usado com o intuito de agrupar colunas que armazenam o mesmo tipo de dados.

Segundo Tiwari (2011), os bancos orientados a colunas são os mais populares entre os bancos não relacionais. Muito disso se deve às pesquisas de engenheiros do Google $\bigcirc$ e pelo crescimento e popularização das redes sociais como Facebook®, LinkedIn® e Twitter®. Embora os bancos de dados orientados a colunas já existem de diferentes formas na academia há alguns anos, eles foram introduzidos para a comunidade de desenvolvedores com as publicações de artigos do Google@ (GHEMAWAT et al., 2003; DEAN; GHEMAWAT, 2008; CHANG et al., 2008).

Este modelo de dados surgiu com o BigTable do Google $($, por isso é comum falar sobre o modelo de dados BigTable. Dentre as características deste modelo pode-se citar o particionamento dos dados, além de oferecer forte consistência, mas não garante alta disponibilidade. Outras soluções surgiram após o BigTable, dentre elas o Cassandra, desenvolvido pelo Facebook® (POKORNY, 2011).

Segue no Quadro 3 comparativo entre os conceitos do modelo orientado a colunas e o modelo relacional: 


\begin{tabular}{c|c}
\hline SGBDRs & Orientado a colunas \\
\hline Instância banco de dados & Cluster \\
Database & Keyspace \\
Tabela & Família de Coluna \\
Linha & Linha \\
Coluna (a mesma para todas as colunas) & Coluna (pode ser diferente por coluna) \\
\hline
\end{tabular}

Quadro 3 - Comparativo modelo relacional X orientado a colunas

Fonte: Adaptado de Sadalage et al. (2013)

Os SGBDs orientados a colunas são superficialmente semelhantes ao modelo relacional, mas na verdade são completamente diferentes. Parte da diferença é o armazenamento de dados por linhas (relacional) contra armazenar dados por colunas (bancos de dados da família de colunas). Mas muito da diferença está relacionada com a natureza conceitual. Não se pode aplicar o mesmo tipo de solução utilizado na forma relacional para um banco de dados orientado a colunas (RAHIEN, 2010).

Segue na Figura 4 exemplo de aplicação de uma família de coluna:

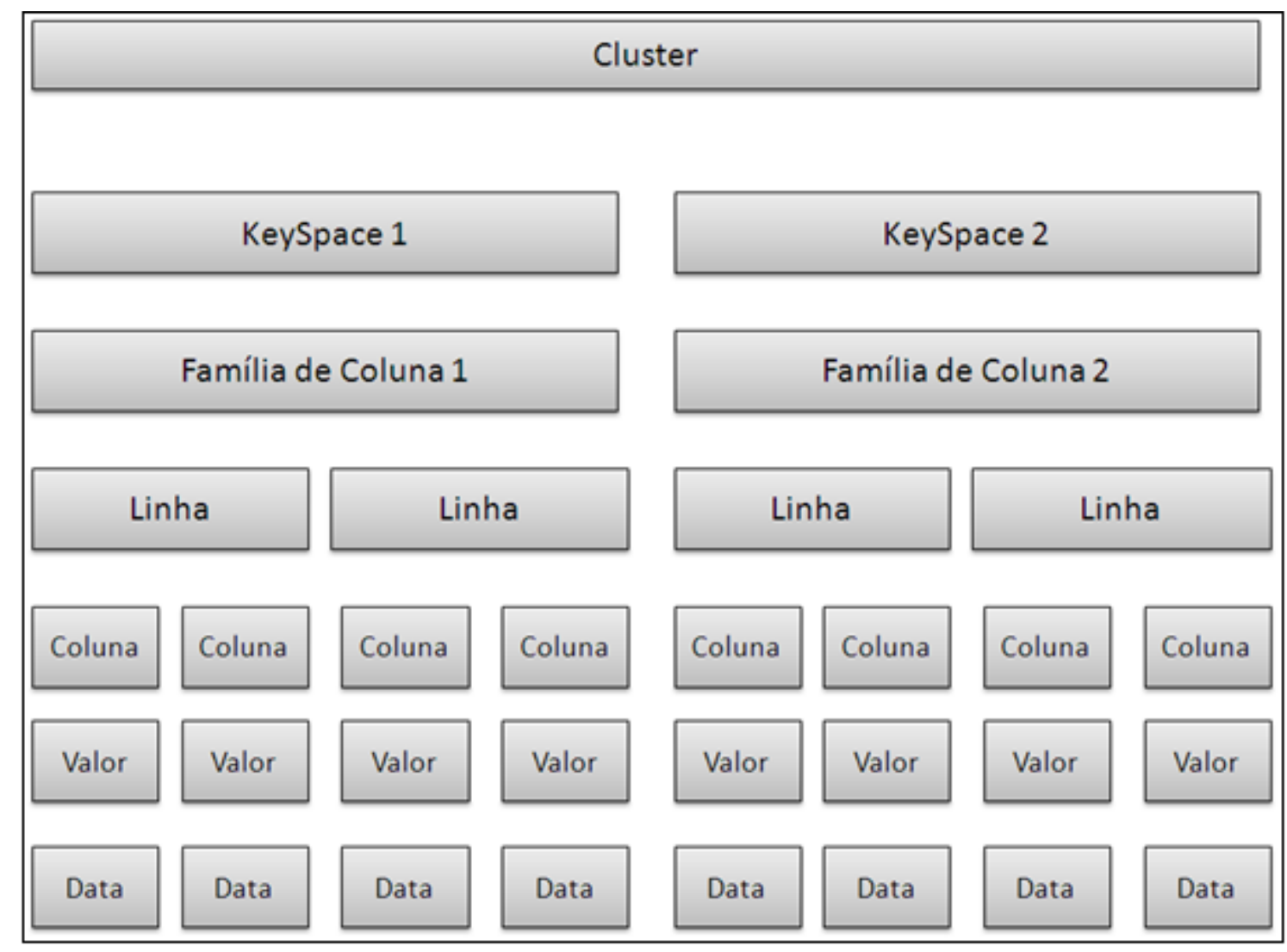

Figura 4 - Modelo Família de Coluna

Fonte: Adaptado de Sadalage et al. (2013) 
Os conceitos de família de colunas, super colunas e colunas são fundamentais para entender o funcionamento das bases de dados orientadas a colunas. Segue a apresentação desses conceitos.

a) Famílias de coluna. É o conceito mais próximo de uma tabela. Ao contrário de uma tabela, a única coisa que é necessária definir em uma família de colunas é o nome e as opções de chave de classificação (não há esquema). Uma família de coluna é a forma como os dados são armazenados no disco. Todos os dados em uma família de coluna única são armazenados no mesmo arquivo (na verdade, um conjunto de arquivos). Uma família de coluna pode conter super colunas ou colunas (RAHIEN, 2010).

b) Super coluna. Uma super coluna é um dicionário, ou seja, é uma coluna que contém outras colunas, mas não outras super colunas.

c) Coluna. A coluna é uma tripla de nome, valor e data e hora (timestamp).

Segundo Sadalage et al. (2013), o modelo chave-valor possui vantagens e desvantagens com o seu uso, dependendo do cenário avaliado a ver:

\section{a) Aplicações do modelo orientado a colunas.}

- Log de eventos. Os bancos orientados a colunas com sua característica de armazenar variados tipos de estrutura de dado é uma ótima escolha para armazenamento de informação de evento, como o estado da aplicação ou erros encontrados. Dentro da organização, todas as aplicações podem escrever seus eventos para o SGBD com suas próprias colunas e linhas no formato: nome da aplicação:timestamp. Desde que seja utilizada esta escala de escrita, o SGBD orientado a coluna pode trabalhar de forma ideal com o log de eventos.

- Contadores. Normalmente, em aplicações Web, existe a necessidade de contar e categorizar visitantes de páginas e efetuar cálculos analíticos. É possível utilizar um recurso que funciona como contador por tipo de coluna durante a criação de uma família de colunas.

- Utilizando expiração. É possível prover acesso teste para usuários por um tempo específico. Isto é possível utilizando-se colunas com expiração. Este tempo é conhecido como TTL (Time To Live) e é definido em segundos. A coluna é apagada depois que o TTL terminar e quando a coluna não existe mais o acesso é revogado. 


\section{b) Desvantagens do modelo orientado a colunas.}

- Existem problemas para os bancos de dados orientados a colunas que fazem com que não sejam as melhores soluções, por exemplo, para sistemas que requerem transações com as propriedades ACID para escrita e leitura. Uma opção de contorno é agregar os dados com o uso de consultas, no entanto é necessário que isto seja feito na camada do cliente utilizando dados recuperados do cliente a partir de todas as linhas.

- O SGBD Cassandra, por exemplo, não é indicado para protótipos ou tecnologias nos seus estados iniciais. Durante estágios iniciais, não se pode definir como as consultas padrões vão ser modificadas, e para modificar as consultas é necessário alterar o design da família de colunas. Isto pode causar atrito para a equipe de desenvolvimento e diminuir a produtividade do desenvolvedor. Bancos de dados relacionais possuem alto custo de alteração de esquema, no entanto possui baixo custo para alteração de consultas, no Cassandra, o custo de alteração de consultas é maior do que no modelo relacional.

\subsection{Orientado a Documentos}

O modelo orientado a documentos armazena coleções de documentos. Um documento é um objeto identificador único e um conjunto de campos, que podem ser strings, listas ou documentos aninhados. Estes campos se assemelham a estrutura chave-valor. No modelo chave-valor, apenas uma única tabela hash é criada para todo o banco. No modelo orientado a documentos existe um conjunto de documentos e em cada documento há um conjunto de campos (chaves) e o valor deste campo (POKORNY, 2011).

Outra característica importante é que o modelo Orientado a Documentos não depende de um esquema rígido, ou seja, não exige uma estrutura fixa como ocorre nos bancos relacionais. Assim é possível que ocorra uma atualização na estrutura do documento, com a adição de novos campos, por exemplo, sem causar problemas ao banco de dados (REDMOND; WILSON, 2012). 
No Quadro 4 há um comparativo entre os conceitos do modelo relacional e o modelo orientado a documentos:

\begin{tabular}{c|c}
\hline SGBDRs & Orientado a Documentos \\
\hline Instância banco de dados & Instância \\
Esquema & Banco de dados \\
Tabela & Coleção \\
Linha & Documento \\
Rowid & id \\
Join & DBRef \\
\hline
\end{tabular}

Quadro 4 - Comparativo modelo relacional X orientado a documentos

Fonte: Adaptado de Sadalage et al. (2013)

As bases de dados orientados a documentos possuem o foco em resolver problemas causados por bancos de dados relacionais. Trata-se do esforço necessário para traduzir objetos de um SGBDR, o que se torna um empecilho para a produtividade do programador quando surge a necessidade de alterar alguma característica da modelagem de dados. Existem ferramentas, como Hibernate, para automatizar esse mapeamento, mas apenas resolvem parcialmente o problema. A modelagem de dados em bancos orientados a documentos são mais flexíveis quanto a alterações. Nos bancos relacionais qualquer tipo de alteração no modelo de dados é custoso, pois os programas precisam ser modificados e compilados em conjunto com a alteração do modelo. Em bases de dados maiores, alteração no modelo envolve na propagação de alterações em vários outros bancos compartilhados. Nas bases de dados orientados a documento, uma aplicação pode modificar a estrutura do documento quanto quiser sem impactos para aplicação, com o custo de riscos de inconsistências ou a existência de documentos obsoletos (HARRISON, 2010).

Numa base de dados orientada a documentos, o documento pode mapear quase que diretamente para linguagem de estrutura de classes. Isto faz com que a programação seja mais fácil, mas faz levantar questões de integridade de dados, uma vez que alguns itens de dados são quase inevitavelmente duplicados (HARRISON, 2010). 


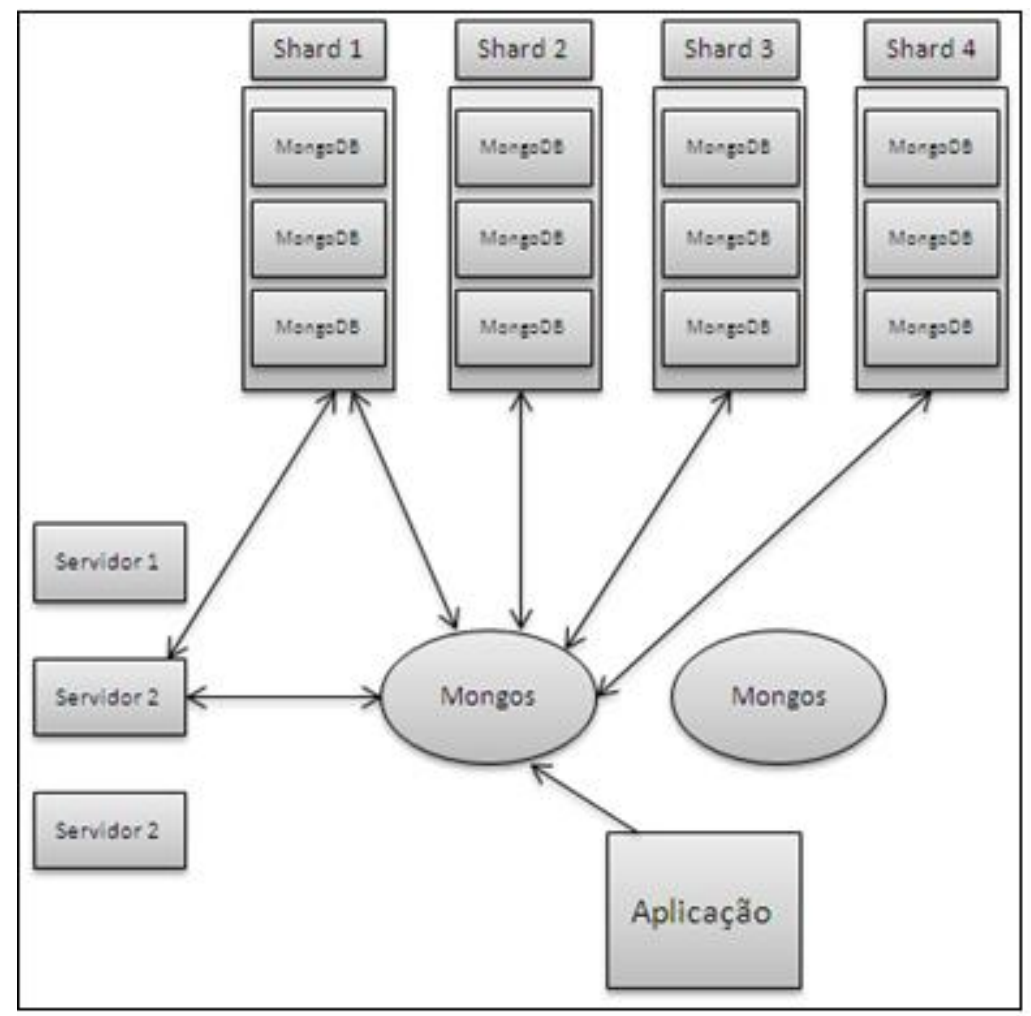

Figura 5 - Estrutura de Sharding Fonte: Adaptado de Tiwari (2011)

Na Figura 5 é apresentado como funciona a estrutura de sharding, onde os dados são divididos em vários shards, cada um contando com sua própria estrutura de replicação.

Uma das características da orientação a documentos é a presença do sharding dos dados, que consiste dividir porções dos dados (gerenciados de forma automática). A leitura e escrita passa a ser direcionado para o shard apropriado. Segundo Tiwari (2011), a presença do sharding possibilita a escalabilidade horizontal, devido à distribuição dos dados em múltiplas máquinas e servidores, onde cada máquina salva parte da coleção de dados. Os Shards são replicados para permitir a continuidade da aplicação caso um dos nós torne-se indisponível.

Um SGBD orientado a documentos pode ser uma excelente escolha para uma classe cada vez maior de projetos Web com dados em grande escala, no entanto requisitos de armazenamento podem tornar o orçamento alto em termos de hardware. Graças a sua falta de esquema estruturado, o SGBD pode crescer e mudar junto com o seu modelo de dados. Uma organização com a necessidade de escalar os servidores horizontalmente pode considerar o uso de um SGBD orientado a documentos como uma opção viável (REDMOND; WILSON, 2012). 
Segundo Sadalage et al. (2013), o uso do modelo orientado a documentos possui vantagens e desvantagens com o seu uso, dependendo do cenário avaliado a ver:

\section{a) Aplicações do modelo orientado a documentos.}

- Log de eventos. As aplicações possuem diferentes necessidades de $\log$ de eventos. Os bancos orientados a documento podem armazenar diferentes tipos de eventos e podem atuar como uma central para armazenamento de informações de eventos.

- Sistemas de gerenciamento de conteúdos e plataformas de blog. Uma vez que os bancos orientados a documentos não possuem esquemas pré-definidos, normalmente compreendidos como documentos no formato JSON, eles podem trabalhar bem no gerenciamento de sistemas de conteúdo ou em aplicações para publicações em Websites, gerenciamento de comentários de usuários, registro de usuários e perfis.

- Web Analytics ou Real-Time Analytics. Os bancos de dados orientados a documentos podem armazenar informação para análises em tempo real desde que partes dos documentos possam ser atualizadas. Esta é uma forma fácil de armazenar visitações de páginas Web e novas métricas podem ser facilmente adicionadas sem alterações no esquema do banco.

- Aplicações de e-commerce. Aplicações de e-commerce normalmente necessitam de ter um esquema flexível para produtos e ordens, assim como a habilidade de modificar seus modelos de dados sem alto custo de refatoração do banco de dados ou migração de dados.

\section{b) Desvantagens do modelo orientado a documentos.}

- Operações complexas com transações. Quando é necessário ter um cruzamento atômico entre operações de documentos, bancos de dados orientados a documentos podem não ser a melhor opção devido não possuir estrutura definida para relacionamentos entre documentos.

- Consultas contra variações de estrutura. O modelo orientado a documento tem a característica de esquema flexível. Esquema flexível significa que o banco de dados não impõe quaisquer restrições de integridade sobre o esquema, os dados são guardados na forma de entidades da aplicação. Caso seja necessário realizar consultas com junções entre entidades é necessário que o dado seja salvo como um agregado, e se o desenho do agregado está em constante 
alteração é necessário salvar o dado no mais baixo nível de granularidade. Basicamente é necessária a normalização do dado. Neste cenário, bancos orientados a documentos podem não funcionar bem para os requisitos da aplicação.

\subsection{Orientado a Grafos}

O modelo orientado a grafos possui três componentes básicos: os nós (são os vértices do grafo), os relacionamentos (são as arestas) e as propriedades (ou atributos) dos nós e relacionamentos. Neste caso, o banco de dados pode ser visto como um multigrafo rotulado e direcionado, onde cada par de nós pode ser conectado por mais de uma aresta. Um exemplo de grafo seria um caso onde se quer representar os dados de uma aplicação que deseja manter informações relativas a locais de viagens e locais onde pessoas residem. Uma consulta relevante para esta aplicação seria: "Quais cidades foram visitadas anteriormente (seja residindo ou viajando) por pessoas que viajaram para o Rio de Janeiro?". No modelo relacional esta consulta poderia ser muito complexa devido à necessidade de múltiplas junções, o que poderia acarretar uma diminuição no desempenho da aplicação e maior tempo de resposta. Porém, por meio dos relacionamentos inerentes aos grafos, estas consultas tornam-se mais simples e diretas (POKORNY, 2011).

O modelo orientado a grafos permite o armazenamento das entidades e os relacionamentos entre as entidades. A organização do grafo permite que o dado seja armazenado de uma forma e interpretado de diferentes formas baseado no seu relacionamento.

A vantagem de utilização do modelo baseado em grafos é clara quando consultas complexas são exigidas pelo modelo de negócio da aplicação. Comparado ao modelo relacional, que para estas situações pode ser muito custoso, o modelo orientado a grafos tem um ganho de desempenho, permitindo um melhor tempo de resposta das aplicações.

No exemplo mostrado na Figura 6, pode-se verificar os nós e os seus relacionamentos. Os nós são as entidades que possuem propriedades, como por exemplo, o nome. O nó Martin é na verdade o nó que possui a propriedade do nome atribuído ao Martin. 


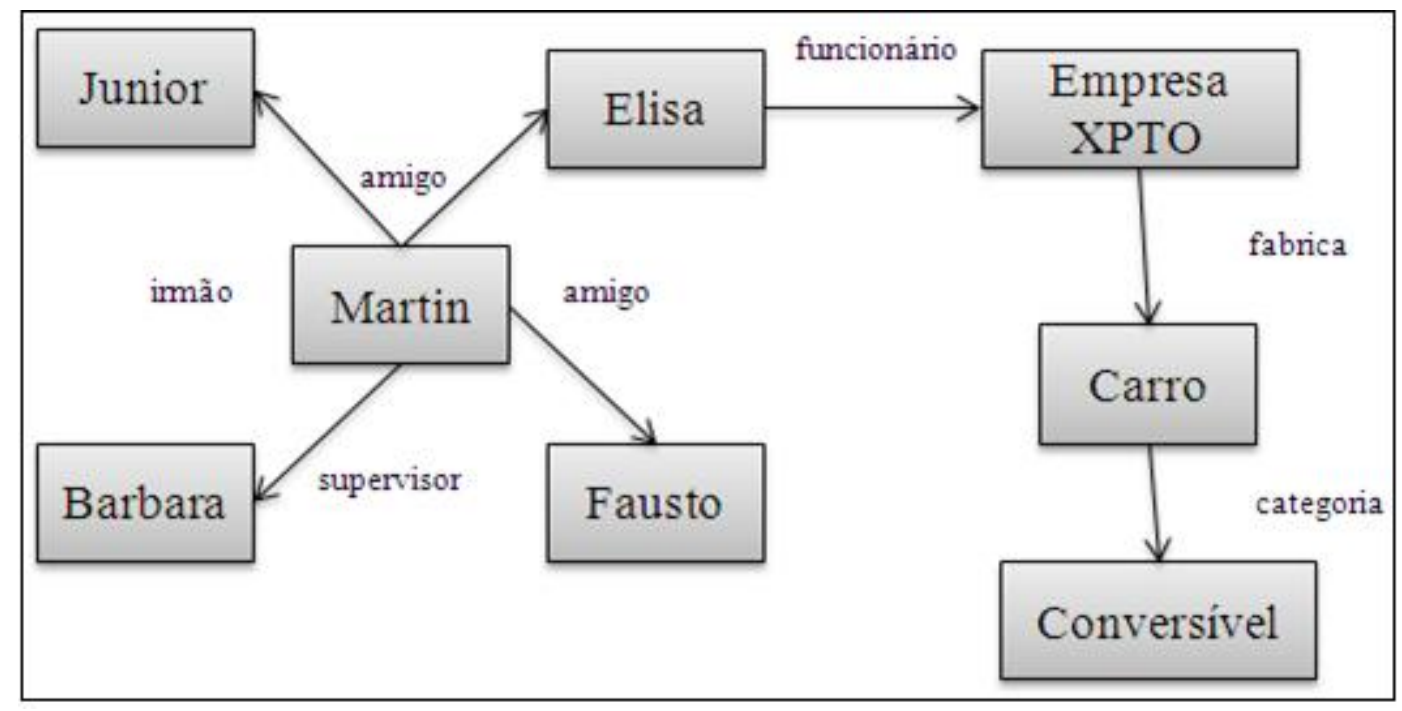

Figura 6 - NoSQL- Banco de Dados em Grafos

Fonte: Adaptado de Sadalage et al. (2013).

Segundo Sadalage et al. (2013), o uso do modelo orientado a grafos possui vantagens e desvantagens que dependem do contexto de uso.

\section{a) Aplicações do modelo orientado a grafos.}

- Dados interligados. As redes sociais são onde os bancos de dados orientados a grafos podem ser utilizados de forma muito efetiva. Os grafos sociais não são utilizados apenas para relações de amizade, mas também pode representar rede de profissionais, seus conhecimentos, onde trabalham com outros profissionais em diferentes projetos. Qualquer domínio de relacionamento pode ser suportado por bancos orientados a grafos. Caso haja relacionamentos entre entidades de diferentes domínios (como social, espacial, comércio) em um único banco de dados, é possível obter maior valor por meio destes relacionamentos por meio da capacidade de se cruzar os diferentes domínios.

- Encaminhamento, expedição e Serviços Baseados em Localização. Toda localização ou endereço de uma entrega é um nó, e todos os nós onde as entregas devem ser feitas podem ser representados em um modelo de relacionamento entre nós. Assim localizações de lugares de interesses e recomendações bem como restaurantes ou opções de entretenimento podem ser melhores representados no modelo orientado a grafos.

- Motores de recomendações: como os nós e relacionamentos são criados no sistema, essas informações podem ser utilizadas para fazer recomendações, como por exemplo, quais amigos que já compraram de determinado local ou quando se 
compra determinado item outros itens também são normalmente comprados. Os modelos baseados em grafos podem ser utilizados para um grande número de nós e seus relacionamentos sobre recomendações, facilitando a busca. Além disso, os dados podem ser utilizados para mineração de informação - por exemplo, quais produtos são comprados juntos, além disso, os grafos podem ser utilizados na obtenção de padrões de transações ou para detecção de fraudes.

\section{b) Desvantagens do modelo orientado a grafos.}

- Em algumas situações, o uso dos bancos de dados orientados a grafos não são apropriados. Quando se deseja atualizar um conjunto ou subconjunto de entidades - por exemplo, em soluções analíticas quando todas as entidades podem precisar atualizar suas propriedades, os bancos de dados orientados a grafos podem não ser a solução ideal, pois podem ser incapazes de modificar a propriedade da informação com grandes volumes de dados em todo modelo do grafo.

É importante deixar claro que um modelo não deve ser considerado melhor que o outro, uma vez que cada tipo de modelo é mais adequado para determinados contextos das aplicações. Por exemplo, para manipulação de dados estatísticos, frequentemente escritos, mas raramente lidos (como um contador de hits na Web), pode ser usado um banco de dados orientado a chave/valor, ou um banco de dados orientado a documentos. Aplicativos de alta disponibilidade, onde a minimização da inatividade é fundamental, pode-se utilizar um banco de dados orientado a colunas. Aplicações que exigem alto desempenho em consultas com muitas junções podem adotar um banco orientado a grafos, pois a consulta em um modelo relacional pode envolver junções em diversas tabelas para se chegar a um resultado que facilmente seria alcançado no modelo orientado a grafos devido a sua característica de relacionamento entre os nós do grafo (LÓSCIO et al., 2011). É importante conhecer cada modelo de dados e adotar aquele que for mais adequado com o contexto da aplicação, contribuindo para a diminuição de custos com o banco de dados, bem como para o aumento da eficiência no processamento dos dados. 


\section{Processo de Seleção de Software}

Este capítulo apresenta as normas de qualidade que são aplicadas em processo de seleção de software. Nesta pesquisa é dado foco principalmente às normas de qualidade ISO/IEC JTC1/SC7 9126 e ao modelo SQuaRE que é uma adaptação da norma ISO/IEC 9126. O modelo SQuaRE categoriza os atributos de qualidade de software em seis características: funcionalidade, confiabilidade, usabilidade, eficiência, manutenabilidade e portabilidade. Essas características são usadas neste trabalho como critérios para seleção de SGBDs.

\subsection{Análise geral das normas de qualidade e avaliação de software}

A avaliação de produto de software tem sido uma das formas empregadas por organizações que produzem ou adquirem software para obtenção de maior qualidade nestes produtos, sejam eles produtos completos ou partes a serem integradas em um sistema ou produto. Para que a avaliação seja mais efetiva é importante que se utilize de um modelo de qualidade que permita estabelecer e avaliar requisitos de qualidade e também que o processo de avaliação possa ser bem organizado e estruturado. As normas ISO/IEC JTC1/SC7 9126 e 14598 descrevem um modelo de qualidade, um processo de avaliação e alguns exemplos de métricas que podem ser utilizadas por organizações que pretendam fazer avaliação de produto de software, onde neste trabalho tem-se principal interesse nos pacotes de SGBD (KOSCIANSKI et al., 1999).

O conjunto das normas da ISO/IEC referentes à avaliação da qualidade do produto de software divide-se em duas famílias relacionadas entre si (9126 e 14598), além da norma ISO/IEC 12119, que aborda de maneira simplificada a definição dos requisitos de qualidade em pacotes de software. As famílias 9126 e 14598 foram desenvolvidas em épocas diferentes, o que faz com que o tratamento dado ao processo de avaliação não seja totalmente homogêneo (ROCHA et al., 2001).

O objetivo da avaliação de qualidade de software é apoiar diretamente o desenvolvimento e a aquisição de software que atenda as necessidades do usuário e do cliente. A meta final é assegurar que o produto forneça a qualidade desejada, atendendo as 
necessidades explícitas e implícitas dos usuários (incluindo operadores), destinatários dos resultados do software, ou mantenedores de software (KOSCIANSKI et al., 1999).

Durante a aquisição de um produto de software convém que aquele que adquire estabeleça requisitos de qualidade, especifique os requisitos para o fornecedor e avalie candidatos potenciais em relação a estes requisitos antes da aquisição. Quando um produto está em fase de desenvolvimento, o objetivo da especificação dos requisitos de qualidade é assegurar que o produto atenda as necessidades explícitas e implícitas do usuário. Na aquisição de um produto de software, a avaliação pode ser utilizada para comparar produtos alternativos e para assegurar que o produto selecionado atende os requisitos de qualidade estabelecidos (KOSCIANSKI et al., 1999).

O modelo de qualidade para características internas e externas classifica os atributos de qualidade de software em seis características que são, por sua vez, desdobradas em subcaracterísticas. As subcaracterísticas podem ser desdobradas em mais níveis que caracterizam os atributos de qualidade. As métricas internas e externas aplicam-se, em geral, ao nível dos atributos de qualidade (ROCHA et al., 2001).

Outros trabalhos realizados com o objetivo de definir as características de qualidade para software ou tecnologias de desenvolvimento específico podem ser consultados na literatura:

\section{a) Qualidade de dados}

Segundo Strong et al. (1997), os problemas na qualidade dos dados estão evidentemente em crescimento, particularmente nos bancos organizacionais. $\mathrm{O}$ impacto social e econômico da qualidade pobre dos dados custa bilhões de dólares. Os bancos de dados organizacionais coletam dados de várias fontes e a informação que é útil é utilizada para a tomada de decisão. A variedade de fontes e a complexidade em se armazenar os dados de forma eficiente contribui para os problemas existentes na qualidade de dados.

\section{b) Qualidade de Sistemas de Informação}

Para Stylianou e Kumar (2000) os problemas de qualidade dos Sistemas de Informações estão relacionados com várias dimensões. Seguem abaixo os seis níveis relacionados com a qualidade dos Sistemas de Informações:

- Infraestrutura. A qualidade de infraestrutura (hardware e software), que são mantidos pelos Sistemas de Informações inclui, por exemplo, a qualidade de rede e sistemas de software. 
- Software. A qualidade de aplicações de software construído, mantido ou suportado pelos Sistemas de Informação.

- Dado. A qualidade do dado que entra por meio de várias fontes de sistemas.

- Informação. É a qualidade do resultado da saída dos sistemas de informação. Em muitos casos, a saída de um sistema provém da entrada de outro. Neste sentido, a qualidade da informação está relacionada com a qualidade do dado.

- Administração. A qualidade da gestão das funções dos Sistemas de Informação inclui a qualidade de orçamento, planejamento e programação.

- Serviço. Refere-se à qualidade dos componentes de gerenciamento das funções do Sistema de Informação, o que inclui a qualidade do suporte ao cliente, processo que está relacionado ao help desk.

As dimensões informadas se sobrepõem, uma vez que a dimensão de um nível pode impactar diretamente na dimensão do outro. Por exemplo, uma diminuição na qualidade de infraestrutura, como interrupções nos serviços de rede, é possível que possa causar problemas reais na qualidade dos dados ou do serviço.

\section{c) Qualidade na utilização}

Segundo Rocha et al. (2001), no modelo de qualidade em uso, os atributos são classificados em quatro características: efetividade, produtividade, segurança e satisfação. A qualidade em uso é a capacidade de o produto de software permitir a determinados usuários atingir metas especificadas com efetividade, produtividade, segurança e satisfação em um contexto de uso especificado. Desta forma podem-se definir as quatro características a seguir:

- Efetividade. Refere-se à capacidade de o produto de software possibilitar aos usuários atingir metas especificadas com acurácia e completeza em um contexto de uso especificado.

- Produtividade. Refere-se à capacidade do produto de software de possibilitar aos usuários utilizar uma quantidade adequada de recursos em relação à efetividade alcançada em um contexto de uso especificado.

- Segurança. Refere-se à capacidade de o produto de software oferecer níveis aceitáveis de risco de danos a pessoas, negócios, software, propriedade ou ao ambiente em um contexto de uso especificado.

- Satisfação. Está relacionado com a capacidade do produto de software em satisfazer usuários em um contexto de uso especificado. 


\section{d) Tomada de decisão para seleção de atributos}

A tomada de decisão para a seleção dos atributos que devem fazer parte dos requisitos de qualidade de um produto é um processo de seleção de alternativas suficientes para alcançar o objetivo desejado e este processo envolve incertezas. O processo de tomada de decisão é centrado em pessoas, com suas inerentes subjetividades e inconsistências na definição do problema. Belchior (1997) propôs a lógica fuzzy para consolidar a opinião de diferentes usuários, considerando seus diferentes perfis. A teoria fuzzy é adequada para lidar com esses problemas por diversos motivos: possui a capacidade de representar atributos, possui formas convenientes e avaliáveis para combinar os atributos que podem estar vagos ou imprecisamente definidos e é capaz de manusear diferentes graus de importância para cada atributo considerado. Segundo Ibrahim e Ayyub (1992), a metodologia Fuzzy consiste na análise multicritério com o uso da priorização de componentes de um sistema, diminuindo o efeito da subjetividade. O método tem como principal objetivo obter um ranking de componentes de software com a maior probabilidade de erro, magnitude, dano e riscos econômicos.

Para Belchior (1997), o modelo fuzzy para avaliação de qualidade pode ser utilizado em três situações distintas: para obter um padrão de qualidade para o produto de software ou para o domínio de aplicação considerado, para avaliar a qualidade de um produto de software segundo um padrão de qualidade já definido e para estimar a qualidade de um produto de software quando não há padrão de qualidade definido.

O interesse nesta pesquisa refere-se à sistemática para avaliação de software, no caso, para avaliação de SGBDs NoSQL. Segundo Belchior (1997), as etapas do modelo fuzzy, que podem ser utilizadas na condução da avaliação de um componente de software, estão descritos a seguir:

- Identificação do objeto a ser avaliado e do conjunto de atributos de qualidade a ser considerado. Nessa etapa é estabelecido qual produto de software será avaliado, ou seja, os vários produtos de software intermediários ou o produto final. Além disso, é definido o conjunto de atributos de qualidade de software considerando-se o objetivo da avaliação, o domínio da aplicação e a tecnologia de desenvolvimento. 
- Escolha de especialistas. Nessa etapa é definido o perfil dos especialistas que irão avaliar os produtos. Para obter uma indicação da importância de cada um deles, é utilizado um Questionário de Identificação do Perfil de Especialista (QIPE). Este questionário é utilizado para avaliar a importância do especialista.

- Determinação do grau de importância de cada característica de qualidade identificada na primeira etapa. Nessa etapa cada especialista define um grau de importância para cada característica de qualidade que está em avaliação.

- Tratamento dos dados. Nessa etapa os prognósticos para cada característica de qualidade são combinados gerando um consenso dos especialistas.

\subsection{Modelo SQuaRE}

A qualidade de um pacote de software deve ser avaliada usando um modelo de qualidade definido. Para Koscianski et al. (1999), o modelo de qualidade deve ser usado para o estabelecimento de metas de qualidade para produtos de software finais e intermediários. A qualidade do produto deve ser hierarquicamente decomposta por meio de um modelo de qualidade composto de características e subcaracterísticas as quais possam ser usadas como uma lista de verificação de tópicos relacionados com qualidade.

O modelo de qualidade SQuaRE faz parte da série ISO/IEC 9126 que categoriza os atributos de qualidade de software em seis características (funcionalidade, confiabilidade, usabilidade, eficiência, manutenabilidade e portabilidade) as quais são subdivididas em subcaracterísticas. As subcaracterísticas podem ser medidas por meio de métricas internas e externas. As características de qualidade do modelo SQuaRE foram utilizadas neste trabalho para compor a lista de critérios que foram utilizados no Painel Delphi com especialistas.

Um modelo de qualidade possui uma estrutura hierárquica e cada característica e subcaracterística do software que influenciam a característica de qualidade. Todas as características de qualidade possuem uma subcaracterística em comum: a conformidade, que pode abranger atributos como padrões internos da empresa ou exigências de legislação aplicáveis. Cada subcaracterística pode ser dividida em atributos, que são elementos presentes no software, como por exemplo, o uso ou não de interface gráfica. A norma ISO/IEC 9126 não define atributos, pois os mesmos podem mudar conforme o produto, cabendo aos usuários da norma identificar os atributos relevantes em um projeto no momento de definir o modelo de qualidade (KOSCIANSKI; SOARES, 2007). 
A divisão hierárquica do modelo permite precisar uma descrição de requisitos de qualidade de um software. No caso deste estudo o modelo de qualidade é utilizado com o objetivo de auxiliar na definição de critérios de avaliação e seleção de SGBDs NoSQL em uma organização em ambiente Web. Assim é necessário definir a importância de cada subcaracterística e os atributos que evidenciem a presença dos requisitos de projeto.

Nos próximos itens são definidos os significados das características e subcaracterísticas do modelo de qualidade SQuaRE, baseado na norma 9126 que foram utilizados neste trabalho.

\subsubsection{Funcionalidade}

A funcionalidade diz respeito àquilo que o software faz quando solicitado pelo usuário, como, por exemplo: imprimir um relatório, apresentar dados na tela ou guardar uma informação em uma base de dados. Esta característica está relacionada com a capacidade no cumprimento de tarefas, ou seja, se uma função foi ou não implementada no programa. A forma como a função é executada é algo que pode ser avaliado em função de outras características.

Segundo Pressman (2001), a funcionalidade, com relação à avaliação de sistemas Web, possui as seguintes características: capacidade de busca e recuperação, características de navegação e browser e características relacionadas ao domínio da aplicação.

Pode-se afirmar que esta característica de funcionalidade é idêntica aos "requisitos funcionais", ou seja, a funcionalidade ou os serviços que se espera que o sistema apresente. A ISO/IEC 9126 determina que seja estabelecido um escopo quando se faz a definição de funcionalidades de um programa (KOSCIANSKI; SOARES, 2007).

A subcaracterística de adequabilidade pode ser representada no software pela capacidade de prover funções definidas para atender às necessidades do usuário.

A acurácia está relacionada com a elaboração de cálculos. Uma vez que existem limitações relacionadas à precisão, os resultados dos cálculos apresentam um valor admissível para o erro bem como o número de dígitos desejados nas respostas (KOSCIANSKI; SOARES, 2007).

Batini et al. (2009), do ponto de vista dos dados, define acurácia como o grau em que os dados estão corretos, confiáveis e certificados. Os dados podem ser especificados como precisos quando os valores de dados armazenados no banco de dados correspondem aos valores reais. A precisão pode ser definida como uma medida de proximidade de um valor de 
dados, v, para outro valor, $\mathrm{v}^{\prime}$, que é considerado corrigir. Em geral, dois tipos de precisão podem ser distinguidos, sintático e semântico. Metodologias de qualidade de dados consideram apenas a precisão sintática e defini-la como a proximidade de um valor v, para os elementos de um domínio de definição correspondendo D. Em precisão sintática não se está interessado comparar v com o seu valor v', em vez disso, o que interessa é verificar se v é qualquer um dos valores em $\mathrm{D}$, ou quão próximo está dos valores em $\mathrm{D}$.

A interoperabilidade é a capacidade de o software interagir com demais recursos do sistema.

A subcaracterística de segurança está relacionada à proteção das informações contra acessos não autorizados. Segue abaixo, segundo Davidson (1982), atributos que podem ser definidos para a subcaracterística de segurança com relação à avaliação e seleção de SGBDs:

- Nível de segurança. Analisar em que nível se encontra a segurança dos dados fornecidos pelo SGBD. Alguns produtos oferecem segurança ao banco de dados em um único nível. Outros produtos fornecem acesso restrito de acordo com o perfil do usuário a determinados campos e tabelas. Outros produtos podem fornecer segurança com base no valor de campos específicos. Isso é chamado de "segurança por valor." Um exemplo seria a de restringir um usuário à visualização de dados para apenas um departamento, ou para impedir um gestor de visualização de dados para os empregados que ganham mais do que ele. Embora não seja amplamente necessário, esse recurso pode ser importante em algumas aplicações e seria interessante que tal lógica fosse garantida pelo SGBD responsável pela manipulação de dados sensíveis.

- Privilégios. Analisar se os privilégios podem ser concedidos e revogados dinamicamente. Em alguns ambientes, pode ser vantajosa a capacidade de modificar privilégios de acesso instantaneamente, sem interferir nos usuários ativos. Algumas aplicações podem exigir autorizações de acesso a ser estabelecida ou excluída.

- Controle de acesso. Avaliar para o caso de dois ou mais aplicativos ou usuários que tentam acessar o mesmo registro exatamente ao mesmo tempo, se ocorre algum tipo de bloqueio. Verificar se é possível dois ou mais usuários realizar acesso ao mesmo registro simultaneamente para operação "read-only" ou "navegação" Alguns softwares permitem apenas um acesso do usuário para um registo, independentemente do tipo de operação executada. Outros pacotes 
bloqueiam a atualização de dados de um registro enquanto outro usuário estiver atualizando, mas permitirá a outros usuários ler ou procurar o registro. Em aplicações que podem existir muitas tentativas de acesso simultâneo para navegar e atualizar o mesmo registro, isso poderá afetar o tempo de resposta para alguns dos usuários. Pode-se utilizar o termo "multi-threading" para descrever esse recurso de acesso simultâneo.

- Mecanismo de backup. Analisar para o SGBD candidato se o fornecedor fornece uma cópia do banco de dados, ou permite o acesso a uma cópia. Caso sim é necessário analisar se haverá uma taxa para isso. O fornecedor do SGBD candidato deve se comprometer a prestar toda a assistência para a correta execução do SGBD, no entanto essa assistência geralmente vem associada a custos de consultoria, custos que devem ser avaliados no momento da escolha do SGBD.

\subsubsection{Manutenabilidade}

Está relacionada com o conjunto de atributos que evidenciam o esforço necessário para fazer modificações específicas no software. Basicamente envolve a facilidade de modificação de um produto de software (KOSCIANSKI et al., 1999).

Segundo Pressman (2001), a manutenabilidade, com relação à avaliação de sistemas Web, possui as seguintes características: Facilidade de correção, adaptabilidade e extensibilidade.

A manutenabilidade é uma característica de especial interesse para os desenvolvedores e não deve ser confundida com a possibilidade de configurar o software. Uma modificação consiste, por exemplo, em uma correção do produto ou de adaptação a mudanças de requisitos (KOSCIANSKI; SOARES, 2007).

A subcaracterística de modificabilidade está relacionada à implementação do software e traduz-se, em geral, por alterações no código. Para Koscianski e Soares (2007) há alguns fatores que podem melhorar a modificabilidade:

- Documentação da estrutura interna do produto.

- Arquitetura adequada do software.

- Clareza do código-fonte. 
A analisabilidade de um produto de software está relacionada com a facilidade com que se podem identificar problemas ou, se houver falhas, os defeitos que as causaram. Um exemplo de uso prático dessa característica poderia ser a disponibilização de informações sobre as operações internas que um software realiza.

A estabilidade do produto é uma forma de robustez: na definição da norma ISO/IEC 9126 trata-se da capacidade de um produto evitar e/ou prevenir que modificações levem a efeitos inesperados (KOSCIANSKI; SOARES, 2007).

A testabilidade, conforme define a norma ISO/IEC 9126, é a capacidade de o produto de software permitir que, uma vez modificado, seja possível sua validação e que possa ser possível sua simulação em ambiente controlado.

\subsubsection{Usabilidade}

A característica de usabilidade representa o conjunto de atributos que evidenciam o esforço necessário para se utilizar o software, bem como o julgamento individual desse uso. Basicamente essa característica representa o quão fácil é fazer uso do software e medir a facilidade com que, intuitivamente, o usuário possa executar suas tarefas (KOSCIANSKI et al., 1999).

Segundo Pressman (2001), a usabilidade, com relação à avaliação de sistemas Web, possui as seguintes características: entendimento global do site, feedback e help on-line, características estéticas e de interface e características especiais.

Pode-se dizer que a usabilidade é uma das características mais difíceis de tratar, tanto durante a definição de requisitos quanto nos estágios posteriores do ciclo de vida, na verificação e validação do produto de software. O motivo para tal é que a característica de usabilidade depende, sobretudo, de interação direta com usuário. Por esse motivo, esta é a característica que envolve a maior quantidade de fatores subjetivos durante a análise (KOSCIANSKI; SOARES, 2007).

Desta forma, durante uma avaliação de usabilidade, é preciso diferenciar a influência do software e a influência do avaliador. Fatores como nível de atenção, habilidades cognitivas e até mesmo motoras podem influenciar o resultado. Além disso, é praticamente impossível determinar o efeito de fatores externos do ambiente como ruídos, desconforto ou talvez uma preocupação pessoal sobre o nível de atenção e desempenho (KOSCIANSKI; SOARES, 2007). 
Segundo Kosciansky e Soares (2007), pode-se dividir a usabilidade em quatro subcaracterísticas:

- Operabilidade. Representa a possibilidade de o software ser controlado pelo usuário. A ausência de certas funcionalidades no sistema pode constatar a falta de operabilidade, por exemplo, a impossibilidade de interromper determinada tarefa para terminá-la posteriormente.

- Compreensibilidade. Segundo a norma ISO/IEC 9126 essa subcaracterística é muito ampla e representa a capacidade do programa permitir que o usuário compreenda - ou decida - se ele é apropriado ou não às suas tarefas. Elementos como a maneira de apresentar informações nas interfaces, sequenciar as tarefas, texto das mensagens impressas e ferramentas de auxílio às dúvidas fazem parte da avaliação dessa subcaracterística.

- Apreensibilidade. Representa a facilidade para aprendizado de uso do programa. Pode-se verificar por meio de interfaces intuitivas, que utilizem elementos de comunicação já de conhecimento do usuário ou de fácil dedução e compreensão. Programas com facilidade em seu entendimento normalmente exigem menores custos de treinamento de pessoal e podem agregar maior produtividade, uma vez que o usuário tende a executar suas tarefas com maior corretitude.

- Atratividade. Essa subcaracterística não está apenas relacionada com a beleza, mas deve-se avaliar a capacidade da interface de atrair e manter a atenção do usuário com o uso de técnicas de psicologia cognitiva combinadas à estatística para estabelecer um grau maior de satisfação e interesse com o uso do produto. Um exemplo pode ser dado com o desenvolvimento de softwares educativos infantis que devem ser projetados para manter o interesse e satisfação da criança.

\subsubsection{Confiabilidade}

A confiabilidade está relacionada com um conjunto de atributos no software que evidenciam a capacidade de manter certo nível de desempenho sob determinadas condições durante um período de tempo estabelecido (KOSCIANSKI et al., 1999).

Segundo Pressman (2001), a confiabilidade, com relação à avaliação de sistemas Web, possui as seguintes características: processamento correto de links, recuperação de erros, validação e recuperação de input de usuário. 
A subcaracterística de tolerância está relacionada se o software é capaz de, dentro de certos limites, continuar a funcionar quando algo inesperado ocorrer. Por exemplo, o espaço em disco necessário à operação torna-se menor do que o especificado nos requisitos do software. Numa situação como essa, seria desejável que o programa contornasse o problema, evitando erros ou, no pior caso, encerrando a execução de uma maneira controlada, mas não abortando a atividade repentinamente (KOSCIANSKI; SOARES, 2007).

A recuperabilidade define o comportamento onde é esperado que o software possa voltar a funcionar corretamente após a ocorrência de falha. Um exemplo muito conhecido é a recuperação de arquivos do editor de texto Word, da Microsoft. Após interrupção externa ao programa, ao ser novamente executado, é capaz de apresentar ao usuário uma versão do documento contento o texto digitado até momentos antes da falha (KOSCIANSKI; SOARES, 2007). Segundo Davidson (1982), a recuperabilidade pode ser subdividida da seguinte forma:

- Recuperação integrada dos recursos. Deve-se verificar se o SGBD contém algum mecanismo de recuperação de todos os recursos de forma integrada. Alguns SGBDs confiam inteiramente em sistema de backup do sistema operacional e nas características de recuperação para proteger os dados. Os sistemas mais sofisticados oferecem algum nível de controle diário de transações, antes da imagem diária, ou pós-imagem diária, ou uma combinação destas opções, ou seja, uma foto exata do banco de dados antes e depois de um dia.

- Recuperação automática. Se a recuperação está prevista, os processos devem ser definidos de forma automática. Na sequência de um acidente, o SGBD deve restaurar os dados com êxito por meio da última transação, logo que o sistema é trazido de volta ao ar. Outros bancos de dados vão exigir um operador ou ação de um programador para restaurar o banco de dados. Se for necessário um pessoal específico para restaurar o banco de dados, é possível haver ter atrasos no sistema de produção caso o responsável não esteja de prontidão assim que ocorrer determinado incidente.

No contexto de banco de dados, o SGBD deve guardar a base de dados com as informações diárias de transações. O SGBD deve fornecer a recuperação automática (restaurar automaticamente o banco de dados para um determinado nível com base em um arquivo de verificação ou quando o sistema é trazido novamente ao ar) sem ser necessário requerer a intervenção de programadores ou operadores para restaurar o banco de dados. 
Alguns SGBDs não oferecem os recursos de recuperação de todos os dados, contando apenas com os procedimentos de recuperação padrão do sistema ou do usuário.

A maturidade é a subcaracterística que define se o software é robusto. A definição diz que o software deve ser capaz de evitar falhas em virtude de defeitos. Isto só será possível se o programa contiver, por exemplo, testes para condições de erro pouco prováveis e tratamento de exceções. É corriqueiro utilizar o termo de maturidade para referir-se a um produto que já foi extensivamente utilizado por vários outros usuários e no qual, falhas já foram encontradas e corrigidas. Quanto maior a maturidade do produto, menor a possibilidade de existirem falhas. Com relação a pacotes de software de SGBD essa é uma das principais características utilizadas atualmente para seleção e um dos maiores entraves para a adoção de SGBD NoSQL, pois devido à tecnologia ainda ser muito recente, não possui maturidade e não foi amplamente utilizado e testado por outros usuários (KOSCIANSKI; SOARES, 2007).

Dentro do contexto de banco de dados a confiabilidade também engloba consistência dos dados. Segundo Batini et al. (2009), consistência refere-se à violação das regras semânticas definidas para o conjunto de dados. Com referência para a teoria relacional, restrições de integridade são como um tipo de regras semânticas que garantem que sejam obedecidas dentro de um determinado domínio, garantindo qualidade aos dados e prevenindo contra eventuais falhas na aplicação com relação ao tratamento do dado. A integridade pode ser definida como o grau em que uma dada coleção de dados inclui dados que descrevem o conjunto correspondente de objetos do mundo real. A integridade está geralmente relacionada com o significado dos valores nulos, onde um valor nulo possui um sentido geral de um dado que está faltando, um valor que existe no mundo real, mas não está disponível na coleção de dados. Dentro do contexto de integridade, é importante entender porque um determinado valor está faltando.

\subsubsection{Eficiência}

Trata-se do conjunto de atributos que evidenciam o relacionamento entre o nível de desempenho do software e a quantidade de recursos usados, sob condições estabelecidas (KOSCIANSKI et al., 1999).

Segundo Pressman (2001), a eficiência, com relação à avaliação de sistemas Web, possui as seguintes características: tempo de resposta, velocidade na geração de páginas e velocidade na geração de gráficos. 
A norma ISO/IEC 9126 estabelece duas dimensões para avaliar a eficiência de um software: o tempo e a utilização de recursos.

Todas as medidas de software devem ser feitas em um ambiente controlado. Algumas dessas medidas, como as utilizadas para avaliar a subcaracterística de comportamento temporal, mostram de maneira evidente a importância desse controle.

A velocidade de operação de um software pode ser afetada por inúmeros fatores: velocidade de CPU, quantidade de memória cache, memória RAM, desempenho de disco rígido, volume de tráfego na rede, interação com outros softwares e com o sistema operacional e suas configurações. Ao especificar o comportamento desejado ou ao medi-lo, o desenvolvedor deve especificar também as condições sob as quais aquela medida será válida (contexto de uso) (KOSCIANSKI; SOARES, 2007).

Na norma ISO/IEC 9126, a subcaracterística - utilização de recursos - define todo recurso que não seja o tempo de CPU: quantidade de memória, carga de CPU, ocupação de risco etc.

Alguns cuidados são necessários para avaliar a medição de eficiência de um programa. É provável que em muitos casos seja difícil ou mesmo impossível controlar com precisão o ambiente de execução do software. Neste caso, deve-se estabelecer os limites mínimo e máximo de operação, assim como um valor médio (KOSCIANSKI; SOARES, 2007).

\subsubsection{Portabilidade}

Trata-se do conjunto de atributos que evidenciam a capacidade do software de ser transferido de um ambiente para outro, ou seja, de ser utilizado em diferentes plataformas. $\mathrm{Na}$ norma ISO/IEC 9126, a definição foi estendida para abranger a ideia de portar aplicações entre organizações diferentes. Em tese, presume-se que um programa possa ser elaborado para operar em ambientes com características diferentes (KOSCIANSKI et al., 1999). A seguir são definidas as subcaracterísticas que compõe o critério de portabilidade.

A subcaracterística de instabilidade está relacionada com o processo de execução de um determinado programa pela primeira vez onde se determina pelo usuário uma série de parâmetros.

A subcaracterística de adaptabilidade está relacionada com a capacidade de o software operar em ambientes diferentes mediante modificação de configurações que já traz embutidas. A adaptação pode, por exemplo, ser realizada por um usuário final em vez de um técnico especializado (KOSCIANSKI; SOARES, 2007). 
A coexistência refere-se ao compartilhamento de recursos com outros produtos e não a troca de dados entre eles.

A característica de substitutibilidade pode ser compreendida como compatibilidade. Essa subcaracterística indica que um dado produto pode ser usado em lugar de outro, em um dado ambiente e para execução de uma determinada tarefa (KOSCIANSKI; SOARES, 2007). 


\section{Projeto de Dados}

Neste capítulo são apresentadas todas as fases que envolvem um projeto de dados, no entanto é dado especial enfoque a fase "Escolha do SGBD", principalmente quanto ao levantamento de critérios para seleção de SGBDs, uma vez que é o principal objeto de estudo deste trabalho.

Segundo Elmasri e Navathe (2005), o problema de um projeto de banco de dados pode ser expresso na definição do projeto lógico e físico da estrutura de um ou mais bancos de dados para acomodar as necessidades de informação dos usuários em uma organização para um conjunto definido de aplicações.

O projeto de um banco de dados possui várias metas e entre elas se destacam: satisfazer os requisitos de informações especificadas por usuários e aplicações; proporcionar uma estrutura natural e fácil para entender a informação e dar suporte a quaisquer requisitos de processo e objetivos de desempenho, como tempo de resposta, tempo de processamento e espaço de armazenamento. Essas metas são difíceis de executar e medir, pois envolvem um intercâmbio intrínseco: se o que se busca é maior 'naturalidade' e 'entendimento' do modelo, pode-se penalizar o desempenho. O problema é agravado porque o projeto começa, frequentemente, com requisitos informais e mal definidos. Em contraste, o resultado da atividade do projeto é um esquema de banco de dados definido de forma rígida, que, uma vez implementado, não pode ser modificado facilmente.

O processo de projeto consiste em duas atividades paralelas. A primeira atividade envolve o projeto do conteúdo e da estrutura dos dados do banco de dados; a segunda relaciona o projeto de aplicações ao banco de dados. A Figura 7 apresenta esse processo e as duas atividades que são entrelaçadas. Por exemplo, analisando as aplicações, pode-se identificar os tipos de dados que serão armazenados no banco de dados. Além disso, é durante a fase do projeto físico do banco de dados que é escolhida a estrutura de armazenamento e o caminho de acesso aos arquivos, dependendo das aplicações que usarão esses arquivos. Porém, normalmente especifica-se o projeto das aplicações do banco de dados recorrendo ao esquema construído para ele, definido durante a primeira atividade. Claramente essas duas atividades têm forte influência sobre a outra. Tradicionalmente, as metodologias de projeto de banco de dados enfatizam primeiro essas atividades, considerando que o projeto de software focalizaria a segunda; este pode ser chamado de projeto dirigido pelos dados (datadriven) versus projeto dirigido pelo processo (process-driven). Os projetistas de banco de 
dados e os engenheiros de software cada vez mais vêm reconhecendo que as duas atividades deveriam se desenvolver conjuntamente e as ferramentas de projeto cada vez mais vêm combinando as duas (ELMASRI; NAVATHE, 2005).

Segundo Elmasri e Navathe (2005) pode-se identificar seis fases principais do projeto global do banco de dados e do processo de implementação:

- Levantamento de Requisitos (Fase 1). A meta desta fase é compreender as necessidades de negócio e o levantamento dos requisitos planejados para o banco de dados.

- Projeto conceitual do banco de dados (Fase 2). A meta desta fase é produzir um esquema conceitual do banco de dados, que é independente de um SGBD específico. Durante esta fase, utiliza-se frequentemente um modelo de dados de alto nível, como os modelos Entidade Relacionamento ou modelagem não relacional NoSQL. Além disso, tanto quanto possível, é interessante especificar as aplicações ou transações conhecidas do banco de dados, usando uma notação independente de qualquer SGBD específico. Frequentemente a escolha do SGBD é feita pela organização, sendo que a intenção do projeto conceitual é manter-se tão independente quanto possível das considerações de implementação.

- Escolha do SGBD (Fase 3). Durante esta fase são levantados os principais critérios para seleção do SGBD e a partir dos mesmos é feita a avaliação dos sistemas candidatos. Os critérios para a seleção são definidos de acordo com os requisitos de negócio e são utilizados na avaliação e escolha do SGBD candidato. Esta é a fase de especial interesse para este trabalho que será apresentada com mais detalhes nas próximas subseções.

- Mapeamento do modelo de dados (Fase 4). Durante esta fase, que também é chamada de projeto lógico de banco de dados, é mapeado (ou transformado) o esquema de dados do modelo conceitual de alto nível usado na Fase 2 para dados no modelo do SGBD escolhido. Esta fase pode ser iniciada depois de escolher um tipo específico de SGBD, por exemplo, se for decidido usar algum SGBDR, mas ainda não ter sido decidido qual em particular. O resultado do projeto lógico é chamado de sistema independente (embora dependa do modelo de dados). O projeto dos esquemas externos (visões) para aplicações específicas normalmente é finalizado durante esta fase. 
- Projeto físico do banco de dados (Fase 5). Durante esta fase, são projetadas as especificações para o banco de dados em termos do armazenamento físico das estruturas, da alocação dos registros e dos índices.

- Implementação e sintonização do sistema de banco de dados (Fase 6). Nesta fase, o banco de dados e os programas da aplicação são implementados, testados e eventualmente utilizados em produção. São testadas também várias transações e aplicações individualmente e, depois, em conjunto. Normalmente, esta fase revela necessidades de alterações no projeto físico, na indexação, na reorganização e na alocação de dados - atividade que se pode chamar de sintonização (afinação, tunning) do banco de dados. Sintonizar é uma atividade contínua - parte da manutenção do sistema que perdura durante todo o ciclo de vida de um banco de dados, contando que o banco de dados e as aplicações continuam evoluindo ou à medida que forem surgindo problemas de desempenho.

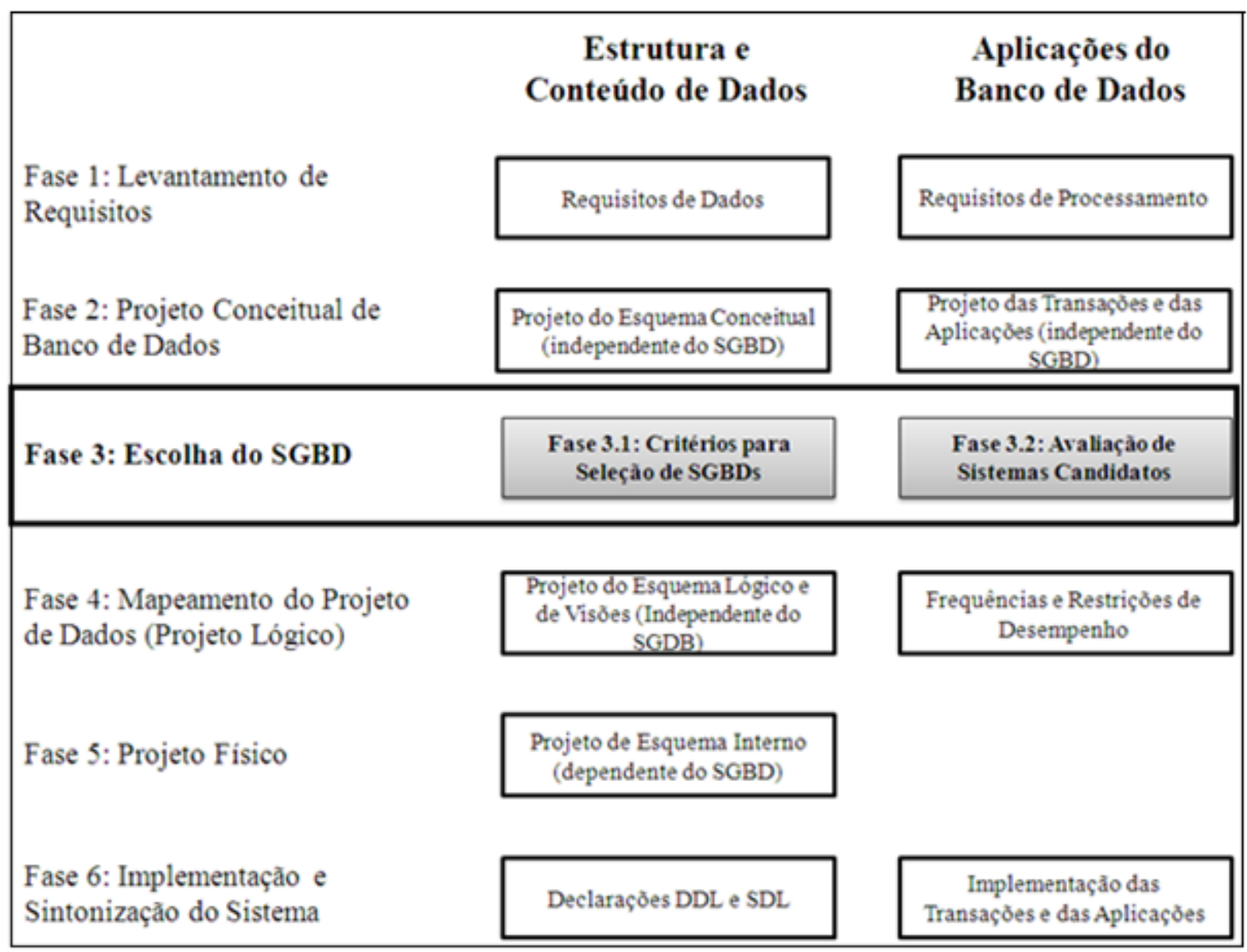

Figura 7 - Fases do projeto de dados Fonte: Adaptado de Elmasri e Navathe (2005) 
As seis fases do projeto de banco de dados não precisam seguir estritamente a sequência descrita. Em muitos casos, é necessário projetar uma fase antes da outra. Feedbacks entre as fases, e também dentro de cada fase, são comuns.

\subsection{Critérios para Seleção de SGBDs}

Segundo Elmasri e Navathe (2005), a escolha de um SGBD é regida por vários critérios - alguns técnicos, outros econômicos e outros ainda ligados à política da organização. Os critérios técnicos se preocupam com a conveniência do SGBD em relação à tarefa que se tem. Aspectos a considerar: o tipo de SGBD (relacional, NoSQL, objetorelacional, objeto, hierárquico, entre outros), a estrutura de armazenamento e os caminhos de acesso que o SGBD suporta, as interfaces disponíveis para usuários e programadores, os tipos de linguagens de consulta de alto nível, a disponibilidade de ferramentas de desenvolvimento, a habilidade para conectar-se a outros SGBDs por meio de interfaces padrão, as opções arquitetônicas relacionadas a operações cliente-servidor e assim por diante. Critérios não técnicos incluem a situação financeira e a estrutura de suporte do fornecedor. No entanto deve-se também considerar outros fatores como: a forma de distribuição e comercialização, escalabilidade, desempenho, qualificação dos profissionais envolvidos, estrutura de treinamento da organização, cultura organizacional, recursos, infraestrutura etc.

Para a avaliação dos vários pacotes candidatos de SGBDs com o objetivo de selecionar um deles para uma determinada aplicação, verificou-se que a existência de uma metodologia clara e concisa seria importante para ajudar neste tipo de tarefa. Com as rápidas mudanças na tecnologia dos computadores e a redução dos custos de hardware, mais e mais aplicações estão voltando à atenção para a questão de SGBDs. Desta forma, um guia para a avaliação de SGBDs seria de grande utilidade para muitas organizações que são confrontadas com a tarefa de selecionar um pacote de software para o gerenciamento de dados de um determinado ambiente ou aplicação.

O foco deste trabalho é o processo de seleção e avaliação de SGBDs e o levantamento de critérios relevantes neste processo. Para o levantamento dos critérios de seleção de SGBDs foi realizada uma revisão sistemática da literatura. Nos demais itens serão discutidos os critérios encontrados na literatura que podem ser utilizados no processo de seleção de SGBDs.

Neste trabalho é realizada uma revisão sistemática da literatura a fim de levantar os critérios de seleção de SGBDs, sendo que para definir a fundamentação teórica também foi 
utilizado um livro, dos autores Elmasri e Navathe (2005). Estes critérios foram utilizados para aplicação do Painel Delphi e a análise dos dados obtidos.

\subsubsection{Protocolo de Revisão Sistemática}

O objetivo do protocolo de revisão sistemática é levantar critérios de seleção e avaliação de SGBDs na literatura, a fim de serem utilizados em processos de seleção de SGBDs NoSQL, em organizações privadas, que possuem ambiente Web. O problema considerado é a inexistência de diretrizes com os critérios mais relevantes para a escolha de um SGBD e a crescente demanda por alto desempenho e armazenamento de dados principalmente nas aplicações Web. Os trabalhos científicos considerados envolvem projetos sobre SGBDs NoSQL, comparação entre SGBDs, processos em desenho de modelos de banco de dados e critérios de seleção de SGBDs. As fontes utilizadas foram consultadas em bases de dados que disponibilizam artigos completos da área de SI, com especial interesse na área de banco de dados.

As buscas foram realizadas utilizando máquinas de busca de editores ou bibliotecas digitais disponíveis. Foram utilizados principalmente o portal IeeeXplore e ACM Digital Library para a realização das buscas. As bases de dados consultadas bem como as palavras chaves usadas nas consultas estão apresentadas no Quadro 5.

\begin{tabular}{|c|c|c|}
\hline Fonte para realização das buscas & Palavras-c & \\
\hline $\begin{array}{l}\text { Biblioteca Digital do IEEE } \\
\text { (http://ieeexplore.ieee.org/Xplore/). }\end{array}$ & $\begin{array}{l}\text { "NoSQL" and "database" } \\
\text { "NoSQL" and "database" and "DBMS". }\end{array}$ & $\begin{array}{l}\text { "Evaluate" e "DBMS" } \\
\text { "Select" e "DBMS" }\end{array}$ \\
\hline $\begin{array}{lccc}\text { Biblioteca Digital } & \text { da } & \text { ACM } \\
\text { (http://portal.acm.org/). } & & \end{array}$ & $\begin{array}{l}\text { "NoSQL" and "database" } \\
\text { "NoSQL" and "database" and "DBMS" }\end{array}$ & $\begin{array}{l}\text { "Evaluate" e "DBMS" } \\
\text { "Select" e "DBMS" }\end{array}$ \\
\hline ISI Web of Knowledge. & $\begin{array}{l}\text { "NoSQL" and "database" } \\
\text { "NoSQL" and "database" and "DBMS" }\end{array}$ & $\begin{array}{l}\text { "Evaluate" e "DBMS" } \\
\text { "Select" e "DBMS" }\end{array}$ \\
\hline $\begin{array}{l}\text { Portal de Periódicos da Capes } \\
\text { (http://novo.periodicos.capes.gov.br/). }\end{array}$ & $\begin{array}{l}\text { "NoSQL" and "database" } \\
\text { "NoSQL" and "database" and "DBMS" }\end{array}$ & $\begin{array}{l}\text { "Evaluate" e "DBMS" } \\
\text { "Select" e "DBMS" }\end{array}$ \\
\hline Scopus (http://www.scopus.com/). & $\begin{array}{l}\text { "NoSQL" and "database" } \\
\text { "NoSQL" and "database" and "DBMS" }\end{array}$ & $\begin{array}{l}\text { "Evaluate" e "DBMS" } \\
\text { "Select" e "DBMS" }\end{array}$ \\
\hline
\end{tabular}

Quadro 5 - Condução das buscas da Revisão Sistemática Fonte: Próprio autor

No total foram encontrados 38 documentos. Após análise dos documentos, foram escolhidos 15 artigos para realização de leitura minuciosa e elaboração de resumos, pois 
traziam a temática de SGBDs NoSQL e tratavam sobre processo de seleção de SGBDs. Após análise dos documentos, foram efetivamente utilizados na pesquisa 12 artigos, conforme apresentado no Quadro 6. Desses 12 artigos, seis estavam relacionados ao conceito de SGBDs NoSQL e publicados em periódicos reconhecidos. Dentre os 12 artigos, foram considerados seis que tratam de critérios para seleção e avaliação de SGBD e critérios para garantir a qualidade de dados: (1) "Data Quality in Context"; (2) "Evaluating database management systems"; (3) "Methodologies for data quality assessment and improvement"; (4) "Selection of Software: The Analytic Hierarchy Process"; (5) "Parallel database systems: The future of high performance database systems" e (6) "Evoluntionary query for heterogenous distributed database systems".

\begin{tabular}{|c|c|c|}
\hline Artigo & Autor & Ano \\
\hline $\begin{array}{l}\text { A comparison between several NoSQL databases } \\
\text { with comments and notes. }\end{array}$ & Tudorica, B.G.; Bucur. & 2011 \\
\hline $\begin{array}{l}\text { A Survey of Large Scale Data Management } \\
\text { Approaches in Cloud Environments. }\end{array}$ & Sakr, S.; Liu, A.; Batista, D.; Alomari, M. & 2011 \\
\hline $\begin{array}{l}\text { A Request Skew Aware Heterogeneous } \\
\text { Distributed Storage System Based on Cassandra. }\end{array}$ & Zhen Ye; Shanping Li. & 2011 \\
\hline Implementation of NoSQL for robotics. & Vijaykumar, S.; Saravanakumar. & 2010 \\
\hline Will NoSQL Databases Live Up to Their Promise? & Leavitt, N. & 2010 \\
\hline Cache and consistency in NOSQL. & Peng Xiang; Ruichun Hou; Zhiming Zhou. & 2010 \\
\hline Evaluating database management systems. & Davidson, Edward. & 1982 \\
\hline Data Quality in Context. & Strong, D. M.; Lee, Y. W.; Wang, R. Y. & 1997 \\
\hline $\begin{array}{l}\text { Methodologies for data quality assessment and } \\
\text { improvement. }\end{array}$ & $\begin{array}{l}\text { Batini, Carlo; Cappiello, Cinzia; } \\
\text { Francalanci, Chiara; } \\
\text { Maurino, Andrea. }\end{array}$ & 2009 \\
\hline $\begin{array}{l}\text { Selection of Software: The Analytic Hierarchy } \\
\text { Process. }\end{array}$ & Min, $\mathrm{H}$. & 1992 \\
\hline $\begin{array}{l}\text { Parallel database systems: The future of high } \\
\text { performance database systems. }\end{array}$ & DeWitt, D. ; Gray, J. & 1992 \\
\hline $\begin{array}{l}\text { Evoluntionary query for heterogenous distributed } \\
\text { database systems. }\end{array}$ & $\begin{array}{l}\text { Ghaemi, R.; Fard, A. M.; Tabatabaee, H.; } \\
\text { Sadeghizadeh, M. }\end{array}$ & 2008 \\
\hline
\end{tabular}

Quadro 6 - Lista de artigos utilizados por meio de levantamento da revisão sistemática Fonte: Próprio autor 


\subsubsection{Resultados da Revisão Sistemática}

A partir dos resultados da revisão sistemática, verificou-se um crescimento no uso de SGBDs NoSQL nas organizações. Os artigos discutem os tipos de aplicações mais adequadas para o uso de SGBDs NoSQL, como por exemplo, sistemas onde o desempenho e alta performance são fundamentais em detrimento de consistência e integridade dos dados.

Para Sakr et al. (2011), com o crescimento constante do poder de processamento e inovações em tecnologia $W e b$, passou-se a exigir uma mudança na arquitetura de computação com relação ao conceito de armazenamento de dados em larga escala e rever os mecanismos de processamento. Muitos projetos começaram a seguir o conceito NoSQL e que têm sido apoiados por diferentes tipos de armazenamentos de dados, tais como, armazenamento por chave-valor, armazenamento por documento e armazenamento por grafo.

Os critérios para seleção e avaliação de SGBDs foram extraídos da revisão sistemática e sua fundamentação teórica complementada pelo trabalho de Elmasri e Navathe (2005). Esses critérios estão reunidos em três grupos e estão apresentados a seguir.

\subsubsection{Fornecedor}

Após a compilação da lista de SGBDs candidatos, cada fornecedor de software deve ser solicitado para enviar a sua proposta, que pode dar uma visão geral dos recursos que o pacote SGBD oferece. Além disso, os fornecedores podem oferecer manuais técnicos, os quais podem ser usados para avaliar exatamente o quão fácil ou difícil é utilizar o SGBD e definir o esforço em se obter recursos específicos, a qualidade e a profundidade da documentação (o quão fácil será o uso dos manuais pela equipe de processamento de dados, qual a formação que será necessária, e assim por diante). Alguns fornecedores podem apresentar ou emprestar o material de forma gratuita. No entanto, não deve haver necessidade de aquisição de materiais até a seleção final ser feita (DAVIDSON, 1982).

Os fornecedores devem ser solicitados a fornecer uma cópia do último relatório anual (empresas, se forem abertas) ou uma descrição da empresa com algumas informações financeiras que podem ser utilizados para avaliar o crescimento e a estabilidade do fornecedor.

Os itens listados a seguir podem ser utilizados para classificar os SGBDs com relação à característica do fornecedor: 


\section{Reputação}

Segundo Davidson (1982) a boa reputação para responder aos pedidos de informação, lidar com os problemas relatados com o SGBD e fornecer apoio técnico. Esta informação pode ser obtida por meio de entrevistas com usuários atuais ou passados do software ou por meio de pesquisas realizadas por periódicos e revistas que tratam sobre o tema de processamento de dados.

A satisfação dos usuários também está relacionada à reputação. Durante entrevistas com os usuários, os comentários podem ser feitos ou solicitados a fim de indicar se podem ou não ser recomendados para outros, se o produto tem ficado acima das suas expectativas, e se o cliente acredita na qualidade do produto do fornecedor a ponto de usar outro software do mesmo fornecedor.

Para Min (1992), a reputação do fornecedor pode ser considerada como o seu círculo de negócio, o que pode ser uma boa referência para avaliação da credibilidade, boa vontade e confiança no fornecedor.

\section{Suporte}

Comunicação de problemas. A comunicação com o fornecedor para relatar problemas com a operação do produto. Muitos fornecedores prestam este serviço. Alguns têm números gratuitos, alguns funcionam vinte e quatro horas por dia, incluindo fins de semana.

Para aplicações que operam durante o horário não comercial, uma linha de atendimento 24 horas pode ser levada em consideração.

Notificação de problemas. Procedimento de notificação para todos os usuários, em uma base regular, de problemas relatados a fim de manter todos os usuários informados sobre o estado do problema do seu produto.

Mecanismos de alarmes. Inclui alarmes e abertura automática de incidente. Este é um quesito crítico para aplicações que exigem alta disponibilidade e total dependência com o banco de dados, onde qualquer tipo de falha ou problema deve ser imediatamente alarmado para os responsáveis pela manutenção e administração do banco de dados ou disparar correção automática no SGBD.

Suporte para instalação. Alguns SGBDs podem ser instalados pelo usuário simplesmente carregamento um ou mais arquivos oferecidos pelo fornecedor. Outros SGBDs requerem maior apoio técnico para instalar. Em determinadas ocasiões, o suporte de instalação do fornecedor é agregado no custo do SGBD, e alguns estão disponíveis em uma taxa base associado ao preço de compra (DAVIDSON, 1982). Segundo Min (1992), o suporte 
do fornecedor depois da aquisição é crítica para o sucesso da instalação e manutenção do software.

\section{Recursos adicionais}

Bases de testes. Fornecimento de bases de dados de teste de pequeno porte para instalação do produto. Alguns fornecedores oferecem um ou vários SGBDs de teste com um pequeno número de registros a serem utilizados pela organização para a aquisição e experimentação com os dados sem ter que definir e carregar os seus dados completos de produção. Este arranjo aumenta significativamente a velocidade quanto à decisão na utilização do produto e permite uma rápida revisão e avaliação de recursos de software e outros procedimentos relacionado ao SGBD avaliado.

Treinamento. Treinamento do cliente quanto ao uso do SGBD. Alguns fornecedores têm excelente formação em programas de treinamento, não só no uso elementar do SGBD, mas em técnicas avançadas, design, melhorias, otimização e assim por diante. Já em outros SGBDs toda a educação, além de uma breve introdução, vem de manuais em uma base do “faça você mesmo". Para organizações com pequenas equipes e uma necessidade para a produtividade rápida, programas de treinamento para o cliente pode ser um fator crítico para o sucesso de determinado projeto (DAVIDSON, 1982). Segundo Min (1992), se o vendedor não fornece serviços de treinamento gratuito para o grupo de usuários, o custo de treinamento será um componente importante do custo total.

Disponibilidade de serviço de venda. É importante a disponibilidade de ajuda de fornecedores que resolvam problemas com o SGBD, uma vez que a migração de dados entre SGBDs geralmente é um grande empreendimento e requer, inicialmente, muita assistência (DAVIDSON, 1982).

\section{Capacidade de investimento e continuidade}

Melhorias futuras e modificações. Avaliar se o SGBD possui planejamento de melhorias para próximas versões a fim de acompanhar as evoluções e complexidade das aplicações. Deve-se verificar se o fornecedor do SGBD tem o compromisso de manter o produto atualizado com os avanços em tecnologia de banco de dados e de acordo com o cenário de constante evolução da TI. Alguns SGBDs possuem a tendência de estabilizar à medida que amadurecem e embora possam satisfazer as exigências atuais, podem não serem capazes de suprir as necessidades futuras. Atualmente as organizações esperam aumentos substanciais no número, tamanho e complexidade do banco de dados e das aplicações que os 
utiliza, desta forma deve ser dada a devida importância para que o SGBD evolua conforme as aplicações do mercado. As melhorias e modificações nos SGBDs sejam para a correção de erros de versões anteriores ou para a adição de novos recursos é importante para que o SGBD possa acompanhar a evolução das aplicações (DAVIDSON, 1982).

Segundo Min (1992), é desejável que haja estabilidade no fornecedor, uma vez que o contato com o fornecedor de curta duração significa extinção rápida de serviços ao usuário. Desta forma, é desejável escolher um fornecedor estabelecido que esteja em atuação por um longo tempo.

\subsubsection{Produto}

Antes do processo de avaliação poder começar, os requisitos operacionais e funcionais que o produto de software para gerenciamento de banco de dados deve satisfazer devem ser documentados. Os requisitos são utilizados para documentar, categorizar e de acordo com a ordem de prioridade dos critérios específicos de avaliação, utilizados para analisar cada pacote candidato.

Após os requisitos específicos serem determinados, eles devem ser priorizados de acordo com sua importância para o sucesso da aplicação. Caso alguns requisitos possuem possibilidades de implementações alternativas (processos de recuperação, de preferência automáticos), as alternativas podem ser priorizadas.

Quando os requisitos priorizados tiverem sido documentados, eles podem ser usados para desenvolver uma lista de critérios que podem ser utilizados na avaliação de SGBDs candidatos. Um dos requisitos pode resultar em vários critérios específicos.

Davidson (1982) fornece por meio de critérios de avaliação os itens listados abaixo que representam possíveis áreas relacionadas com a avaliação de SGBDs. Estes itens, e qualquer outro que os membros da organização possam sugerir, devem ser revistos para a aplicação dos requisitos do sistema.

\section{Desempenho}

As características de desempenho devem ser analisadas ao se adotar ou não um SGBD NoSQL, pois aplicações que exigem alto desempenho em consultas realizadas em grande volume de dados como aplicações Web, podem ter determinados módulos do sistema suportados por SGBDs NoSQL. 
Segue abaixo critérios relevantes sobre a análise de características de desempenho de um SGBD:

Otimização de consultas. Analisar se o SGBD está preparado para otimizar múltiplas consultas. Alguns SGBDs irão determinar o menor caminho para os dados descritos pelas teclas combinadas analisando o número de registros de qualificação de cada chave e selecionando o menor caminho de acesso. Outros SGBDs analisarão registros com base na ordem das chaves expressas na consulta ou instrução. Dependendo do número de registros para determinação de cada chave, uma técnica pode resultar em melhor desempenho que a outra. Estas preocupações se aplicam principalmente para SGBDs gerenciais. A otimização de queries pode ser definida também melhoria no processo de consulta (GHAEMI ET AL., 2008). A otimização de consultas é fundamental para o desempenho geral de um sistema, utilizando-se de vários algoritmos complexos, responsáveis por melhorar processamento de consultas. Para garantir a otimização de consultas é utilizado um plano de execução da consulta.

Execução nativa ou em modo de compatibilidade. Avaliar se o SGBD será executado no modo "nativo" ou no "modo de compatibilidade". Processamento de modo nativo é o mais eficiente, tendo proveito dos recursos de hardware e software do sistema. Geralmente é escrito ou compilado na linguagem assembler do sistema em que está hospedado. No modo "compatibilidade" o SGBD emula outro sistema operacional para executar o software. A emulação pode ter um impacto significativo sobre desempenho.

Capacidade de múltiplas bases. Verificar se há limitações no que diz respeito ao número de bases de dados suportado pelo SGBD, como por exemplo, se há alguma limitação ao número de arquivos por banco de dados, número de registros por arquivo ou número de bytes por registro. Determinadas aplicações com requisitos de grandes quantidades de dados podem encontrar SGBDs específicos muito restritivos ou limitado no que respeito à quantidade de dados que pode ser manipulados.

Paralelismo. Segundo DeWitt e Gray (1992), o ideal em sistemas paralelos é possuir duas propriedades chaves: (1) velocidade linear: o dobro da capacidade de hardware pode executar a tarefa pela metade do tempo, e (2) escala linear: o dobro do hardware pode executar no mesmo tempo uma tarefa duas vezes maior. Conforme mencionado anteriormente, é sempre desejável a melhoria em desempenho em bancos de dados por meio de escalabilidade horizontal, requisito garantido pela capacidade de paralelismo do SGBD. 


\section{Recursos de administração}

Segundo Davidson (1982), os recursos de administração auxiliam os profissionais envolvidos diretamente com a administração e modelagem de dados a realizarem alterações. É desejável para a seleção de um SGBD que o mesmo forneça recursos de administração a fim de facilitar e tornar mais ágeis alterações no modelo de dados. Seguem a seguir critérios relacionados com recursos de administração de dados:

Dicionário de Dados. A avaliação do SGBD deve verificar se o mesmo possui um dicionário de dados integrado e caso sim, se o dicionário de dados é ativo ou passivo. A maioria dos SGBDs possui dicionário de dados. Os SGBDs mais sofisticados têm dicionários que possuem o controle de todo acesso aos dados de usuários e administradores de banco de dados. O dicionário de dados permite o acesso a uma determinada parte dos dados para visualização de forma consistente, eliminando a necessidade de ter instruções de definição de dados em cada programa, padroniza os nomes de cada campo, e possui os controles de acesso ao banco de dados, arquivo e / ou nível de campo. Alguns destes também são utilizados para armazenar consultas pré-codificadas e visões do usuário. Um dicionário de dados passivo possui algumas informações sobre os dados para fins de documentação, mas não exercem qualquer controle sobre o acesso aos dados.

Interface amigável. Analisar se o SGBD possui características de uso amigável, ou seja, de fácil manipulação, afim que possibilite reduzir o esforço de desenvolvimento de aplicações, permitir menor investimento em qualificação de pessoal e sem a necessidade de ser essencialmente técnico para tornar efetiva a utilização dos dados. Algumas características a serem consideradas incluem complexidade nas instalações, linguagens de consulta integradas, relatórios, comandos de ajuda acessíveis de forma interativa, alarme de erros significativos e mensagens de diagnóstico. Atualmente a abordagem de SGBDs NoSQL sofre neste quesito, onde a linguagem de consulta inexiste como a linguagem SQL nos SGBDRs e a garantia da consistência dos dados fica a cargo da aplicação, não sendo garantida pelo SGBD, tornando ainda mais complexa a atividade do desenvolvimento e sempre necessitando de um especialista para o acesso e recuperação dos dados.

Ferramentas de administração de dados. Alguns SGBDs disponibilizam ferramentas que facilitam a administração de dados como: editores de texto e navegadores (browsers), geradores de relatórios, software de comunicação (frequentemente chamados de monitores de teleprocessamento), ferramentas de busca e acesso que podem ser usadas na World Wide Web (facilidades para $\mathrm{Web}$ ) e ferramentas gráficas para projeto de banco de dados. 
Manuais técnicos. Manuais técnicos descritos de forma clara com exemplos e ilustrações adequados. Alguns produtos têm suas documentações mal descritas ou até mesmo inexistentes, o que aumenta o esforço necessário para aprender e usar o SGBD eficazmente. Muitos projetos de software não têm orçamentos para treinamento de equipe e o tempo de trabalho geralmente é curto. Para maximizar o esforço de desenvolvimento, a equipe deve ser capaz de rapidamente encontrar e compreender as informações necessárias na documentação, sem ter que constantemente chamar o pessoal técnico do fornecedor para interpretação ou explicação. Exemplos de programas e rotinas, bem como exemplos de instruções individuais, onde as instruções fornecidas são descritos, podem melhorar muito a eficiência da documentação do SGBD.

\section{Disponibilidade}

Disponibilidade. Deve ser avaliado se o banco de dados deve ser desativado para execução de quaisquer ou todas as funções de administração de banco como a definição de um novo campo, a expansão no tamanho de um campo, a exclusão de um campo, atribuição de uma nova chave, ou a concessão ou revogação de privilégios de acesso. Alguns SGBDs permitem que muitas atividades de administração de banco de dados possam ser dinâmicas e não oferecer impacto sobre a execução das aplicações, exceto para componentes diretamente afetados por alterações específicas. Essa característica pode ter grande impacto em ambientes de constantes alterações no seu software. Soluções alternativas para este problema podem ser definidas como realizar modificações nas bases de dados durante períodos de pouco ou nenhum uso da aplicação (noites, fins de semana, ou feriados) ou inatividade do banco de dados pré-agendada durante a manutenção.

Processamento concorrente. Verificar se o SGBD avaliado possui um suporte para o processamento concorrente por múltiplos usuários ou por lote. Alguns SGBDs não permitem que mais de uma aplicação ou usuário realize acesso no mesmo momento. Outros podem ter que limitar o número de utilizadores ativos ou aplicações que podem processar simultaneamente. O projeto e uso potencial de uma aplicação pode exigir a capacidade de suportar vários usuários simultâneos.

Ghaemi et al. (2008) explica que a utilização de recursos distribuídos ao longo de um local, área geográfica ou rede em uma ampla área melhora a confiabilidade, desempenho e disponibilidade. 


\section{Flexibilidade}

Portabilidade. A portabilidade sobre o hardware do computador e sob quais sistemas operacionais deve suportar. O cronograma de implementação em hardware deve ser o mesmo para diferentes sistemas operacionais, devendo ser possível sua execução em qualquer tipo de hardware e sistema operacional. Para Davidson (1982) antes de selecionar SGBDs candidatos para uma avaliação, deve ser determinado o ambiente em que este software estará operando, o hardware do computador e a especificação do sistema operacional instalado. Deve ser levado em consideração também as possíveis instalações subsequentes do sistema. Será que todas as instalações envolvem o mesmo hardware e sistema operacional? Alguns SGBDs, especialmente aqueles comercializados pelos fornecedores de hardware em si, podem ser limitados a um tipo específico de hardware ou sistema operacional, enquanto que outros pacotes podem ser executados em uma ampla variedade de sistemas. Embora o uso de um pacote único possa resolver a necessidade atual, pode limitar o crescimento futuro ou dispersão da aplicação para outros modelos de negócio, limitando um possível crescimento da aplicação.

Flexibilidade. O SGBD deve possuir dicionário de dados integrado com linguagem de consulta e disponibilizar geração dinâmica ou supressão de chaves do usuário, pontos de vista e privilégios de acesso de forma flexível. O SGBD deve suportar múltiplos usuários ao mesmo tempo e também múltiplos bancos de dados. O SGBD deve suportar processamento distribuído e vários usuários online ao mesmo tempo.

Alterações DDL dinamicamente. Analisar na avaliação, quando relevante para a aplicação, se será possível ao SGBD permitir que os principais campos e as visões dos usuários possam ser criados e excluídos dinamicamente e se é possível ao SGBD que novos itens de dados sejam definidos dinamicamente. Em ambientes onde os requisitos de dados irão continuamente mudar, pode ser vantajoso a capacidade de expandir o banco de dados, criar e excluir chaves, criar, modificar e excluir exibições de usuário sem ser necessário restringir a utilização do banco de dados ou exigir que o banco de dados seja temporariamente desativado. Em algumas aplicações, onde os requisitos de dados são estáticos, estes recursos podem não ser necessários.

Suporte a múltiplas consultas. Analisa se o SGBD permite a consulta de vários bancos de dados em uma tentativa de acesso. Alguns SGBDs só pode acessar um banco de dados de cada vez. Alguns SGBDs restringem consultas e chamadas para um arquivo de banco de dados de cada vez, exigindo múltiplas consultas ou chamadas para satisfazer os complexos 
pedidos de recuperação. Alguns SGBDs permitem múltiplos acessos em uma única consulta, simplificando o procedimento de acesso e aumentando a flexibilidade do sistema.

Flexibilidade de plataforma. A análise deve considerar se o SGBD pode ser executado em qualquer hardware / sistema operacional. Alguns SGBDs, especialmente aqueles desenvolvidos ou comercializados por um determinado fornecedor, podem ser restritos a plataforma do próprio fornecedor. Configurações de hardware que permitem apenas SGBDs específicos ser executados pode ser um fator de limitação para a aplicação. Uma questão relacionada é se o software é executado no modo nativo ou no modo de compatibilidade (emulação) sobre o hardware no qual ele é executado.

\section{Licença de uso}

Proprietário. O software proprietário, particular ou não livre é um software para computadores que é licenciado com direitos exclusivos para o produtor. Conforme o local de comercialização do software este pode ser abrangido por patentes, direitos de autor assim como limitações para a sua exportação e uso em países terceiros. Seu uso, redistribuição ou modificação é proibido, ou requer que você peça permissão, ou é restrito de tal forma que você não possa efetivamente fazê-lo livremente. Neste caso a distribuição do SGBD é controlada e há custos inerentes a contratação do pacote, que variam conforme acordo feito com o fornecedor, mas normalmente a licença é orçada de acordo com a quantidade de CPUs que possui o banco de dados onde o SGBD será instalado.

Aberta. Este tipo de licença trata-se de qualquer programa que tem a liberdade de ser usado, copiado, modificado e redistribuído. Opõe-se ao conceito de software proprietário. Pode ser vendido ou disponibilizado gratuitamente. Normalmente os SGBDs NoSQL são de licença aberta, como por exemplo, o MongoDB e o Cassandra. Esse tipo de licença possui variações com relação a sua forma de distribuição e suporte. Os SGBDs NoSQL usualmente não possuem suporte, mas é possível encontrar suporte na comunidade e também em empresas especializadas na tecnologia.

\subsubsection{Organização}

Os critérios listados a seguir estão relacionados com a organização, ou seja, dependem diretamente de questões ligadas diretamente ao contexto organizacional para a avaliação e seleção de um SGBD. A filosofia da organização pode ser um critério dominante que afeta a aceitabilidade na organização de um modelo de dados em específico (por exemplo, relacional 
contra o NoSQL), de certo fornecedor ou de certa metodologia e ferramentas de desenvolvimento (por exemplo, o uso da análise NoSQL e de metodologias e ferramentas de projeto que podem ser necessários para as novas aplicações).

Segundo Davidson (1982), vários critérios econômicos e organizacionais afetam a escolha de um SGBD, como os itens descritos a seguir:

\section{Critérios econômicos}

Custo de aquisição. Este é o custo inicial mais alto para a compra de SGBD e englobam as opções de linguagens, as diferentes interfaces, como formulários, menus e ferramentas Web para interface gráfica com o usuário, as opções de backup, os métodos de acesso especiais e a documentação. É necessário selecionar a versão correta do SGBD para um sistema operacional específico. Normalmente as ferramentas de desenvolvimento, de projeto e suporte adicional à linguagem não estão incluídas na estimativa básica. A organização, no momento da aquisição, deve rever os preços para as várias opções no que diz respeito às características oferecidas pelo produto, o apoio disponível e a reputação do fornecedor e do produto. Um produto mais caro não é necessariamente um produto melhor.

Custo de manutenção. Este custo ocorre periodicamente ao contratar a manutenção padrão do fornecedor ou para manter a versão do SGBD atualizada.

Custo de aquisição de hardware. Pode ser necessária a aquisição de um hardware novo, como memória adicional, terminais, unidades de disco e controladores, ou memória especializada para o SGBD.

Custo de criação e de conversão do banco de dados. Este é o custo para criar o SGBD pela primeira vez, ou para converter um sistema existente no novo software do SGBD. No último caso, é habitual operar o sistema já existente paralelamente ao novo sistema até que todas as aplicações sejam completamente implementadas e testadas. Este custo é difícil de ser estimado e, em geral, é subestimado, pois o custo de migração dos dados de uma plataforma para outra normalmente não são corretamente mensurados no momento da definição do novo SGBD.

Custo de pessoal. A primeira aquisição do SGBD é frequentemente acompanhada pela criação, ou reorganização, do departamento de processamento de dados. Há, na maioria das empresas que adotaram SGBDs, cargos para pessoal de DBA e sua equipe relacionada com a atividade de administração de dados.

Custo de treinamento. Como os SGBDs são sistemas extremamente complexos, frequentemente há necessidade de treinamento de pessoal para usar e programar o SGBD. O 
treinamento é necessário em todos os níveis, inclusive em programação, desenvolvimento de aplicações e administração de banco de dados.

Custo operacional. O custo da operação continuada do SGBD não é normalmente considerado nas alternativas de avaliação porque ele ocorre independentemente do SGBD selecionado.

Otimização de espaço em disco. Analisar se o SGBD prevê a compressão / descompressão dos espaços em branco repetidos, os campos com zero ou com valores nulos de forma a otimizar o espaço em disco. Para muitas aplicações com alto volume de geração de dados, este critério pode ser de grande importância para que seja possível escalar soluções que atendam aos requisitos do negócio sem a necessidade de aumentar recursos de infraestrutura, como maior alocação de máquinas e storage.

Segundo Min (1992), caso os custos da compra do software de fornecedores externos excedam os custos de desenvolvimento de um software dentro da organização, o software comercial deve ficar fora de consideração. Desta forma é importante estimar cuidadosamente o custo de aquisição, instalação e manutenção do software, bem como o custo de grupos de usuários dos empregados de treinamento. Para estimar o custo total do uso do software, o usuário deve saber o valor da compra de uma única vez ou preço recorrente por encomenda de alteração de algum módulo do sistema. A taxa de manutenção não está incluída no preço de compra, assim, a taxa de manutenção deve ser adicionada ao componente de custo. Caso o vendedor não forneça serviços de treinamento gratuito para o grupo de usuários, o custo de treinamento torna-se um componente importante do custo total.

Com relação à qualidade de dados, segundo Batini et al. (2009), os custos são uma perspectiva relevante, devido aos efeitos da baixa qualidade dos dados sobre as atividades que consomem recursos. O custo da qualidade dos dados é a soma do custo de avaliação e melhoria de atividades de qualidade de dados e os custos associados à má qualidade dos dados. O custo de má qualidade pode ser reduzido por meio da implementação de um programa de qualidade de dados mais eficaz.

\section{Inovação}

A inovação faz parte da filosofia da organização que define se a mesma valoriza novas tecnologias ou se prioriza a continuidade das aplicações de forma convencional privilegiando a robustez e conformidade. Esse critério pode ser determinante para a avaliação do uso de um SGBD NoSQL uma vez que este é um modelo inovador que exige investimento neste campo. 


\section{Perfil de risco}

Está relacionado também com a filosofia da organização, e verifica se a mesma aceita riscos inerentes a novas tecnologias. Este critério avalia se a organização está disposta a investir em novas tecnologias e modelos, mesmo diante dos riscos e dificuldades encontrados durante processos de mudança.

A implantação de um SGBD é um projeto e de acordo como define o PMBOK® (2004), na gestão de projetos deve-se considerar os riscos, considerando que o risco é um evento ou condição incerta que, se ocorrer, terá um efeito positivo ou negativo sobre o objetivo do projeto, como tempo, custo, escopo ou qualidade. Um dos primeiros passos com relação ao risco de implantação de um SGBD é verificar o perfil dos stakeholders, uma vez que há empresas muito rigorosas com relação a risco, o que poderia inviabilizar um processo de implantação ou mudança de um pacote SGBD para outro de um conceito inovador como, por exemplo, o conceito NoSQL.

\section{Importância atribuída a TI}

Está relacionado ao treinamento disponibilizado, reconhecimento da importância dos SGBDs, valorização dos profissionais de TI e como a organização encara o grau de contribuição da TI para o negócio. Este critério verifica se a organização admite a importância da TI através de investimentos na área, investindo em melhorias e promovendo o desenvolvimento da área de TI.

\section{Profissional de TI}

Deve-se considerar também os profissionais envolvidos na organização para escolha de um candidato a SGBD. Os profissionais podem oferecer resistência a determinadas tecnologias que não dominam e o conhecimento de determinado projeto pode ficar restrito a um determinado grupo que detém o conhecimento de um SGBD específico. Esta é uma grande preocupação quando se opta fazer a escolha de um SGBD que não oferece suporte e ainda não é amplamente difundido no mercado, a exemplo dos SGBDs NoSQL. Para evitar essas situações é importante a organização mensurar o impacto de um possível treinamento da equipe nesta nova tecnologia e analisar as dificuldades que as equipes de desenvolvimento poderiam enfrentar com esta nova realidade de modelagem de dados. Conforme mencionado nos itens anteriores, o gerenciamento de dados em estruturas NoSQL demandam maior esforço com relação a programação que passa a depender de habilidades de query programming uma vez que a integridade dos dados e a garantia das propriedades $A C I D$ 
passam a ficar a cargo da aplicação, tornando assim mais complexa a atividade de desenvolvimento.

Familiaridade. Este critério define se os programadores da organização estão familiarizados com um SGBD em particular, neste caso pode ser favorecido de forma a reduzir treinamento e tempo de aprendizagem.

Satisfação do profissional. Também está relacionado com a satisfação dos usuários (profissionais de TI). Neste quesito também é avaliada a importância que a organização dá aos profissionais com a aplicação de treinamentos em novas tecnologias e incentivo ao profissional a se adaptar a novas realidades do mercado, sendo um critério importante para adoção de novas tecnologias, como os SGBDs NoSQL.

\subsection{Avaliação de Sistemas Candidatos}

Quando os requisitos de sistema e critérios de avaliação foram definidos e priorizados e após a revisão da documentação solicitada aos fornecedores, podem ser iniciadas a avaliação e a revisão de SGBDs candidatos (DAVIDSON, 1982).

Para Davidson (1982), pode ser vantajoso para o desenvolvimento existir alguma forma de documentação que resuma os requisitos específicos, critérios de avaliação e características desejadas do software de modo que observações apropriadas e comentários podem ser feitos como informação sobre as capacidades de cada produto. Além disso, podem ser especificados perguntas ou pontos de interesse a serem discutidos com o usuário, a ser realizado em um local onde seja possível gravar as suas respostas. Estes tipos de formulários irão padronizar as informações recolhidas durante a avaliação e simplificar para posterior decisão.

Não há nenhum método específico ou documentação para avaliação de fornecedor. Uma vez que os fornecedores não salientam as características ou capacidades que fornecem, é necessário identificar tais características, capacidades e eventualmente deficiências que eles não fornecem e inferir um fornecedor melhor do que o outro. Muitos fornecedores oferecem um resumo das características de software. O resumo indica que o software pode fazer, mas não explica como isso é feito. O resumo é normalmente um catálogo de vendas, que não deve ser utilizado como a única fonte de informação acerca de um produto (DAVIDSON, 1982).

A documentação de cada produto deve ser revista a respeito das informações relativas aos requisitos ou critérios específicos. Esta avaliação pode ser realizada em vários passos, cada um pode se aprofundar gradativamente em aspectos técnicos da estrutura de dados, 
comandos, sequência de comandos, funções de utilidade e características e assim por diante (DAVIDSON, 1982).

O primeiro passo é tentar identificar os produtos que claramente estão faltando em um ou mais critérios ou requisitos elencados. A decisão pode ser feita para eliminar estes produtos inteiramente ou fazer concessões para os critérios que possuem alguma falta de conformidade (DAVIDSON, 1982).

O objeto dessas avaliações é gradualmente eliminar os SGBDs que claramente não satisfaçam os requisitos. Eventualmente pode ocorrer que nenhum dos sistemas candidatos combine com todas as necessidades, e uma decisão pode ter de ser feita para relaxar e revisar os requisitos ou desenvolver um sistema de gerenciamento de dados próprio da organização, voltado para suas necessidades e requisitos específicos.

Os benefícios advindos da aquisição de um SGBD não são fáceis de medir e quantificar, pois um SGBD possui vantagens intangíveis sobre os sistemas de arquivo tradicionais, como facilidade de uso, consolidação de informação de uma grande empresa, disponibilidade mais ampla de dados e acesso mais rápido à informação. $\mathrm{O}$ acesso com base em Web pode tornar parte dos dados acessíveis a todos os empregados ou mesmo a usuários externos. Benefícios mais tangíveis incluem o custo reduzido para o desenvolvimento de aplicações, redução da redundância de dados, melhor controle e segurança. Embora os bancos de dados estejam fortemente inseridos na maioria das organizações, a decisão de migrar de uma aplicação arquivo-baseada para uma abordagem centrada em banco de dados ainda surge com frequência. Para Elmasri e Navathe (2005), essa migração geralmente ocorre pelos seguintes fatores:

1. Complexidade de dados: Como os relacionamentos entre os dados são mais complexos, a necessidade de um SGBD torna-se mais efetiva.

2. Compartilhamento entre aplicações: O maior compartilhamento de dados entre aplicações e a maior redundância entre os arquivos aumentam, consequentemente, a necessidade de um SGBD.

3. Evolução dinâmica ou crescimento dos dados: Como os dados são alterados constantemente, é mais fácil atender a essas mudanças usando um SGBD do que um sistema de arquivos.

4. Frequência de consultas ad hoc aos dados: Os sistemas de arquivo não facilitam a recuperação de dados ad hoc.

5. Volume de dados e necessidade de controle: $\mathrm{O}$ volume de dados e a necessidade de controlá-los exigem um SGBD. 
Verifica-se neste estudo que é complexa a atividade de desenvolver um conjunto genérico de diretrizes que possam adotar uma única abordagem para a administração dos dados de uma organização — se relacional, orientado a objeto, objeto-relacional ou NoSQL. Vários fatores devem ser analisados, como por exemplo, a cultura organizacional, pois de nada adianta a escolha de um SGBD adequado ao contexto da aplicação se a organização oferece forte resistência a mudanças (DAVIDSON, 1982).

Uma grande quantidade de softwares para 'terceiros' deve estar disponível para proporcionar funcionalidades ao SGBD em cada uma das áreas anteriores. Em raras situações pode ser preferível desenvolver o sistema de gerenciamento de dados in-house (doméstico) em vez de usar um SGBD já existente - por exemplo, se as aplicações são muito bem definidas e totalmente conhecidas. Em tais circunstâncias, um SGBD projetado e customizado in-house (desenvolvido pela equipe da própria organização) pode ser apropriado para implementar as aplicações conhecidas de modo mais eficiente, como por exemplo, os já citados exemplos na Amazon (C com o desenvolvimento do SGBD NoSQL Dynamo. Na maioria dos casos, porém, novas aplicações, não previstas em tempo de projetos, aparecem após a implementação do sistema. É precisamente por isso que os SGBDs tornaram-se tão populares: eles facilitam a incorporação de novas aplicações apenas com modificações incrementais ao projeto existente do banco de dados. Tal evolução de projeto — ou evolução de esquema - é uma característica presente, em graus variados, nos SGBDs comerciais.

Em levantamento apresentado por Stonebraker (2011), as empresas ainda não tem demonstrado interesse durante o processo de escolha de um SGBD para a abordagem NoSQL, sendo que $44 \%$ dos usuários corporativos questionados nunca ouviram falar de NoSQL e um adicional de $17 \%$ não tinham interesse. Isto ocorre principalmente devido aos problemas de consistência dos SGBDs NoSQL, treinamento e até mesmo desconhecimento da tecnologia.

Para Tudorica e Bucur (2011), alguns itens podem ser utilizados para uma avaliação qualitativa e quantitativa de um SGBD: persistência, replicação, alta disponibilidade, transações, consistência em rack, linguagem de implementação, influências / patrocinadores, tipos de licença. Um comparativo pode ser verificado no Quadro 7, no qual se pode ver que os três produtos oferecem as mesmas características, apenas as diferenças estão relacionadas com relação as transações, linguagem de implementação e tipo de licença. 


\begin{tabular}{|c|c|c|c|}
\hline Características & Cassandra & HBase & $M y S Q L \circledR$ \\
\hline Persistência & Sim & Sim & $\begin{array}{l}\text { Sim (utilizando um } \\
\text { diferente tipo de conexão do } \\
\text { que tipicamente existe) }\end{array}$ \\
\hline Replicação & Sim & Sim & Sim \\
\hline Alta disponibilidade & Distribuído. & Distribuído & $\begin{array}{l}\text { Distribuído, disponível com } \\
\text { MySQL@ Cluster }\end{array}$ \\
\hline Transações & Consistência eventual & $\begin{array}{l}\text { Localmente } \\
\text { (consistência no nível } \\
\text { de linha) }\end{array}$ & $\begin{array}{l}\text { Consistente (todas as } \\
\text { características ACID atuais) }\end{array}$ \\
\hline Consistência & Sim (herdado do Hadoop) & $\begin{array}{l}\text { Sim (herdado do } \\
\text { Hadoop) }\end{array}$ & $\begin{array}{ll}\text { Sim } & \text { (com MySQL® } \\
\text { Cluster) } & \end{array}$ \\
\hline Linguagem & Java® & Java® & ANSI C / ANSI C++ \\
\hline Influências / patrocinadores & $\begin{array}{l}\text { Dynamo and BigTable, } \\
\text { Facebook@/Digg/Rackspa } \\
\text { ce }\end{array}$ & BigTable® & Oracle® \\
\hline Tipos de licença & Apache 2.0® & Apache 2.0® & Oracle® \\
\hline
\end{tabular}

Quadro 7 - Comparativo entre SGBDs

Fonte: Adaptado de Tudorica e Bucur (2011) 


\section{Método da Pesquisa}

Neste capítulo estão descritas as características da pesquisa bem como os procedimentos metodológicos adotados. Inicialmente é definido o tipo de pesquisa adotado e posteriormente são definidas as fases da pesquisa, o seu escopo, e a técnica Delphi em particular. Em seguida, são descritos o método e o instrumento de coleta de dados.

Segundo Dickson e Nechis (1980), quando um problema não é definido o suficiente para ser analisado por técnicas analíticas, a técnica Delphi pode ser uma opção viável, uma vez que aumenta o consenso sobre o que o levantamento poderia atingir, ainda que não se tenha como objetivo a previsão de eventos futuros. Existem poucos estudos relacionados com SGBDs NoSQL e com processo de seleção de SGBD, não sendo viável o uso de técnicas analíticas convencionais, justificando assim a aplicação do painel Delphi.

A técnica Delphi tem a vantagem de exigir um grupo menor de participantes que outras técnicas, uma vez que os participantes são especialistas no campo do conhecimento estudado. Assim, adotou-se neste trabalho a técnica Delphi que constitui uma técnica de natureza qualitativa. Esta técnica permitiu classificar, por meio de um consenso entre um grupo de especialistas, os principais critérios que devem ser considerados no processo de seleção e avaliação de um SGBD NoSQL.

\subsection{Tipo de Pesquisa}

A discussão sobre instrumentos de pesquisa e seu papel nas investigações científicas é crucial para garantir os objetivos traçados em uma pesquisa. Muitos caminhos diferentes podem ser adotados e cada um deles oferecerá vantagens e restrições. Uma variedade de procedimentos metodológicos pode ser empregada para a investigação de questões de pesquisa. A indicação do tipo de pesquisa é importante, pois permite identificar os caminhos que serão percorridos pelo pesquisador e também tem implicações nos métodos e técnicas de pesquisa adotadas. Cervo e Bervian (2006) e Creswell (2007) apresentam a possibilidade de se escolher métodos de caráter quantitativos, qualitativos ou ainda mistos, e destacam que os métodos qualitativos diferem dos quantitativos em relação à ênfase e à forma, mas que não se pode afirmar que sejam opostos.

O propósito da pesquisa qualitativa é promover a compreensão da complexidade e a interação com o problema de pesquisa sem ter a estatística como foco principal. Nesse caso, o 
ambiente natural é a fonte direta de dados e o pesquisador, o seu instrumento fundamental. Os estudos qualitativos apresentam certas características: os dados são coletados no contexto onde acontecem os fenômenos, a análise de dados ocorre durante o processo de levantamento, os estudos são apresentados em descrição, com foco na compreensão e na interpretação dos fatos e exige ainda uma interação entre pesquisador e pesquisado (CRESWELL, 2007).

A pesquisa quantitativa, por sua vez, permite a quantificação de dados e o seu tratamento por meio de técnicas estatísticas simples ou complexas. O objetivo é conferir exatidão aos resultados, redução de possíveis distorções ocorridas a partir da análise e interpretação dos dados e consequente ampliação da margem de segurança quanto às inferências. O uso de métodos múltiplos de investigação que combinam os dois tipos de pesquisa - qualitativa e quantitativa - cria o chamado método misto de pesquisa científica. $\mathrm{O}$ método misto surge a partir da necessidade de se esclarecer questões e promover a compreensão de análises complexas a partir da reunião de dados qualitativos e quantitativos em uma única pesquisa (CRESWELL, 2007).

O tipo de pesquisa adotado neste estudo é a pesquisa qualitativa. Apesar de não ter sido adotado um método múltiplo (qualitativo e quantitativo), foram utilizadas estatísticas descritivas para apoiar as análises qualitativas.

\subsection{Fases da Pesquisa}

As fases da pesquisa foram definidas de modo a atingir os objetivos da pesquisa. Elas estão divididas em quatro fases conforme mostra o Quadro 8.

\begin{tabular}{|c|c|c|c|c|}
\hline $\begin{array}{l}\text { Fase da } \\
\text { pesquisa }\end{array}$ & Entrada & Saída & Ferramenta & $\begin{array}{c}\text { Objetivo da pesquisa } \\
\text { (localização no } \\
\text { texto) }\end{array}$ \\
\hline $\begin{array}{l}\text { Primeira } \\
\end{array}$ & $\begin{array}{l}\text { Literatura sobre } \\
\text { SGBD }\end{array}$ & $\begin{array}{c}\text { Critérios para seleção } \\
\text { de SGBDs }\end{array}$ & $\begin{array}{l}\text { Revisão da Literatura } \\
\text { e Revisão Sistemática }\end{array}$ & $1.3(\mathrm{a})$ \\
\hline Segunda & $\begin{array}{c}\text { Critérios para seleção } \\
\text { de SGBDs }\end{array}$ & $\begin{array}{c}\text { Critérios para seleção } \\
\text { de SGBD NoSQL }\end{array}$ & $\begin{array}{c}\text { Técnica Delphi } \\
\left(1^{\mathrm{a}} . \text { Rodada }\right)\end{array}$ & $1.3(\mathrm{~b})$ \\
\hline Terceira & $\begin{array}{c}\text { Critérios para seleção } \\
\text { de SGBDs NoSQL }\end{array}$ & $\begin{array}{c}\text { Ordem de } \\
\text { importância dos } \\
\text { critérios }\end{array}$ & $\begin{array}{l}\text { Técnica Delphi } \\
\left(2^{\mathrm{a}} . \text { Rodada }\right)\end{array}$ & $1.3(\mathrm{c})$ \\
\hline Quarta & $\begin{array}{c}\text { Critérios para seleção } \\
\text { de SGBDs NoSQL }\end{array}$ & $\begin{array}{l}\text { Análises em função } \\
\text { do contexto }\end{array}$ & Estatística descritiva & $1.3(\mathrm{~d})$ \\
\hline
\end{tabular}




\begin{tabular}{l|c|c|l|l}
\hline $\begin{array}{c}\text { classificados por } \\
\text { ordem de importância }\end{array}$ & $\begin{array}{c}\text { organizacional e dos } \\
\text { diferentes grupos de } \\
\text { especialistas }\end{array}$ & & \\
\hline
\end{tabular}

Quadro 8 - Fases da Pesquisa

Fonte: Próprio autor

\section{a) Primeira Fase}

A partir de uma revisão da literatura foram identificados os critérios de seleção de SGBDs descritos em trabalhos científicos. Para isso foi feita uma revisão sistemática em bases de dados relacionadas ao tema e uma revisão sobre modelos de qualidade para seleção de software, com ênfase no modelo SQuaRE (norma ISO/IEC 9126). Na Figura 8 são apresentados os critérios obtidos por meio dessas revisões.

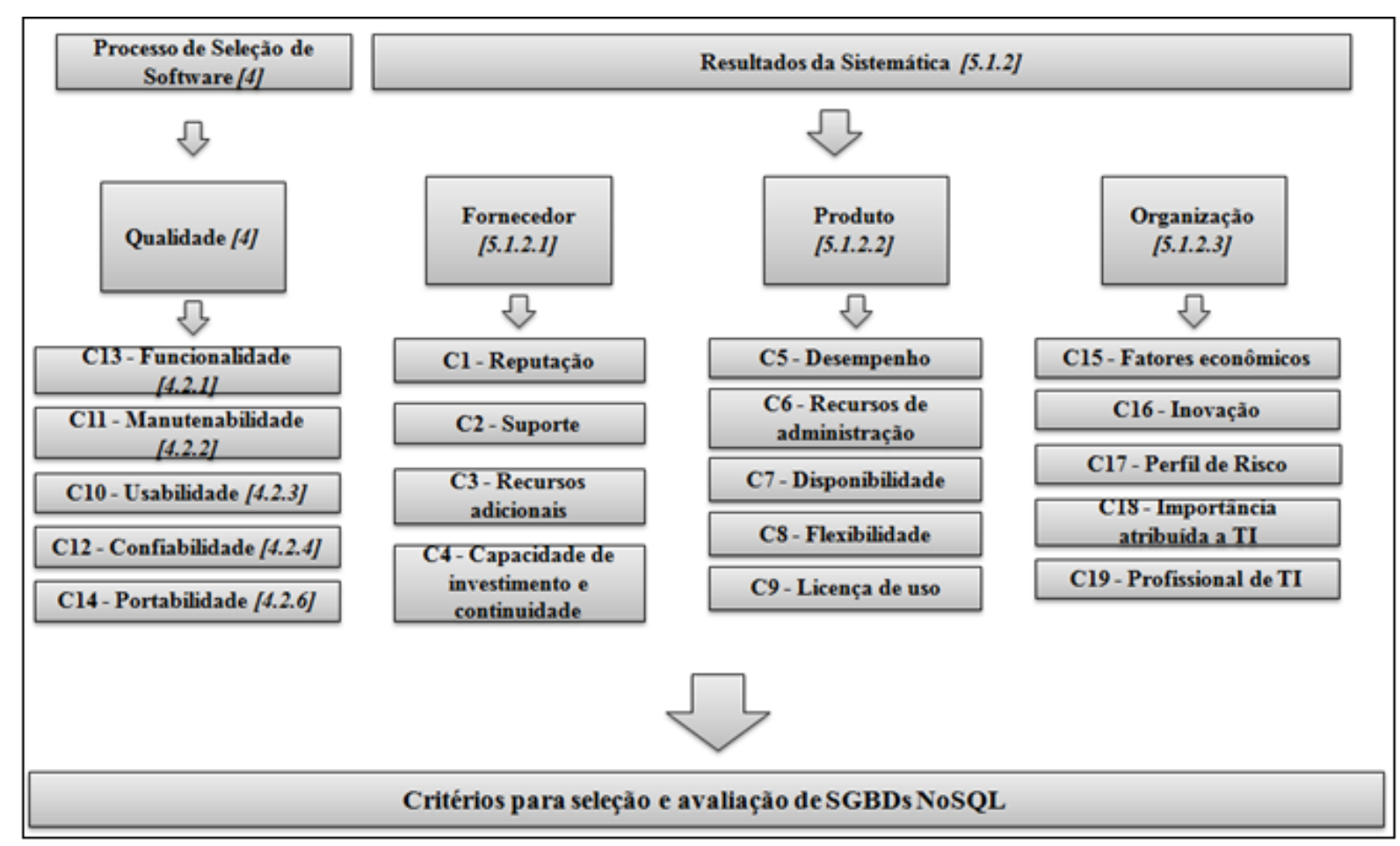

Figura 8 - Critérios de Seleção de SGBD.

Fonte: Próprio autor

\section{b) Segunda Fase}

A partir dos critérios de seleção de SGBDs obtidos com a revisão da literatura foi aplicada a Técnica Delphi. Essa técnica permitiu, por meio da aplicação de painel com especialistas no tema banco de dados ( $1^{\mathrm{a}}$ rodada), obter os principais critérios para avaliação de SGBDs NoSQL. 


\section{c) Terceira Fase}

Os critérios de seleção de SGBDs NoSQL obtidos na segunda fase da pesquisa foram ordenados pelo critério de importância. Isso foi realizado por meio da aplicação de Painel Delphi (2 $2^{\mathrm{a}}$ rodada).

\section{d) Quarta Fase}

A partir dos critérios de seleção de SGBDs NoSQL, obtidos na segunda fase da pesquisa, foram feitas análises considerando os diferentes grupos de especialistas.

\subsection{Escopo de aplicação da Pesquisa}

O escopo desta pesquisa abrange organizações que atendem a três critérios:

- Organizações privadas. O estudo foi feito considerando organizações privadas uma vez que em organizações públicas existem processos de seleção diferenciados, que envolvem inclusive processos de licitação que privilegiam questões econômicas, diminuindo ou alterando a relevância dos demais critérios de seleção.

- Ambiente Web. Os critérios se aplicam a este tipo de ambiente devido a sua relação com o Big Data, ou seja, volumes extremos de dados, o que justifica a abordagem por meio de SGBDs NoSQL. Observa-se com menos intensidade esta situação em outros tipos de organizações, como por exemplo, em organizações bancárias que necessitam de forte consistência e integridade de dados, onde o volume de dados não é um gargalo.

- Processo de seleção e avaliação de SGBDs. O presente estudo se restringe a fase de seleção e avaliação de SGBDs NoSQL nas organizações.

\subsection{Técnica Delphi}

A técnica Delphi passou a ser disseminada no começo dos anos $60 \mathrm{com}$ base em trabalhos desenvolvidos por Olaf Helmer e Norman Dalker, pesquisadores da Rand Corporation. O objetivo original era desenvolver uma técnica para aprimorar o uso da opinião de especialistas na previsão tecnológica. Segundo Martino (1993), a metodologia desenvolvida obedece três condições básicas: o anonimato dos respondentes, a representação 
estatística da distribuição dos resultados e o feedback da resposta do grupo para reavaliação nas rodadas subsequentes.

O Delphi é um método que busca obter a opinião coletiva mais assertiva de um grupo de especialistas, aos quais são aplicados questionários individuais com a utilização de um feedback controlado durante uma série de ciclos. Neste processo, quando não se atinge um consenso, ao menos permite à convergência das respostas ao final da aplicação dos ciclos.

Nesta seção são apresentadas as vantagens e desvantagens do painel Delphi, bem como os passos para a aplicação dela.

\subsubsection{Vantagens e Desvantagens}

O Delphi é uma técnica para a busca de um consenso de opiniões de um grupo de especialistas a respeito de eventos futuros por meio de um questionário, que é repassado continuadas vezes até que seja obtida uma convergência das respostas, um consenso, que representa uma consolidação do julgamento intuitivo do grupo. $\mathrm{O}$ anonimato dos respondentes, a representação estatística da distribuição dos resultados e o feedback de respostas do grupo para reavaliação nas rodadas subsequentes são as principais características deste método (TERENCE; GIOVINAZZO, 2000).

Para Terence e Giovinazzo (2000), a evolução em direção a um consenso obtido no processo da aplicação do painel Delphi representa uma consolidação do julgamento intuitivo de um grupo de peritos sobre eventos futuros e tendências. Neste trabalho a técnica Delphi foi utilizada, não objetivando a previsão de eventos futuros, mas priorizando os pontos chaves em Sistemas de Informação, e pretende-se ser um instrumento adequado para classificar por consenso os critérios mais relevantes para avaliação e seleção de SGBDs NoSQL.

A técnica Delphi é especialmente recomendável quando não se dispõe de dados quantitativos ou estes não podem ser projetados para o futuro com segurança, em face de expectativa de mudanças estruturais nos fatores determinantes das tendências futuras ou simplesmente pela insuficiência de dados sobre o assunto abordado. Desta forma, a técnica Delphi é aplicável para este estudo, uma vez que os SGBDs NoSQL ainda possuem baixa aceitação no mercado e, portanto há poucos dados para serem coletados e analisados.

Nesta pesquisa a utilização do painel Delphi possibilita que os especialistas possam contribuir com a sugestão de novos critérios que possam julgar relevantes, consolidando os critérios existentes na literatura. A fase de consolidação de critérios é de grande importância para o trabalho, uma vez que foram encontrados poucos trabalhos na literatura sobre critérios 
de seleção de SGBD e alguns trabalhos são antigos, necessitando assim de uma validação para o contexto atual de gerenciamento de dados.

Quanto à aplicação do método, segundo Terence e Giovinazzo (2000), as respostas das questões quantitativas devem ser tabuladas e os resultados devem ser devolvidos aos participantes na próxima rodada. Quando há justificativas e opiniões qualitativas associadas a previsões quantitativas, a coordenação busca relacionar os argumentos às projeções quantitativas correspondentes. Nesta pesquisa os resultados foram tabulados em forma de ranking de critérios e foram devolvidos aos participantes da primeira rodada.

A cada nova rodada as perguntas devem ser repetidas e os participantes irão reavaliar suas respostas de acordo com as respostas numéricas e das justificativas coletadas com os demais respondentes na rodada anterior. Este processo é repetido nas sucessivas rodadas do questionário até que a divergência de opiniões entre especialistas tenha se reduzido a um nível satisfatório e a resposta da última rodada seja considerada como a opinião do grupo sobre determinado assunto (TERENCE; GIOVINAZZO, 2000).

Para Mitchell (1992), o feedback estabelecido por meio de diversas rodadas permite a troca de informações entre os diversos participantes e, em geral, conduz a uma convergência rumo a uma posição de consenso. A evolução em direção ao consenso nesta pesquisa é medida por meio do coeficiente de concordância $\mathrm{W}$, onde a decisão de encerrar a realização dos ciclos é tomada quando encontrado um valor satisfatório. O coeficiente de concordância de Kendall e Smith (1939) expressa a associação simultânea entre n conjuntos de classificação. Esta variável é comumente utilizada para avaliar a confiabilidade de julgadores. Neste trabalho os julgadores são representados pelos especialistas e o coeficiente de concordância W servirá para medir o grau de consenso entre eles. Mais detalhes sobre os procedimentos para atingir a convergência são fornecidos no capítulo sobre a realização do Painel Delphi.

$\mathrm{O}$ anonimato das respostas e o fato de não haver uma reunião física reduzem a influência de fatores psicológicos como, por exemplo, os efeitos da capacidade de persuasão, a relutância em abandonar posições assumidas e a dominância de grupos majoritários em relação a opiniões minoritárias. Desta forma o anonimato contribui para que se obtenha um resultado mais confiável, sem a influência de fatores externos (TERENCE; GIOVINAZZO, 2000).

As características essenciais do painel Delphi são a troca de informações e opiniões entre os respondentes, o anonimato das respostas e a possibilidade de revisão de visões individuais sobre o futuro, diante das previsões e argumentos dos demais respondentes, com 
base em uma representação estatística da visão do grupo. Mais detalhes sobre a representação estatística da aplicação da técnica são definidos no capítulo sobre a realização do Painel Delphi (TERENCE; GIOVINAZZO, 2000).

O Delphi tem sido utilizado como um instrumento para coletar e discutir elementos que constituam os cenários do futuro, visando indicar caminhos tecnológicos. Para Terence e Giovinazzo (2000), o método de pesquisa Delphi apresenta vantagens e desvantagens a ver:

\section{Vantagens}

a) Realização de previsões em situações de carência de dados históricos.

b) Consulta a um grupo de especialistas traz à análise do problema pelo menos ao nível de informação do membro melhor informado, e, em geral, traz um volume muito maior de informação.

c) Uso de questionários e respostas escritas conduz a uma maior reflexão, facilitando o seu registro em comparação a uma discussão em grupo.

d) Anonimato nas respostas elimina a influência de fatores como o "status" acadêmico ou profissional do respondente, ou sua capacidade de oratória na consideração da validade de seus argumentos.

e) Outros fatores restritivos da dinâmica de grupo são reduzidos, como a supressão de posições minoritárias, a omissão de participantes, a adesão espúria às posições majoritárias, a manipulação política etc.

f) Com o envio de questionários por correio ou meios eletrônicos não há custos de deslocamento de pessoal e os especialistas podem responder sem a restrição de conciliar agendas para reunião.

g) Custos são provavelmente menores do que aqueles associados à reunião física de um grande grupo de especialistas, apesar de o custo de preparação do questionário ser maior.

h) Efetivo engajamento no processo de um grande número de participantes é uma importante vantagem que induz à criatividade e confere credibilidade ao estudo.

\section{Desvantagens}

a) Seleção de amostra de respondentes e tratamento dos resultados estatisticamente não aceitáveis. 
b) Excessiva dependência dos resultados em relação à escolha dos especialistas, com a possibilidade de introdução de viés pela escolha dos respondentes.

c) Possibilidade de se forçar o consenso indevidamente.

d) Dificuldade de se redigir um questionário sem ambiguidades e não viesado sobre tendências futuras.

e) Demora excessiva para realização do processo completo, especialmente no caso de envio de questionário.

f) Custos de elaboração de questionário elevados.

\subsubsection{Planejamento da aplicação da técnica}

Neste trabalho a aplicação do painel Delphi deve-se principalmente ao fato de não se ter disponíveis dados quantitativos sobre a adoção de SGBDs NoSQL nas empresas brasileiras e para se buscar uma consolidação junto a especialistas sobre os critérios de seleção de SGBDs NoSQL. A Figura 9 mostra as fases do processo de execução de uma pesquisa Delphi, mostrando os procedimentos executados pelo coordenador da pesquisa e pelos respondentes.

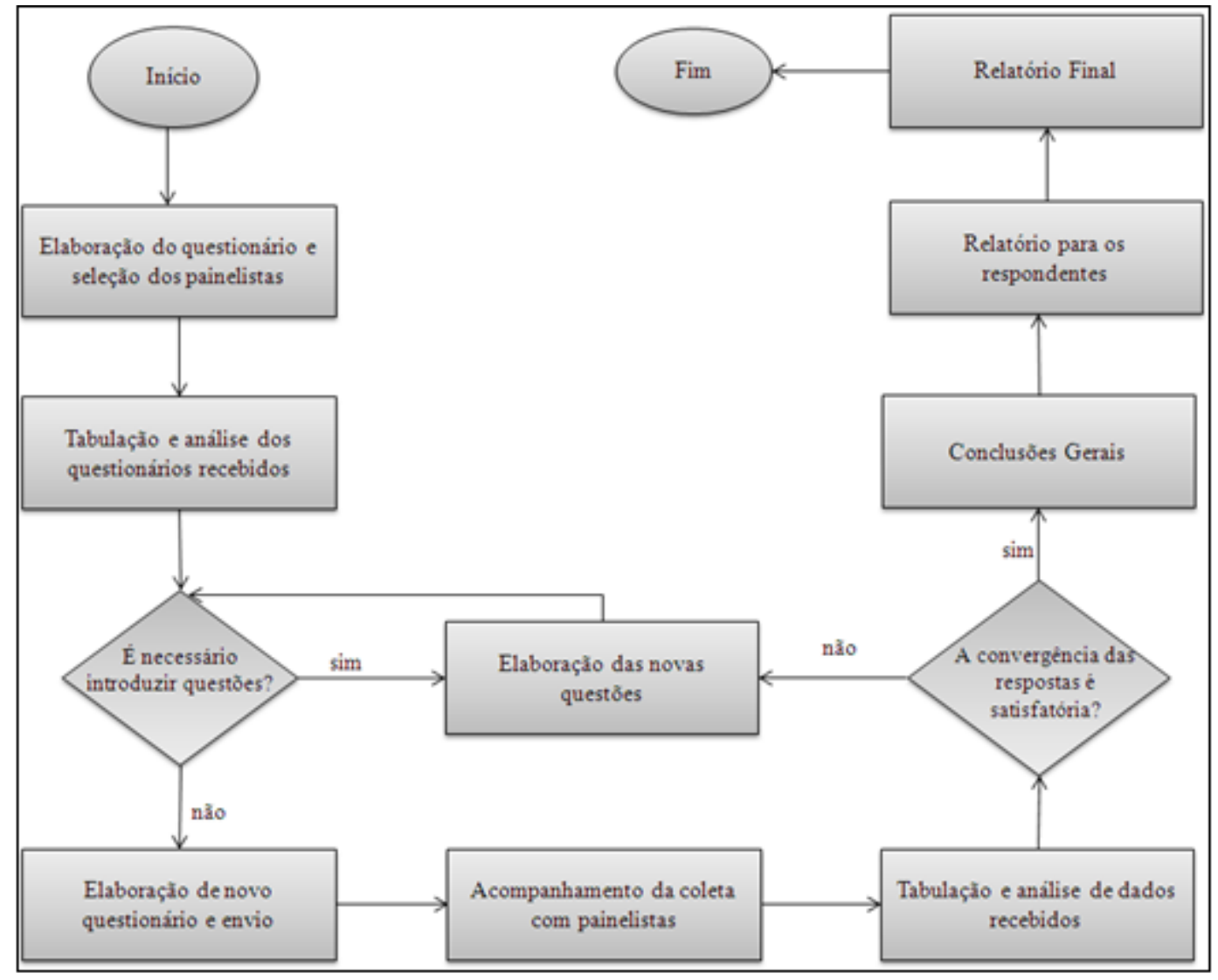

Figura 9 - Fluxo de um questionário Delphi

Fonte: Adaptado de Terence e Giovinazzo (2000) 
A alternativa do survey com a aplicação de entrevistas, como por exemplo, o método Focus Group, não foi considerado, pois possibilita a interação entre os participantes, dado que os trabalhos são realizados em sessões ou reuniões das quais todos os painelistas participam, violando o pressuposto da preservação do anonimato requerido pelo painel Delphi. Além disso, há ainda a questão logística que pode ser impactante, pois todos os participantes devem estar reunidos em um único local físico. O método de entrevista Staticized Group também não foi considerado, pois apesar de ser semelhante ao Delphi, limita-se a realização de um único ciclo ou rodada, não buscando o consenso de opiniões dos especialistas de forma sistêmica (HALlOWELL; GAMBATESE, 2010). Como consequência, a aplicação de um survey com especialistas, em um Painel Delphi, se mostrou a estratégia mais adequada.

Quando a técnica Delphi é realizada de forma convencional costuma produzir um número de, no máximo, quatro rodadas. Um número maior não é aconselhável por restrições de tempo e, principalmente pelo fato de não existirem mudanças de opinião significativas nas rodadas posteriores (KAYO; SECURATO, 1997). Nesta pesquisa o Painel Delphi foi aplicado em duas rodadas.

Quanto à forma de aplicação do painel Delphi, foi escolhida para este trabalho a modalidade ranking form, por ser possível levantar, de forma ordenada, critérios de seleção de SGBDs NoSQL mais relevantes. No que diz respeito à aplicação do Delphi na forma de ranking, Schmidt (1997) propõe uma sistemática que nesta pesquisa foi aplicada de acordo com as etapas a seguir: identificar e determinar critérios mais relevantes e ordenar os critérios, analisar resultados e apresentar resultados. Em detalhe, segue esquema adotado para esta pesquisa:

\section{a) Etapa 1 - Identificar e determinar critérios mais importantes:}

- Cada critério deve, na medida do possível, ser acompanhado de uma descrição, que torne suficientemente claro o seu significado.

- Os critérios constantes da lista elaborada devem ser colocados numa sequência aleatória e assim enviados aos painelistas, aos quais será solicitado indicar o grau de importância que atribui para cada um e indicar algum critério que não esteja na lista, caso assim desejar.

- Os painelistas são encorajados a indicar o maior número possível de critérios de modo a garantir que os mais relevantes sejam, de fato, lembrados e indicados. 
- Uma vez feitas as indicações e definições de importância dos critérios por parte de todos os painelistas, o pesquisador deve interpretá-las e consolidá-las numa lista única ordenada por grau de importância.

- De posse da lista ordenada por cada um dos painelistas, o pesquisador deve consolidá-las, para finalmente obter um ranking representativo da opinião coletiva.

- Uma vez obtido o ranking coletivo, é importante verificar o grau de concordância existente entre os painelistas, o que pode ser medido pela estatística $\mathrm{W}$, denominada coeficiente de concordância. É igualmente relevante que a significância de W seja verificada, o que pode ser feito com o emprego de um teste de $\mathrm{X}^{2}$.

- Foi utilizada de técnica estatística, com o cálculo do coeficiente de concordância W, como instrumento para sinalizar quando a série de ciclos pode ser interrompida, quando não há mais um aumento significativo na concordância entre os painelistas.

b) Etapa 2 - Analisar resultados:

- O ranking definitivo é analisado, buscando-se dele extrair conclusões relativas ao objeto da pesquisa.

\section{c) Etapa 3 - Apresentar resultados:}

- Esta apresentação pode se dar sob diversas formas: texto, tabelas, quadros explicativos e gráficos.

- Descrever os cálculos utilizados, os valores obtidos para as estatísticas adotadas e outros dados quantitativos relevantes.

- Descrição de todas as etapas do processo e relato das ocorrências relevantes.

- Tabulação dos resultados e atribuição dos pesos relativos ao nível de importância. No caso desta pesquisa, os resultados foram tabulados e foi atribuída pontuação para definição do nível de importância.

A sistemática proposta de aplicação do Painel Delphi definida por Schmidt (1997) sugere eliminar os critérios que não foram escolhidos pela maioria dos respondentes mais um.

Depois de obtida a ordenação coletiva, o grau de concordância entre os painelistas é verificado por meio do cálculo da estatística W (denominada coeficiente de concordância), 
conforme proposto por Kendall \& Smith (1939). A interpretação do grau de concordância é feita empregando as faixas sugeridas por Schmidt (1997):

\begin{tabular}{l|l}
\hline \multicolumn{1}{c|}{$\begin{array}{c}\text { Faixas para o Grau de } \\
\text { Concordância }\end{array}$} & \multicolumn{1}{c}{ Significado } \\
\hline Até 0,1 & Muito baixo \\
Acima de 0,1 e até 0,3 & Baixo \\
Acima de 0,3 e até 0,5 & Moderado \\
Acima de 0,3 e até 0,5 & Alto \\
Acima de 0,7 e até 0,9 & Muito alto \\
\hline \multicolumn{2}{c}{ Quadro 9- Significado para o grau de concordância W } \\
\hline
\end{tabular}

Não há um consenso sobre o número de participantes e nem uma regra universalmente aceita. Analisando trabalhos correlatos, verificou-se uma ampla variação na quantidade de painelistas utilizados, sendo que a maior concentração fica entre quatro e 37 participantes. Neste trabalho foi utilizada uma amostra de 32 painelistas.

$\mathrm{Na}$ primeira rodada os especialistas recebem um questionário preparado por uma equipe de coordenação, que são solicitados a responder individualmente, usualmente com respostas quantitativas apoiadas por justificativas e informações qualitativas. O questionário, em geral, é bastante elaborado, apresentando para cada questão uma síntese das principais informações conhecidas sobre o assunto (TERENCE; GIOVINAZZO, 2000).

Antes da realização da primeira rodada, é feita a seleção dos painelistas. Conforme afirmam Terence e Giovinazzo (2000), a qualidade do resultado depende essencialmente dos participantes do estudo. Todos os painelistas que irão responder a pesquisa devem ter experiência comprovada em atividades ligadas à temática de banco de dados e SGBDs para projetos de TI, inclusive os profissionais acadêmicos, deseja-se que estejam ligados com a temática de banco de dados.

A aplicação da segunda rodada é feita convidando os participantes da primeira rodada a participarem novamente. Para que os painelistas possam participar adequadamente, eles recebem um relatório sobre a primeira rodada e são orientados novamente de acordo com o relatório de respostas, a responderem se os critérios, conforme classificados na primeira rodada deveriam ser mantidos ou se eles poderiam ser omitidos (TERENCE; GIOVINAZZO, 2000). 
Para definição da significância estatística do coeficiente de concordância W é utilizado o teste de $\mathrm{X}^{2}$ para obtenção do valor-p ou nível descritivo a fim de sintetizar o resultado do teste de hipótese. O Quadro 10 mostra as faixas do valor-p para definição da significância estatística.

\begin{tabular}{l|l}
\hline \multicolumn{1}{c|}{ Valor de $p$} & \multicolumn{1}{c}{ Significado } \\
\hline$>0,05$ & Pouco significante \\
0,01 a 0,05 & Significante \\
0,001 a 0,01 & Muito significante \\
$<0,001$ & Extremamente significante \\
\hline
\end{tabular}

Quadro 10 - Significância Estatística Conforme valor de p

Fonte: Adaptado de Friedman (1940)

\subsection{Instrumento de Coleta de Dados}

Segundo Marconi e Lakatos (2007), o instrumento de pesquisa é o meio que permite ao pesquisador mensurar determinado fenômeno com a obtenção de dados, por meio da utilização de questionários, inventários, testes, entrevistas, enquetes, aparelhos eletrônicos, sistemas etc.

Para Marconi e Lakatos (2007) há vários procedimentos para coleta de dados os quais devem ser utilizados conforme as circunstâncias ou tipo de investigação: coleta documental, observação, entrevista, questionário, formulário, medidas de opinião e atitudes, técnicas mercadológicas, sociometria, análise de conteúdo, história de vida, entre outros.

A coleta de dados é a operação pela qual se obtém os dados ou as informações a partir do fenômeno de pesquisa. Essa operação é efetuada pelo instrumento de pesquisa (MARCONI; LAKATOS, 2007). Neste trabalho a coleta de dados foi feita por meio da aplicação de questionário que pode ser consultado no Apêndice A. O questionário foi composto de questões usando escala do tipo Likert de seis pontos, evitando-se assim uma posição de centro, de modo que a opinião do especialista sobre determinado critério refle uma posição de concordância ou não. O questionário foi elaborado com questões fechadas para definição do grau de importância dos critérios levantados.

Dada a natureza da pesquisa e a dificuldade em se obter dados quantitativos sobre critérios de seleção de SGBD NoSQL, a aplicação do painel Delphi foi considerada a melhor estratégia para atender aos objetivos da pesquisa, uma vez que a técnica permite a 
participação de um grupo reduzido de respondentes com uso estruturado do conhecimento, da experiência e da criatividade em um painel de especialistas, pressupondo-se que o julgamento coletivo, quando organizado de forma adequada, é melhor que a opinião de um só indivíduo (TERENCE; GIOVINAZZO, 2000). 


\section{Realização do Painel Delphi}

Esta seção descreve o processo de aplicação do Painel Delphi, mostrando as fases de esquematização do painel, definição dos grupos de especialistas e a realização dos ciclos. $\mathrm{O}$ Painel Delphi foi realizado para atender o segundo e o terceiro objetivos específicos desta pesquisa, ou seja, de elaborar uma lista ordenada de critérios para avaliação e seleção de SGBDs NoSQL.

A realização do Painel Delphi pode ser resumida por meio de ciclos. Neste trabalho os ciclos foram aplicados da seguinte forma: o Ciclo 0 correspondeu ao ciclo preliminar a pesquisa, destinado ao mapeamento do perfil dos profissionais de TI participantes do painel. O Ciclo 1 foi o primeiro voltado à exploração do tema da pesquisa e à definição dos principais critérios para seleção de SGBDs NoSQL. Neste Ciclo também é apresentada ao painelista a opção de incluir algum critério que não esteja na relação daqueles levantados na literatura, mas que ele venha a julgar relevante. O Ciclo 2 aprofundou a investigação do tema, iniciando a composição dos rankings de critérios de seleção de SGBDs NoSQL, mostrando ao painelista o resultado da rodada anterior, possibilitando comparar sua resposta com a resposta dada pela maioria e o convidando a definir nova resposta. A quantidade de ciclos foi determinada pela convergência da opinião dos especialistas. Esta convergência foi medida por meio do coeficiente de concordância W, cujo grau pode ser verificado de acordo com as faixas definidas por Schmidt (1997).

O Painel Delphi foi aplicado entre janeiro de 2013 e março de 2013, seguindo a ordem dos ciclos descritos na Figura 10:

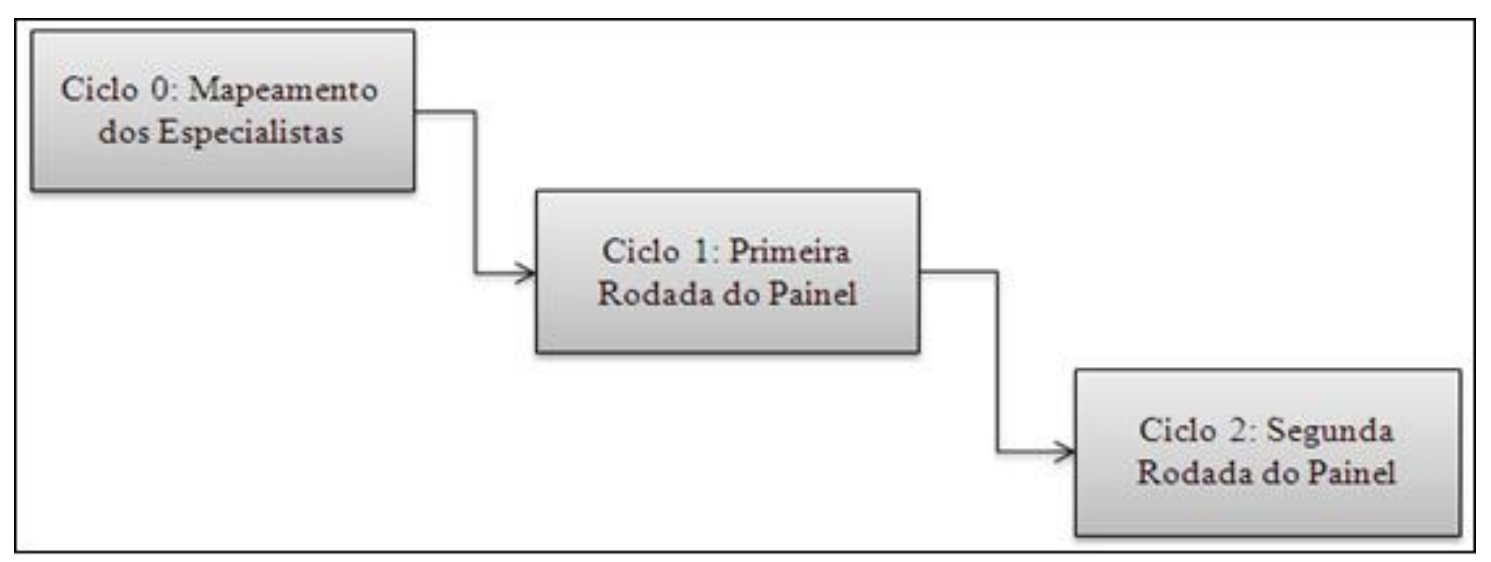

Figura 10 - Ciclos do Painel Delphi.

Fonte: Próprio autor 


\subsection{Ciclo 0: Mapeamento dos Especialistas}

Os especialistas foram selecionados com base no grau de experiência profissional, conhecimentos sobre o tema NoSQL e sua aplicação em organizações, formação acadêmica e vivência na área de projetos que envolveram banco de dados. Os especialistas foram escolhidos a partir da rede de relacionamentos profissionais do autor e também em contato com especialistas sobre o tema em fóruns e comunidades bem como em empresas que vivenciam o contexto da pesquisa de massivo volume de dados.

Foram apenas selecionados painelistas que atuam ou tem experiência em SGBD NoSQL aplicados dentro do escopo definido nesta pesquisa, ou seja, atuam ou já atuaram em empresas Web e vivenciaram a realidade do Big Data em ambiente de massivo volume de dados. As únicas exceções quanto à vivência em organizações Web são os painelistas dos grupos Fornecedores e Acadêmicos, porque é inerente a sua atividade lidar em distintos contextos.

Previamente ao início da aplicação da primeira rodada do Painel Delphi, foi realizado um mapeamento do perfil dos profissionais de mercado e acadêmicos participantes do painel. Com o mapeamento foi possível classificar os painelistas e definir um peso para cada respondente de acordo com sua experiência profissional e conhecimento sobre o tema de banco de dados. Seguem na Tabela 1 os especialistas que foram utilizados no painel Delphi. O grupo Demais Profissionais de TI engloba os subgrupos: Gerentes, Acadêmicos e Fornecedores, sendo considerado individualmente cada grupo para a composição dos pesos destes especialistas. Os demais grupos não possuem subgrupos.

\begin{tabular}{|c|c|c|c|c|}
\hline Grupo & Subgrupo & Cod. Painelista & Pontos & Peso \\
\hline \multirow[t]{12}{*}{ DBAs / DAs } & & 2 & 80 & 1,7 \\
\hline & & 16 & 80 & 1,7 \\
\hline & & 25 & 80 & 1,7 \\
\hline & & 30 & 80 & 1,7 \\
\hline & & 18 & 75 & 1,5 \\
\hline & & 1 & 72 & 1,5 \\
\hline & & 20 & 72 & 1,5 \\
\hline & & 12 & 68 & 1,4 \\
\hline & & 22 & 68 & 1,4 \\
\hline & & 27 & 68 & 1,4 \\
\hline & & 28 & 68 & 1,4 \\
\hline & & 5 & 48 & 1 \\
\hline
\end{tabular}


Desenvolvedores

21

$116 \quad 2,6$

$9 \quad 80 \quad 1,8$

$8 \quad 71 \quad 1,6$

$\begin{array}{lll}7 & 60 & 1,4\end{array}$

$23 \quad 60 \quad 1,4$

$4 \quad 44 \quad 1$

$11 \quad 44 \quad 1$

$13 \quad 44 \quad 1$

$15 \quad 44 \quad 1$

$19 \quad 44 \quad 1$

$24 \quad 44 \quad 1$

\begin{tabular}{lcccc} 
& & 26 & 44 & 1 \\
\hline Demais Profissionais de TI & Gerentes & 31 & 92 & 2,1 \\
& & 32 & 76 & 1,7 \\
& & 14 & 64 & 1,5 \\
& & 6 & 60 & 1,4 \\
& 29 & 52 & 1,2 \\
& 10 & 44 & 1 \\
\hline & Fornecedores & 3 & 44 & 1 \\
& Acadêmicos & 17 & 64 & 1 \\
\hline
\end{tabular}

Tabela 1 - Composição pesos especialistas

Fonte: Próprio autor

Para realização do mapeamento foi elaborado um questionário, apresentado no Apêndice B, com o qual foi possível comparar a experiência e o conhecimento de cada um dos participantes em relação ao tema da pesquisa. A partir das respostas do questionário foi possível definir um peso para cada participante, conforme pode ser verificado na Tabela 1 . O objetivo foi compor um grupo de especialistas na área de TI que não tivessem uma visão exclusivamente técnica. Para definir um peso para cada um dos respondentes, o mapeamento considerou os seguintes critérios:

- Anos de experiência de TI.

- Grau de conhecimento e vivência em projetos com banco de dados.

- Participação em processo de seleção de SGBDs.

- Formação acadêmica.

- Formação acadêmica na área de TI.

- Desenvolvimento de projetos suportados por SGBDs NoSQL.

- Grau de domínio no desenvolvimento de aplicações suportadas por SGBDs NoSQL. 
Para o cálculo do peso do participante foi adotado o seguinte critério: a pontuação obtida por cada respondente é composta de acordo com as respostas fornecidas no questionário de mapeamento de perfil. A pontuação de cada painelista é dividida pela menor pontuação obtida em seu grupo. Por exemplo, o painelista de código 21 obteve 116 pontos, definidos de acordo com a aplicação do questionário de mapeamento de perfil, sendo que a menor pontuação do seu grupo, Desenvolvedores, foi de 44 pontos, sendo assim o seu peso é de 116/44 = 2,6, ou seja, o peso deste painelista é 2,6.

Os profissionais selecionados foram agrupados em três perfis: DAs e DBAs, Desenvolvedores, Demais Profissionais de TI. Cada perfil representa um grupo com diferentes interesses na organização, possibilitando considerar na pesquisa um leque mais amplo de opiniões. Esta composição do grupo de painelistas tem a vantagem de dotar o grupo de uma visão mais ampla sobre o tema, mesclando experiências e conhecimentos práticos com diferentes visões dentro do contexto da organização. Como neste trabalho busca-se uma abordagem técnica e gerencial sobre os critérios para seleção de SGBDs NoSQL, foi essencial compor o grupo com especialistas com uma visão ampla sobre o tema. A seguir uma descrição de cada perfil:

a) DAs e DBAs. Profissionais diretamente ligados com banco de dados compondo o grupo de administração de dados.

b) Desenvolvedores. Possuem a visão de como os SGBDs NoSQL impactam no desenho e desenvolvimento de aplicações.

c) Demais Profissionais de TI. A participação de gerentes de TI foi conveniente, pois são eles os interessados nas análises finais do trabalho. Este perfil também contou com a participação de um fornecedor de SGBD, que pôde contribuir com sua visão de mercado, sob o ponto de vista das características relevantes para quem oferece soluções em SGBD e um profissional da área acadêmica, que possui conhecimento técnico e de pesquisa científica sobre os aspectos importantes na escolha de um SGBD trazendo uma visão diferenciada e importante para o trabalho. Nesta pesquisa optou-se em considerar os profissionais gerentes, fornecedores e acadêmicos no mesmo perfil, uma vez que são profissionais que não se relacionam diretamente com os requisitos técnicos de banco de dados e possuem uma visão diferenciada dos demais, sendo assim importante o seu agrupamento.

Foram convidados a participar do painel 33 profissionais de TI, sendo que apenas um profissional declinou de participar. A Tabela 2 mostra um resumo dos perfis profissionais de acordo com as características para composição do peso dos especialistas. 


\begin{tabular}{c|c|c|c|c|c|c|c|c|c|c} 
& $\begin{array}{c}\text { Experiência TI } \\
\text { (anos) }\end{array}$ & \multicolumn{2}{c|}{$\begin{array}{c}\text { Experiência } \\
\text { BD }\end{array}$} & \multicolumn{2}{c|}{$\begin{array}{c}\text { Part. Seleção } \\
\text { SGBD }\end{array}$} & \multicolumn{2}{c|}{$\begin{array}{c}\text { Formação } \\
\text { Acadêmica }\end{array}$} & \multicolumn{2}{c}{ Empresa } \\
\cline { 2 - 11 } $\begin{array}{c}\text { Grupo de } \\
\text { Painelistas }\end{array}$ & $\begin{array}{c}\text { Até } \\
10\end{array}$ & $\begin{array}{c}\text { Acima } \\
\text { de 10 }\end{array}$ & Baixa & Alta & Sim & Não & $\begin{array}{c}\text { Até } \\
\text { graduaçãa } \\
\text { o }\end{array}$ & $\begin{array}{c}\text { Pós- } \\
\text { graduaçã } \\
\text { o }\end{array}$ & Web & $\begin{array}{c}\text { Acadêmico } \\
\text { s / Demais } \\
\text { Ramos }\end{array}$ \\
\cline { 2 - 11 } & 18 & 14 & 1 & 31 & 14 & 18 & 28 & 4 & 24 & 8 \\
\hline $\begin{array}{c}\text { Desenvol- } \\
\text { vedores }\end{array}$ & $61 \%$ & $7 \%$ & $0 \%$ & $39 \%$ & $7 \%$ & $61 \%$ & $43 \%$ & $0 \%$ & $\begin{array}{c}37,50 \\
\%\end{array}$ & $37,50 \%$ \\
\hline $\begin{array}{c}\text { DAs e } \\
\text { DBAs }\end{array}$ & $17 \%$ & $64 \%$ & $0 \%$ & $39 \%$ & $79 \%$ & $6 \%$ & $43 \%$ & $0 \%$ & $\begin{array}{c}37,50 \\
\%\end{array}$ & $37,50 \%$ \\
\hline $\begin{array}{c}\text { Demais } \\
\text { Profissionai } \\
\text { s de TI }\end{array}$ & $22 \%$ & $29 \%$ & $100 \%$ & $23 \%$ & $14 \%$ & $33 \%$ & $14 \%$ & $100 \%$ & $25 \%$ & $25 \%$
\end{tabular}

Tabela 2 - Características do Grupo de Painelistas

Fonte: Próprio autor

\subsection{Ciclo 1: Primeira Rodada do Painel}

O instrumento utilizado na realização do Ciclo 1 do Painel Delphi foi um questionário on-line. A aplicação do painel Delphi pela internet foi feita entre os meses de janeiro e março de 2013, sendo que a primeira rodada foi feita por meio de questionário aplicado pela ferramenta Survey Monkey®. O questionário da primeira rodada pode ser verificado por meio do link: "http://www.surveymonkey.com/s/NGN25TR".

A primeira rodada do painel foi realizada com a apresentação dos critérios encontrados na literatura para que o painelista defina o grau de importância que atribui para o mesmo e no final do questionário o painelista pôde informar algum critério que acha importante e que não estava na lista. Cogitou-se também adotar a estratégia de estabelecer a primeira rodada como etapa exploratória, com questão aberta apenas para sugestões de critérios pelos painelistas, no entanto, decidiu-se que a apresentação dos principais critérios que existem na literatura seria eficiente, dando a oportunidade ao mesmo agregar mais critérios caso ache necessário, eliminando a possibilidade de sugestão de critérios que já existem na literatura.

Ao responder o questionário, cada painelista indicou um grau de importância para os critérios de seleção de SGBD NoSQL e a tabulação das respostas produziu um ranking consolidado. Os participantes convidados anteriormente por telefone, mensagem eletrônica ou pessoalmente receberam uma mensagem via e-mail, anunciando o início da pesquisa e convocando-os a participar. No Apêndice C pode ser verificado o e-mail convite, no qual contém as instruções a serem seguidas e o link a ser utilizado para acesso ao questionário. 
O questionário é constituído de duas partes, sendo a primeira para identificação do respondente. A segunda é onde ele define o grau de importância para cada critério relacionado à escolha e seleção de SGBDs NoSQL. Foi adotada uma escala de Likert com seis pontos, variando de forma ordenada entre 0 (para nenhum grau de importância) até 5 (total grau de importância). Nesta primeira rodada foram apresentados aos respondentes os 19 critérios levantados na literatura, onde o respondente tem a opção de acrescentar novos critérios que não estejam na lista, caso considere relevante.

A identificação do painelista fez-se necessário para controlar o andamento da pesquisa e possibilitar novas chamadas aos que ainda não haviam respondido o questionário até o final do período de disponibilidade, a fim de somente enviar o questionário da segunda rodada aos participantes da primeira rodada.

Houve a preocupação em se preservar o anonimato do painelista. O anonimato faz parte dos requisitos que a técnica pressupõe e permite a obtenção de um consenso mais confiável já que os painelistas não se conhecem, diminuindo assim a chance de um painelista influenciar na resposta do outro.

O e-mail convite possibilitava o acesso ao questionário. Neste $e$-mail havia instruções detalhadas para que o painelista pudesse definir o grau de importância para cada um dos critérios para seleção e avaliação de SGBDs NoSQL. As explicações de cada critério tinham no máximo quatro linhas, a fim de não cansar o respondente, o que pareceu ser suficiente, uma vez tratar-se de um grupo de conhecedores do tema. Eventualmente o especialista solicitava informações para o pesquisador com objetivo de elucidar alguma dúvida, o que permitiu também obter percepções dos painelistas durante a aplicação da primeira rodada da pesquisa.

O questionário foi enviado para 32 painelistas, o qual todos responderam. Dois painelistas fizeram sugestões de novos critérios acrescentados para a segunda rodada.

A pontuação e classificação dos critérios estão resumidas na Tabela 3. Nesta tabela estão as respostas consolidadas dos critérios de seleção de SGBD NoSQL classificados de acordo com a pontuação obtida. A pontuação de cada critério é calculada somando-se as respostas dos painelistas multiplicadas pelos seus pesos.

Essa forma de composição da pontuação por meio de atribuição de pesos aos respondentes confere maior confiabilidade ao ranking obtido uma vez que a experiência e conhecimento do especialista influenciaram diretamente na pontuação de dado critério.

Foi elaborada uma tabela com os cálculos necessários para avaliar o grau de concordância dos especialistas. Os cálculos indicaram, face aos valores obtidos para o 
coeficiente de concordância W $(0,882)$, que havia um grau alto de concordância já que apresentou valor superior a 0,7 de acordo com as faixas sugeridas por Schmidt (1997). Mesmo com grau alto de concordância já na primeira rodada do painel optou-se pela aplicação de uma segunda rodada para verificar se poderia haver um aumento no grau de concordância e também para medir a percepção de todos os painelistas sobre os novos critérios sugeridos. Na primeira e segunda rodada foi aplicado o peso do painelista na composição da pontuação efetiva, multiplicando-se o peso do painelista pela pontuação obtida no critério.

\begin{tabular}{|c|c|c|c|c|c|c|c|c|}
\hline \multirow[b]{2}{*}{ Critério } & \multicolumn{6}{|c|}{ Grau de Importância (\%) } & \multirow{2}{*}{$\begin{array}{l}\text { Pontua- } \\
\text { ção }\end{array}$} & \multirow{2}{*}{$\begin{array}{c}\text { Classifi- } \\
\text { cação }\end{array}$} \\
\hline & $\begin{array}{c}\text { Nenhu- } \\
\text { ma }\end{array}$ & $\begin{array}{l}\text { Muito } \\
\text { pouca }\end{array}$ & Pouca & Moderada & Muita & $\begin{array}{c}\text { Tot } \\
\text { al }\end{array}$ & & \\
\hline Confiabilidade C12 & 0,0 & 0,0 & 3,1 & 6,3 & 34,4 & 59,4 & 203,4 & 1 \\
\hline Disponibilidade C7 & 0,0 & 0,0 & 3,1 & 3,1 & 50,0 & 43,8 & 198,8 & 2 \\
\hline Desempenho C5 & 0,0 & 0,0 & 3,1 & 3,1 & 40,6 & 53,1 & 196,5 & 3 \\
\hline Flexibilidade C8 & 0,0 & 0,0 & 9,4 & 15,6 & 56,3 & 18,8 & 173,7 & 4 \\
\hline $\begin{array}{c}\text { Manutenabilidade } \\
\text { C11 }\end{array}$ & 0,0 & 0,0 & 9,4 & 18,8 & 53,1 & 18,8 & 172,4 & 5 \\
\hline $\begin{array}{c}\text { Funcionalidade } \\
\text { C13 }\end{array}$ & 0,0 & 3,1 & 12,5 & 18,8 & 46,9 & 21,9 & 166,4 & 6 \\
\hline $\begin{array}{c}\text { Capacidade de } \\
\text { investimento C4 }\end{array}$ & 0,0 & 0,0 & 0,0 & 43,8 & 46,9 & 9,4 & 162,9 & 7 \\
\hline $\begin{array}{l}\text { Fatores econômicos } \\
\text { C15 } \\
\end{array}$ & 3,2 & 3,2 & 9,7 & 29,0 & 29,0 & 25,8 & 157,1 & 8 \\
\hline Reputação C1 & 0,0 & 0,0 & 15,6 & 40,6 & 34,4 & 12,5 & 156,5 & 9 \\
\hline Licença de uso C9 & 0,0 & 3,2 & 19,4 & 35,5 & 22,6 & 19,4 & 152,0 & 10 \\
\hline $\begin{array}{c}\text { Recursos de } \\
\text { administração C6 } \\
\end{array}$ & 0,0 & 12,5 & 3,1 & 37,5 & 37,5 & 9,4 & 150,6 & 11 \\
\hline $\begin{array}{c}\text { Profissional de TI } \\
\text { C19 } \\
\end{array}$ & 3,3 & 0,0 & 20,0 & 30,0 & 30,0 & 16,7 & 145,0 & 12 \\
\hline Suporte C2 & 0,0 & 6,5 & 22,6 & 29,0 & 32,3 & 16,1 & 142,3 & 13 \\
\hline Perfil de Risco C17 & 3,1 & 3,1 & 12,5 & 43,8 & 34,4 & 3,1 & 141,9 & 14 \\
\hline $\begin{array}{c}\text { Importância } \\
\text { atribuída a TI C18 }\end{array}$ & 3,2 & 6,5 & 19,4 & 32,3 & 25,8 & 12,9 & 138,7 & 15 \\
\hline Inovação C16 & 3,1 & 12,5 & 9,4 & 34,4 & 34,4 & 6,3 & 138,0 & 16 \\
\hline Usabilidade C10 & 0,0 & 6,3 & 25,0 & 40,6 & 18,8 & 9,4 & 137,0 & 17 \\
\hline Portabilidade C14 & 0,0 & 12,5 & 21,9 & 31,3 & 28,1 & 6,3 & 130,8 & 18 \\
\hline $\begin{array}{l}\text { Recursos adicionais } \\
\text { C3 }\end{array}$ & 3,1 & 6,3 & 31,3 & 46,9 & 9,4 & 3,1 & 119,0 & 19 \\
\hline
\end{tabular}

Tabela 3 - Classificação das respostas dos especialistas $-1^{\text {a }}$ Rodada

Fonte: Próprio autor

Nesta rodada foi utilizado o teste de $X^{2}$ para a definição da significância do coeficiente de concordância W e foi mostrado no teste que W tinha significância de valor $p=0,00001$, 
sendo este "extremamente significante" de acordo com o Quadro 10, ou seja, o valor do coeficiente de concordância $\mathrm{W}$ mostra que as respostas convergiram. $\mathrm{O}$ valor $\mathrm{p}$ foi calculado utilizando o valor do teste de $X^{2}$ e os graus de liberdade da amostra ( $\left.n-1\right)$, neste caso, $n$ representado pelos critérios de seleção de SGBD NoSQL (JOHNSON et al., 1970).

A pontuação das respostas foi utilizada para cálculo do coeficiente de concordância W e para realizar o teste de $X^{2}$, que pode ser verificada na Tabela 4.

\begin{tabular}{|c|c|c|c|c|c|c|c|c|c|c|c|c|c|c|c|c|c|c|c|}
\hline \multirow{2}{*}{$\begin{array}{c}\text { Paine- } \\
\text { listas }\end{array}$} & \multicolumn{19}{|c|}{ Criterios de Seleção de SGBD NoSQL } \\
\hline & C1 & C2 & C3 & $\mathrm{C} 4$ & $\mathrm{C5}$ & C6 & $\mathrm{C7}$ & $\mathrm{C} 8$ & C9 & $\mathrm{C} 10$ & C11 & $\mathrm{C} 12$ & $\mathrm{C} 13$ & C14 & C15 & C16 & C17 & C18 & C19 \\
\hline 1 & 2 & 2 & 2 & 3 & 4 & 4 & 4 & 3 & 5 & 4 & 4 & 5 & 3 & 2 & 4 & 1 & 2 & 3 & 3 \\
\hline 2 & 4,5 & 3 & 3 & 6 & 6 & 4,5 & 6 & 6 & 6 & 3 & 3 & 6 & 3 & 3 & 3 & 6 & 6 & 0 & 0 \\
\hline 3 & 6 & 4,8 & 3,6 & 4,8 & 4,8 & 3,6 & 3,6 & 2,4 & 3,6 & 2,4 & 4,8 & 4,8 & 4,8 & 3,6 & 2,4 & 3,6 & 3,6 & 3,6 & 3,6 \\
\hline 4 & 4,2 & 4,2 & 1,4 & 5,6 & 4,2 & 2,8 & 5,6 & 5,6 & 7 & 7 & 5,6 & 4,2 & 2,8 & 4,2 & 4,2 & 4,2 & 4,2 & 5,6 & 5,6 \\
\hline 5 & 5,6 & 5,6 & 5,6 & 5,6 & 7 & 4,2 & 7 & 7 & 4,2 & 4,2 & 4,2 & 7 & 5,6 & 5,6 & 7 & 4,2 & 5,6 & 4,2 & 5,6 \\
\hline 6 & 4 & 3 & 3 & 4 & 4 & 1 & 5 & 3 & 3 & 1 & 4 & 5 & 3 & 1 & 5 & 3 & 2 & 1 & 2 \\
\hline 7 & 4,5 & 6 & 3 & 6 & 7,5 & 7,5 & 7,5 & 6 & 1,5 & 3 & 4,5 & 7,5 & 6 & 1,5 & 6 & 6 & 6 & 3 & 3 \\
\hline 8 & 4,2 & 4,2 & 2,8 & 5,6 & 5,6 & 5,6 & 7 & 5,6 & 2,8 & 5,6 & 5,6 & 7 & 1,4 & 4,2 & 1,4 & 4,2 & 4,2 & 2,8 & 2,8 \\
\hline 9 & 6,8 & 6,8 & 5,1 & 5,1 & 6,8 & 5,1 & 6,8 & 5,1 & 5,1 & 5,1 & 6,8 & 6,8 & 6,8 & 5,1 & 3,4 & 3,4 & 5,1 & 6,8 & 5,1 \\
\hline 10 & 5,6 & 0 & 4,2 & 5,6 & 5,6 & 1,4 & 5,6 & 4,2 & 4,2 & 1,4 & 4,2 & 5,6 & 4,2 & 1,4 & 4,2 & 1,4 & 1,4 & 1,4 & 4,2 \\
\hline 11 & 6,8 & 5,1 & 5,1 & 5,1 & 8,5 & 5,1 & 8,5 & 5,1 & 6,8 & 8,5 & 8,5 & 8,5 & 8,5 & 6,8 & 5,1 & 5,1 & 5,1 & 5,1 & 5,1 \\
\hline 12 & 5,6 & 2,8 & 4,2 & 7 & 7 & 1,4 & 5,6 & 5,6 & 7 & 4,2 & 2,8 & 5,6 & 4,2 & 2,8 & 0 & 1,4 & 0 & 4,2 & 0 \\
\hline 13 & 6,8 & 6,8 & 5,1 & 5,1 & 6,8 & 6,8 & 6,8 & 6,8 & 5,1 & 3,4 & 3,4 & 6,8 & 6,8 & 3,4 & 5,1 & 1,7 & 3,4 & 3,4 & 5,1 \\
\hline 14 & 7,5 & 7,5 & 6 & 4,5 & 7,5 & 6 & 7,5 & 6 & 4,5 & 4,5 & 6 & 7,5 & 6 & 4,5 & 4,5 & 4,5 & 4,5 & 3 & 3 \\
\hline 15 & 4,5 & 4,5 & 4,5 & 6 & 7,5 & 6 & 7,5 & 7,5 & 7,5 & 4,5 & 7,5 & 7,5 & 6 & 4,5 & 7,5 & 6 & 4,5 & 7,5 & 7,5 \\
\hline 16 & 4,2 & 1,4 & 2,8 & 5,6 & 5,6 & 4,2 & 5,6 & 5,6 & 4,2 & 5,6 & 5,6 & 4,2 & 2,8 & 1,4 & 7 & 5,6 & 4,2 & 4,2 & 2,8 \\
\hline 17 & 3 & 1 & 2 & 4 & 4 & 3 & 4 & 4 & 3 & 4 & 4 & 3 & 2 & 1 & 5 & 4 & 3 & 3 & 2 \\
\hline 18 & 3 & 5 & 3 & 3 & 5 & 3 & 4 & 4 & 3 & 2 & 3 & 4 & 5 & 2 & 3 & 0 & 4 & 4 & 5 \\
\hline 19 & 10,4 & 13 & 10,4 & 10,4 & 13 & 13 & 13 & 10,4 & 10,4 & 10,4 & 10,4 & 13 & 10,4 & 10,4 & 10,4 & 7,8 & 10,4 & 13 & 13 \\
\hline 20 & 2 & 3 & 2 & 3 & 4 & 3 & 5 & 5 & 4 & 4 & 5 & 5 & 5 & 4 & 4 & 4 & 4 & 4 & 4 \\
\hline 21 & 3 & 4 & 5 & 3 & 5 & 4 & 5 & 5 & 0 & 3 & 5 & 5 & 4 & 4 & 5 & 4 & 4 & 4 & 5 \\
\hline 22 & 4,8 & 6,4 & 3,2 & 4,8 & 8 & 6,4 & 6,4 & 6,4 & 3,2 & 4,8 & 6,4 & 6,4 & 6,4 & 3,2 & 6,4 & 6,4 & 4,8 & 4,8 & 6,4 \\
\hline 23 & 2,8 & 2,8 & 4,2 & 7 & 7 & 5,6 & 7 & 7 & 2,8 & 4,2 & 5,6 & 7 & 7 & 5,6 & 7 & 4,2 & 5,6 & 7 & 5,6 \\
\hline 24 & 9 & 5,4 & 3,6 & 5,4 & 9 & 5,4 & 7,2 & 3,6 & 5,4 & 5,4 & 5,4 & 9 & 7,2 & 3,6 & 5,4 & 3,6 & 3,6 & 3,6 & 3,6 \\
\hline 25 & 4 & 4 & 2 & 3 & 5 & 4 & 4 & 4 & 4 & 3 & 4 & 4 & 4 & 3 & 4 & 5 & 3 & 4 & 4 \\
\hline 26 & 3 & 1 & 1 & 3 & 4 & 1 & 2 & 2 & 2 & 3 & 4 & 5 & 3 & 5 & 5 & 4 & 3 & 4 & 4 \\
\hline 27 & 2 & 2 & 3 & 4 & 5 & 3 & 4 & 4 & 5 & 3 & 4 & 2 & 2 & 4 & 0 & 2 & 3 & 4 & 4 \\
\hline 28 & 3 & 2 & 0 & 4 & 5 & 5 & 5 & 5 & 5 & 5 & 5 & 5 & 5 & 5 & 5 & 5 & 5 & 5 & 5 \\
\hline 29 & 8,5 & 8,5 & 5,1 & 5,1 & 6,8 & 5,1 & 8,5 & 6,8 & 6,8 & 3,4 & 6,8 & 8,5 & 8,5 & 5,1 & 5,1 & 6,8 & 6,8 & 5,1 & 5,1 \\
\hline 30 & 3,4 & 5,1 & 3,4 & 5,1 & 3,4 & 6,8 & 6,8 & 6,8 & 6,8 & 5,1 & 8,5 & 8,5 & 6,8 & 6,8 & 6,8 & 6,8 & 6,8 & 5,1 & 6,8 \\
\hline 31 & 8,4 & 6,3 & 6,3 & 8,4 & 10,5 & 6,3 & 10,5 & 8,4 & 6,3 & 4,2 & 6,3 & 10,5 & 8,4 & 6,3 & 8,4 & 6,3 & 6,3 & 4,2 & 6,3 \\
\hline 32 & 3,4 & 5,1 & 3,4 & 5,1 & 3,4 & 6,8 & 6,8 & 6,8 & 6,8 & 5,1 & 8,5 & 8,5 & 6,8 & 6,8 & 6,8 & 6,8 & 6,8 & 5,1 & 6,8 \\
\hline Posição & 9 & 13 & 19 & 7 & 3 & 11 & 2 & 4 & 10 & 17 & 5 & 1 & 6 & 18 & 8 & 16 & 14 & 15 & 12 \\
\hline & & & & & $\mathrm{n}=$ & 19 & $\bar{x}=$ & & 320,0 & & $V=$ & 0,882 & & & & & & & \\
\hline & & & & & $\mathrm{m}=$ & 32 & $S=$ & & 4791,3 & & $2=$ & 508,018 & & & & & & & \\
\hline
\end{tabular}

Legenda: As fórmulas de cálculo envolvidas, bem como o significado das variáveis utilizadas constam no Anexo A.

Tabela 4 - Respostas dos especialistas $-1^{\text {a }}$ Rodada Fonte: Próprio autor 
Com relação aos critérios para seleção de SGBDs NoSQL, a compilação e interpretação das indicações feitas pelos painelistas levaram a obtenção de uma lista consolidada com 22 critérios, com o acréscimo de três critérios, SGBD Open Source (C20), Apoio da Comunidade (C21) e Escalabilidade horizontal (C22), que foram aplicados na segunda rodada.

\subsection{Ciclo 2: Segunda Rodada do Painel}

Este ciclo abrangeu a apresentação das respostas obtidas com a primeira rodada ao painelista e no preparo e envio do segundo questionário da pesquisa. $\mathrm{O}$ e-mail convite para segunda rodada enviado para os painelistas pode ser verificado no Apêndice E desta pesquisa.

A segunda rodada do painel utilizou o recurso de planilhas do Google Docs do Google $\odot$, onde foi enviado para cada participante um resumo do resultado da primeira rodada e um convite para responder novamente o questionário avaliando a resposta dos demais participantes. A personalização de envio foi feita nesta rodada, pois foi necessário informar ao painelista qual foi sua resposta para os critérios na rodada anterior, permitindo que o mesmo pudesse informar uma nova resposta reavaliando sua antiga posição com base no resultado consolidado da rodada anterior.

Foi feito o acréscimo de mais três novos critérios que foram sugeridos pelos painelistas durante a primeira rodada. Foi enviado um questionário para cada painelista contendo o resumo e o resultado da primeira rodada, com a pontuação obtida em cada critério, sendo solicitada uma nova resposta. O painelista teve a opção de manter sua posição dada na rodada anterior ou mudar de acordo com o resultado consolidado da primeira rodada. $\mathrm{O}$ resultado da aplicação da segunda rodada do painel pode ser verificado na Tabela 5.

\begin{tabular}{|c|c|c|c|c|c|c|c|c|}
\hline \multirow[b]{2}{*}{ Critério } & \multicolumn{6}{|c|}{ Grau de Importância (\%) } & \multirow{2}{*}{$\begin{array}{l}\text { Pontua- } \\
\text { ção }\end{array}$} & \multirow{2}{*}{$\begin{array}{l}\text { Classi- } \\
\text { ficação }\end{array}$} \\
\hline & Nenhuma & $\begin{array}{l}\text { Muito } \\
\text { pouca }\end{array}$ & Pouca & Moderada & Muita & Total & & \\
\hline Desempenho C5 & 0,0 & 0,0 & 0,0 & 3,3 & 26,7 & 70,0 & 201,1 & 1 \\
\hline Confiabilidade C12 & 0,0 & 0,0 & 0,0 & 13,3 & 20,0 & 66,7 & 195,5 & 2 \\
\hline Disponibilidade C7 & 0,0 & 0,0 & 3,3 & 6,7 & 46,7 & 43,3 & 186,6 & 3 \\
\hline $\begin{array}{c}\text { Escalabilidade } \\
\text { Horizontal C22 }\end{array}$ & 0,0 & 0,0 & 0,0 & 16,7 & 40,0 & 43,3 & 182,1 & 4 \\
\hline $\begin{array}{c}\text { Manutenabilidade } \\
\text { C11 } \\
\end{array}$ & 0,0 & 0,0 & 0,0 & 16,7 & 66,7 & 16,7 & 171,0 & 5 \\
\hline Funcionalidade & 0,0 & 3,3 & 0,0 & 20,0 & 60,0 & 16,7 & 166,6 & 6 \\
\hline
\end{tabular}




\begin{tabular}{|c|c|c|c|c|c|c|c|c|} 
C13 & & & & & & & & \\
\hline Flexibilidade C8 & 0,0 & 0,0 & 0,0 & 23,3 & 66,7 & 10,0 & 165,4 & 7 \\
\hline $\begin{array}{c}\text { Capacidade de } \\
\text { investimento C4 }\end{array}$ & 0,0 & 0,0 & 0,0 & 30,0 & 63,3 & 6,7 & 160,9 & 8 \\
\hline $\begin{array}{c}\text { Apoio da } \\
\text { Comunidade C21 }\end{array}$ & 3,3 & 0,0 & 0,0 & 30,0 & 56,7 & 10,0 & 157,8 & 9 \\
\hline Economia C15 & 3,3 & 3,3 & 6,7 & 26,7 & 40,0 & 20,0 & 150,3 & 10 \\
\hline $\begin{array}{c}\text { Recursos de } \\
\text { Administração C6 }\end{array}$ & 0,0 & 3,3 & 6,7 & 40,0 & 43,3 & 6,7 & 149,3 & 11 \\
\hline Reputação C1 & 0,0 & 0,0 & 13,3 & 46,7 & 40,0 & 0,0 & 142,7 & 12 \\
\hline $\begin{array}{c}\text { SGBD Open } \\
\text { Source C20 }\end{array}$ & 0,0 & 6,7 & 10,0 & 46,7 & 30,0 & 6,7 & 138,0 & 14 \\
\hline $\begin{array}{c}\text { Profissional de TI } \\
\text { C19 }\end{array}$ & 3,3 & 0,0 & 20,0 & 33,3 & 33,3 & 10,0 & 137,9 & 13 \\
\hline Suporte C2 & 0,0 & 10,0 & 10,0 & 43,3 & 33,3 & 3,3 & 137,7 & 16 \\
\hline Licença de Uso C9 & 0,0 & 3,3 & 16,7 & 50,0 & 16,7 & 13,3 & 136,8 & 15 \\
\hline $\begin{array}{c}\text { Importância } \\
\text { atribuída a TI C18 }\end{array}$ & 0,0 & 3,3 & 20,0 & 43,3 & 26,7 & 6,7 & 132,6 & 17 \\
\hline Perfil de Risco C17 & 3,3 & 3,3 & 13,3 & 50,0 & 30,0 & 0,0 & 129,5 & 18 \\
\hline Usabilidade C10 & 0,0 & 6,7 & 16,7 & 56,7 & 16,7 & 3,3 & 126,9 & 19 \\
\hline Portabilidade C14 & 0,0 & 10,0 & 23,3 & 36,7 & 26,7 & 3,3 & 126,0 & 21 \\
\hline Inovação C16 & 3,3 & 13,3 & 6,7 & 40,0 & 36,7 & 0,0 & 126,1 & 20 \\
\hline $\begin{array}{c}\text { Recursos } \\
\text { adicionais C3 }\end{array}$ & 0,0 & 13,3 & 30,0 & 46,7 & 6,7 & 3,3 & 113,7 & 22 \\
\hline
\end{tabular}

Tabela 5 - Classificação das respostas dos especialistas $-2^{a}$ Rodada Fonte: Próprio autor

Lembretes periódicos também foram enviados com o intuito de reduzir o impacto causado por possíveis atrasos por parte dos respondentes. $\mathrm{O} e$-mail lembrete pode ser visto no Apêndice D. Este $e$-mail foi enviado para aqueles painelistas que não responderam no tempo previsto.

A pontuação das respostas dos painelistas na segunda rodada foi utilizada para definir o ranking de critérios e para elaborar os cálculos para o coeficiente $\mathrm{W}$ e o teste de $X^{2}$ que pode ser verificada na Tabela 6 . 


\begin{tabular}{|c|c|c|c|c|c|c|c|c|c|c|c|c|c|c|c|c|c|c|c|c|c|c|}
\hline \multirow{2}{*}{\begin{tabular}{|c|} 
Paine- \\
listas \\
\end{tabular}} & \multicolumn{22}{|c|}{ Criterios de Seleção de SGBD NoSQL } \\
\hline & C1 & $\mathrm{C} 2$ & $\mathrm{C} 3$ & $\mathrm{C} 4$ & $\mathrm{C} 5$ & C6 & C7 & $\mathrm{c} 8$ & $\mathrm{Cg}$ & $\mathrm{C} 10$ & $\mathrm{C} 11$ & $\mathrm{C} 12$ & $\mathrm{C} 13$ & C14 & $\mathrm{C} 15$ & $\mathrm{C} 16$ & $\mathrm{C} 17$ & C18 & $\mathrm{C} 19$ & $\mathrm{C} 20$ & $\mathrm{C} 21$ & $\mathrm{C} 22$ \\
\hline 1 & 2 & 2 & 2 & 3 & 4 & 4 & 4 & 3 & 5 & 4 & 4 & 5 & 3 & 2 & 4 & 1 & 2 & 3 & 3 & 3 & 4 & 3 \\
\hline 3 & 4,8 & 4,8 & 3,6 & 4,8 & 4,8 & 3,6 & 3,6 & 3,6 & 3,6 & 2,4 & 4,8 & 4,8 & 4,8 & 3,6 & 2,4 & 3,6 & 3,6 & 3,6 & 3,6 & 1,2 & 0 & 4,8 \\
\hline 4 & 4,2 & 4,2 & 1,4 & 5,6 & 4,2 & 2,8 & 5,6 & 5,6 & 7 & 5,6 & 5,6 & 4,2 & 4,2 & 4,2 & 4,2 & 4,2 & 4,2 & 5,6 & 5,6 & 4,2 & 5,6 & 7 \\
\hline 5 & 4,2 & 5,6 & 4,2 & 5,6 & 7 & 5,6 & 7 & 5,6 & 4,2 & 4,2 & 5,6 & 7 & 5,6 & 4,2 & 5,6 & 4,2 & 4,2 & 4,2 & 5,6 & 4,2 & 4,2 & 4,2 \\
\hline 6 & 4 & 3 & 3 & 4 & 4 & 3 & 5 & 3 & 3 & 1 & 4 & 5 & 3 & 1 & 5 & 3 & 2 & 2 & 2 & 3 & 3 & 4 \\
\hline 7 & 4,5 & 6 & 3 & 6 & 7,5 & 7,5 & 7,5 & 6 & 1,5 & 3 & 4,5 & 7,5 & 6 & 1,5 & 6 & 6 & 6 & 3 & 3 & 1,5 & 6 & 6 \\
\hline 8 & 4,2 & 4,2 & 2,8 & 5,6 & 5,6 & 5,6 & 7 & 5,6 & 2,8 & 5,6 & 5,6 & 7 & 1,4 & 4,2 & 1,4 & 4,2 & 4,2 & 2,8 & 2,8 & 2,8 & 5,6 & 7 \\
\hline 9 & 6,8 & 6,8 & 5,1 & 5,1 & 6,8 & 5,1 & 6,8 & 5,1 & 5,1 & 5,1 & 6,8 & 6,8 & 6,8 & 5,1 & 3,4 & 3,4 & 5,1 & 6,8 & 5,1 & 3,4 & 5,1 & 8,5 \\
\hline 10 & 5,6 & 4,2 & 4,2 & 5,6 & 5,6 & 4,2 & 5,6 & 4,2 & 4,2 & 1,4 & 5,6 & 5,6 & 5,6 & 2,8 & 4,2 & 1,4 & 1,4 & 1,4 & 4,2 & 4,2 & 5,6 & 7 \\
\hline 11 & 6,8 & 5,1 & 5,1 & 5,1 & 8,5 & 5,1 & 8,5 & 5,1 & 6,8 & 8,5 & 8,5 & 8,5 & 8,5 & 6,8 & 5,1 & 5,1 & 5,1 & 5,1 & 5,1 & 5,1 & 6,8 & 8,5 \\
\hline 12 & 5,6 & 2,8 & 2,8 & 7 & 7 & 1,4 & 5,6 & 5,6 & 7 & 4,2 & 4,2 & 5,6 & 4,2 & 4,2 & 0 & 1,4 & 0 & 4,2 & 0 & 4,2 & 5,6 & 7 \\
\hline 13 & 5,1 & 6,8 & 5,1 & 5,1 & 8,5 & 6,8 & 8,5 & 6,8 & 5,1 & 3,4 & 6,8 & 8,5 & 6,8 & 3,4 & 5,1 & 1,7 & 3,4 & 3,4 & 5,1 & 5,1 & 6,8 & 6,8 \\
\hline 14 & 6 & 6 & 4,5 & 4,5 & 7,5 & 6 & 6 & 6 & 4,5 & 4,5 & 6 & 7,5 & 6 & 6 & 4,5 & 4,5 & 4,5 & 4,5 & 4,5 & 4,5 & 6 & 7,5 \\
\hline 15 & 4,5 & 4,5 & 4,5 & 6 & 7,5 & 6 & 7,5 & 6 & 3 & 4,5 & 7,5 & 7,5 & 6 & 4,5 & 7,5 & 6 & 4,5 & 7,5 & 7,5 & 7,5 & 7,5 & 7,5 \\
\hline 16 & 2,8 & 1,4 & 2,8 & 5,6 & 5,6 & 4,2 & 4,2 & 5,6 & 4,2 & 4,2 & 5,6 & 4,2 & 4,2 & 2,8 & 5,6 & 5,6 & 4,2 & 4,2 & 2,8 & 5,6 & 4,2 & 4,2 \\
\hline 17 & 3 & 1 & 2 & 4 & 4 & 3 & 4 & 4 & 3 & 4 & 4 & 5 & 4 & 1 & 5 & 4 & 3 & 3 & 2 & 2 & 3 & 4 \\
\hline 18 & 3 & 5 & 3 & 3 & 5 & 3 & 4 & 4 & 3 & 2 & 3 & 4 & 5 & 2 & 3 & 0 & 4 & 4 & 5 & 4 & 4 & 3 \\
\hline 19 & 10 & 10 & 10 & 10 & 13 & 13 & 13 & 10 & 10 & 10 & 10 & 13 & 10 & 10 & 10 & 7,8 & 10 & 10 & 10 & 10 & 10 & 10 \\
\hline 20 & 3 & 3 & 4 & 4 & 5 & 4 & 5 & 4 & 3 & 3 & 4 & 5 & 5 & 4 & 4 & 3 & 3 & 3 & 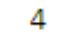 & 3 & 3 & 3 \\
\hline 21 & 3 & 4 & 5 & 3 & 5 & 4 & 5 & 5 & 3 & 3 & 5 & 5 & 4 & 3 & 5 & 4 & 4 & 4 & 5 & 4 & 4 & 5 \\
\hline 22 & 4,8 & 6,4 & 3,2 & 6,4 & 8 & 6,4 & 6,4 & 8 & 3,2 & 4,8 & 6,4 & 4,8 & 6,4 & 3,2 & 6,4 & 6,4 & 4,8 & 4,8 & 6,4 & 6,4 & 6,4 & 6,4 \\
\hline 23 & 2,8 & 2,8 & 4,2 & 7 & 7 & 5,6 & 7 & 7 & 2,8 & 4,2 & 5,6 & 7 & 7 & 5,6 & 7 & 4,2 & 5,6 & 7 & 5,6 & 4,2 & 4,2 & 5,6 \\
\hline 24 & 7,2 & 5,4 & 3,6 & 5,4 & 9 & 5,4 & 7,2 & 5,4 & 5,4 & 5,4 & 5,4 & 9 & 7,2 & 3,6 & 5,4 & 3,6 & 3,6 & 3,6 & 3,6 & 5,4 & 5,4 & 7,2 \\
\hline 25 & 4 & 4 & 2 & 4 & 5 & 4 & 4 & 4 & 4 & 3 & 4 & 4 & 4 & 3 & 4 & 4 & 3 & 4 & 3 & 4 & 4 & 5 \\
\hline 26 & 3 & 3 & 1 & 4 & 5 & 2 & 2 & 4 & 2 & 3 & 4 & 5 & 3 & 5 & 5 & 4 & 3 & 4 & 4 & 5 & 5 & 5 \\
\hline 27 & 2 & 2 & 3 & 4 & 5 & 3 & 4 & 4 & 5 & 3 & 4 & 3 & 4 & 4 & 4 & 3 & 4 & 4 & 4 & 3 & 4 & 4 \\
\hline 29 & 6,8 & 6,8 & 5,1 & 6,8 & 8,5 & 5,1 & 8,5 & 6,8 & 5,1 & 5,1 & 6,8 & 8,5 & 8,5 & 5,1 & 5,1 & 6,8 & 6,8 & 5,1 & 5,1 & 6,8 & 8,5 & 6,8 \\
\hline 30 & 5,1 & 5,1 & 3,4 & 6,8 & 8,5 & 6,8 & 6,8 & 6,8 & 6,8 & 5,1 & 8,5 & 8,5 & 6,8 & 6,8 & 6,8 & 6,8 & 6,8 & 5,1 & 6,8 & 5,1 & 6,8 & 8,5 \\
\hline 31 & 8,4 & 6,3 & 6,3 & 8,4 & 11 & 6,3 & 11 & 8,4 & 6,3 & 4,2 & 6,3 & 11 & 8,4 & 6,3 & 8,4 & 6,3 & 6,3 & 4,2 & 6,3 & 8,4 & 6,3 & 8,4 \\
\hline 32 & 5,1 & 5,1 & 3,4 & 5,1 & 8,5 & 6,8 & 6,8 & 6,8 & 6,8 & 5,1 & 8,5 & 8,5 & 6,8 & 6,8 & 6,8 & 6,8 & 6,8 & 5,1 & 6,8 & 6,8 & 6,8 & 6,8 \\
\hline Posição & 12 & 15 & 22 & 8 & 1 & 11 & 3 & 7 & 16 & 19 & 5 & 2 & 6 & 21 & 10 & 20 & 18 & 17 & 14 & 13 & 9 & 4 \\
\hline & & & & & & & & $\begin{array}{l}22 \\
30\end{array}$ & & $\begin{array}{l}\overline{\mathbf{x}}= \\
\mathrm{S}=\end{array}$ & $\begin{array}{r}3 \\
8383 \\
\end{array}$ & $\begin{array}{l}345,0 \\
385,1\end{array}$ & & $\begin{array}{l}W= \\
x^{2}=\end{array}$ & 662 , & $\begin{array}{l}052 \\
755\end{array}$ & & & & & & \\
\hline
\end{tabular}

Legenda: As fórmulas de cálculo envolvidas, bem como o significado das variáveis utilizadas constam no Anexo A.

Tabela 6 - Respostas dos especialistas $-2^{\text {a }}$ Rodada

Fonte: Próprio autor

Segundo o valor do coeficiente W $(1,052)$, houve um grau muito alto de concordância já que apresentou valor superior a 0,9 de acordo com as faixas sugeridas por Schmidt (1997). Verificou-se também um aumento no grau de concordância na segunda rodada comparando-se com a primeira. Foi possível constatar que a variação do grau de concordância foi pequena, o que levou a decisão de encerrar as rodadas com os especialistas já que se encontrou um nível satisfatório de consenso. Mesmo com a inclusão de três novos critérios que não estavam presentes na primeira rodada, observou-se um aumento no grau de concordância entre os 
especialistas na segunda rodada. Além disso, a observação no aumento do grau de concordância também pode ser verificada pelo fato de que os principais critérios votados na rodada anterior tiveram suas frequências de votos aumentadas na segunda rodada.

Nesta rodada foi utilizado o teste de $X^{2}$ para a definição da significância do coeficiente de concordância W e foi mostrado no teste que W tinha significância de valor $p=0,00001$, sendo este "extremamente significante" de acordo com o Quadro 10, ou seja, o valor do coeficiente de concordância $\mathrm{W}$ mostra que as respostas convergiram. $\mathrm{O}$ valor $\mathrm{p}$ foi calculado utilizando o valor do teste de $X^{2}$ e os graus de liberdade da amostra ( $\left.n-1\right)$, neste caso, $n$ representado pelos critérios de seleção de SGBD NoSQL (JOHNSON et al., 1970).

Com a obtenção de um grau satisfatório para o coeficiente de concordância W e a demonstração de sua validade por meio da aplicação do teste de $\mathrm{X}^{2}$, optou-se pelo encerramento do Painel Delphi neste ciclo.

A partir da lista apresentada na Tabela 5, foi possível definir os critérios mais relevantes para a escolha de SGBDs NoSQL com a aplicação de uma média dos pontos obtidos entre os critérios e eliminando-se os critérios que ficaram com a pontuação abaixo da média de 151,6 pontos. Após a aplicação do corte com o uso da média de pontos foi obtida uma lista com os nove primeiros critérios mais pontuados. 


\section{Análise dos Resultados}

Esta seção apresenta a análise dos resultados obtidos com a aplicação do Painel Delphi. Foi possível encerrar a aplicação do painel e consolidar uma lista com os principais critérios de seleção de SGBDs NoSQL, pois foi obtida convergência. Nesta seção são apresentadas análises para cada um dos grupos de especialistas e também uma análise considerando todos os participantes. Considera-se a partir deste ponto a denominação Grupo Geral para designação do grupo que envolve todos os participantes do Painel Delphi.

O Painel Delphi mostrou quais foram os principais critérios para seleção de SGBDs NoSQL sob o ponto de vista de especialistas atuantes em organizações privadas em ambiente Web. Os critérios de seleção considerando toda a amostra de especialistas estão reproduzidos na Tabela 5. Essa tabela mostra que, no ranking coletivo, há uma prevalência, em termos de atenção requerida na avaliação de SGBDs NoSQL, para critérios relacionados com o produto. Esta constatação fica clara, pois entre os critérios que ocupam as quatro primeiras posições do ranking, três deles são critérios de Produto. Os critérios de Qualidade ocupam a segunda posição no ranking, seguido de critérios do Fornecedor e por último, critérios referentes à Organização.

A seguir são feitas análises por grupos de painelistas, apresentando análises dos critérios mais relevantes e desconsiderando os critérios que ficaram com pontuação abaixo da média do grupo.

\subsection{Análise conjunta do grupo Desenvolvedores}

A Tabela 7 apresenta as respostas sobre a priorização de critérios de seleção de SGBDs NoSQL feita pelo grupo Desenvolvedores. Os principais critérios para este grupo são: Confiabilidade (C12), Desempenho (C5), Escalabilidade Horizontal (C22), Disponibilidade (C7), Manutenabilidade (C11), Flexibilidade (C8), Apoio da Comunidade (C21), Funcionalidade (C8), Recursos de Administração (C6) e Capacidade de Investimento (C4). 


\begin{tabular}{|c|c|c|c|c|c|c|c|c|c|c|c|c|c|c|c|c|c|c|c|c|c|c|}
\hline \multirow{2}{*}{$\begin{array}{l}\text { Paine- } \\
\text { lista }\end{array}$} & \multicolumn{22}{|c|}{ Criterios de Seleção de SGBD NoSQL } \\
\hline & C1 & $\mathrm{C} 2$ & $\mathrm{C} 3$ & $\mathrm{C4}$ & $\mathrm{C5}$ & $\mathrm{C6}$ & $\mathrm{C7}$ & $\mathrm{C} 8$ & $\mathrm{Cg}$ & $\mathrm{C} 10$ & C11 & $\mathrm{C} 12$ & $\mathrm{C} 13$ & $\mathrm{C} 14$ & $\mathrm{C} 15$ & $\mathrm{C} 16$ & $\mathrm{C} 17$ & $\mathrm{C} 18$ & $\mathrm{C} 19$ & $\mathrm{C} 20$ & $\mathrm{C} 21$ & $\mathrm{C} 22$ \\
\hline 4 & 4,2 & 4,2 & 1,4 & 5,6 & 4,2 & 2,8 & 5,6 & 5,6 & 7 & 5,6 & 5,6 & 4,2 & 4,2 & 4,2 & 4,2 & 4,2 & 4,2 & 5,6 & 5,6 & 4,2 & 5,6 & 7 \\
\hline 7 & 4,5 & 6 & 3 & 6 & 7,5 & 7,5 & 7,5 & 6 & 1,5 & 3 & 4,5 & 7,5 & 6 & 1,5 & 6 & 6 & 6 & 3 & 3 & 1,5 & 6 & 6 \\
\hline 8 & 4,2 & 4,2 & 2,8 & 5,6 & 5,6 & 5,6 & 7 & 5,6 & 2,8 & 5,6 & 5,6 & 7 & 1,4 & 4,2 & 1,4 & 4,2 & 4,2 & 2,8 & 2,8 & 2,8 & 5,6 & 7 \\
\hline 9 & 6,8 & 6,8 & 5,1 & 5,1 & 6,8 & 5,1 & 6,8 & 5,1 & 5,1 & 5,1 & 6,8 & 6,8 & 6,8 & 5,1 & 3,4 & 3,4 & 5,1 & 6,8 & 5,1 & 3,4 & 5,1 & 8,5 \\
\hline 11 & 6,8 & 5,1 & 5,1 & 5,1 & 8,5 & 5,1 & 8,5 & 5,1 & 6,8 & 8,5 & 8,5 & 8,5 & 8,5 & 6,8 & 5,1 & 5,1 & 5,1 & 5,1 & 5,1 & 5,1 & 6,8 & 8,5 \\
\hline 13 & 5,1 & 6,8 & 5,1 & 5,1 & 8,5 & 6,8 & 8,5 & 6,8 & 5,1 & 3,4 & 6,8 & 8,5 & 6,8 & 3,4 & 5,1 & 1,7 & 3,4 & 3,4 & 5,1 & 5,1 & 6,8 & 6,8 \\
\hline 15 & 4,5 & 4,5 & 4,5 & 6 & 7,5 & 6 & 7,5 & 6 & 3 & 4,5 & 7,5 & 7,5 & 6 & 4,5 & 7,5 & 6 & 4,5 & 7,5 & 7,5 & 7,5 & 7,5 & 7,5 \\
\hline 19 & 10 & 10 & 10 & 10 & 13 & 13 & 13 & 10 & 10 & 10 & 10 & 13 & 10 & 10 & 10 & 7,8 & 10 & 10 & 10 & 10 & 10 & 10 \\
\hline 21 & 3 & 4 & 5 & 3 & 5 & 4 & 5 & 5 & 3 & 3 & 5 & 5 & 4 & 3 & 5 & 4 & 4 & 4 & 5 & 4 & 4 & 5 \\
\hline 23 & 2,8 & 2,8 & 4,2 & 7 & 7 & 5,6 & 7 & 7 & 2,8 & 4,2 & 5,6 & 7 & 7 & 5,6 & 7 & 4,2 & 5,6 & 7 & 5,6 & 4,2 & 4,2 & 5,6 \\
\hline 24 & 7,2 & 5,4 & 3,6 & 5,4 & 9 & 5,4 & 7,2 & 5,4 & 5,4 & 5,4 & 5,4 & 9 & 7,2 & 3,6 & 5,4 & 3,6 & 3,6 & 3,6 & 3,6 & 5,4 & 5,4 & 7,2 \\
\hline 26 & 3 & 3 & 1 & 4 & 5 & 2 & 2 & 4 & 2 & 3 & 4 & 5 & 3 & 5 & 5 & 4 & 3 & 4 & 4 & 5 & 5 & 5 \\
\hline Posicao & 15 & 13 & 22 & 10 & 2 & 9 & 3 & 7 & 20 & 16 & 5 & 1 & 8 & 19 & 11 & 21 & 17 & 12 & 14 & 18 & 6 & 4 \\
\hline & & & & $\begin{array}{l}\mathrm{n} \\
\mathrm{m}\end{array}$ & & $\begin{array}{l}22 \\
12\end{array}$ & & $\begin{array}{l}\bar{x}= \\
S=\end{array}$ & 111 & $\begin{array}{r}138,0 \\
299,3\end{array}$ & & $\begin{array}{l}w= \\
\chi^{2}=\end{array}$ & 21 & $\begin{array}{r}0,873 \\
19,959 \\
\end{array}$ & & & & & & & & \\
\hline
\end{tabular}

Legenda: As fórmulas de cálculo envolvidas, bem como o significado das variáveis utilizadas constam no Anexo A

Tabela 7 - Respostas dos especialistas na $2^{\text {a }}$ Rodada - Desenvolvedores Fonte: Próprio autor

Pode ser verificado nos resultados do painel um alto grau de concordância segundo as faixas sugeridas por Schmidt (1997). O coeficiente de concordância calculado para o grupo Desenvolvedores foi de 0,873 , possuindo um alto grau de concordância, sendo, no entanto menor do que o coeficiente de concordância do grupo Geral. Isso mostra uma maior discordância entre os elementos deste grupo comparado com os demais grupos. Além disso, verifica-se que o ranking dos critérios, obtido para o grupo Desenvolvedores, possui pouca diferença nas posições se comparando ao grupo Geral.

Analisando os critérios de seleção de SGBDs NoSQL mais relevantes para o grupo de Desenvolvedores é plausível considerar que:

a) Confiabilidade (C12). Alçada à condição de critério mais relevante, a confiabilidade refere-se à capacidade do SGBD de manter o nível de desempenho, ser tolerante e continuar funcionando em situações inesperadas, como por exemplo, possuir mecanismos de Backup, recuperação de falhas, suporte a replicação de dados etc. Em uma situação inesperada de falha, é desejável que o SGBD possa contornar o problema evitando erros. Sendo assim, mesmo sendo a proposta principal dos SGBDs NoSQL resolver problemas de desempenho em ambientes de massivo volume de dados, especialistas ligados com o desenvolvimento de aplicações consideram a confiabilidade como item mais 
importante na escolha de um SGBD NoSQL. Este resultado indica que é essencial que as aplicações continuem acessando o banco de dados de forma confiável, mantendo os níveis de serviço estáveis.

b) Desempenho (C5). É o segundo critério mais importante para os desenvolvedores. Quando a aplicação possui requisitos de alto desempenho, principalmente no que se refere a aplicações Web (nas quais as consultas necessitam de tempo de resposta on-line em situações de atendimento ao cliente, por exemplo), a escolha de um SGBD NoSQL é recomendável. Os SGBDs NoSQL atendem aos critérios de desempenho por meio de processos de otimização de consultas, capacidade de realização de processamento paralelo e de sua estrutura de dados simplificada, a qual permite um acesso mais eficiente aos dados.

c) Disponibilidade (C7). Critério que ocupa a terceira posição no ranking dos especialistas Desenvolvedores, também é mencionado neste trabalho como um critério atingido normalmente por meio do uso SGBDs NoSQL. A disponibilidade em aplicações que utilizam SGBDs NoSQL é garantida por meio da característica nativa de replicação que tais sistemas possuem. Como exemplo, pode-se citar o SGBD NoSQL orientado a colunas Cassandra, no qual as indisponibilidades de um nó são automaticamente contornadas onde outro nó assume, permitindo a continuidade da execução da aplicação. Além disso, os SGBDs NoSQL permitem alterações em sua estrutura de forma transparente para a aplicação, como é o caso do MongoDB que permite que o modelo de dados seja modificado sem causar qualquer indisponibilidade para a aplicação. Sendo assim, para especialistas desenvolvedores, quando há requisitos de alta disponibilidade de suas aplicações, pode-se cogitar a escolha de um SGBD NoSQL ao invés do tradicional modelo relacional.

d) Escalabilidade Horizontal (C22). Este critério ocupa a quarta posição, sendo sugerido por um dos especialistas na primeira rodada e é citado neste trabalho como um ponto forte dos SGBDs NoSQL. Tradicionalmente as aplicações escalam de forma vertical com relação ao seu banco de dados, ou seja, para que se possa acompanhar o aumento no volume de dados e processamento, é necessário substituir as máquinas existentes por outras melhores e com maior capacidade de armazenamento para obter-se melhoria de desempenho. Já com a escalabilidade horizontal ocorre um aumento no número de máquinas disponíveis para o armazenamento e processamento de dados. Em comparação com a escalabilidade vertical, a escalabilidade horizontal tende a ser uma solução mais viável, porém requer que diversas threads/processos de uma tarefa sejam criadas e distribuídas. Neste caso, o uso de um banco de dados relacional poderia ser inviável, uma vez que diversos processos conectando simultaneamente em um mesmo conjunto de dados causaria uma alta concorrência, 
aumentando, consequentemente, o tempo de acesso às tabelas envolvidas. A ausência de controle de bloqueios e a facilidade de se trabalhar em sistemas distribuídos são características dos SGBDs NoSQL que permitem a escalabilidade horizontal. Desta forma, de acordo com a opinião de especialistas desenvolvedores, a necessidade de se contornar os problemas de gerenciamento de grandes volumes de dados faz com que o critério C22 tenha grande importância para a escolha de um SGBD NoSQL.

e) Manutenabilidade (C11). Quinto critério mais bem colocado pelos especialistas e que de certa forma está também relacionada com a disponibilidade, pois se refere à facilidade que o SGBD oferece para fazer manutenções, alterações em sua estrutura, e conforme mencionado, em alguns SGBDs NoSQL ainda é possível fazer alterações estruturais de forma transparente para a aplicação, favorecendo requisitos de manutenabilidade.

f) Apoio da Comunidade (C21). É o sexto critério mais bem pontuado, podendo ser definido como a facilidade de se encontrar informações, melhores práticas e fóruns de discussão de determinado SGBD NoSQL. Este critério pode ser decisivo para a implantação de um SGBD NoSQL uma vez que este conceito ainda não está disseminado entre os profissionais de TI e ainda não está totalmente consolidado no mercado. Desta forma desenvolvedores consideram importante o apoio da comunidade para tornar mais fácil a atividade de desenvolvimento de aplicações suportadas por SGBDs NoSQL. Este foi o grupo que melhor pontuou este critério, e isto se justifica já que o desenvolvedor considera muito importante o apoio da comunidade para conhecimento de novas tecnologias que possibilitem o auxílio e esclarecimentos em fóruns especializados de eventuais dúvidas durante a atividade de desenvolvimento.

g) Flexibilidade (C8). É o sétimo critério melhor pontuado e para o grupo Desenvolvedores, critérios de flexibilidade são importantes para a aplicação, uma vez que possibilita a alteração e manutenção no banco de dados sem impactar ou deixar a aplicação indisponível.

h) Funcionalidade (C13). Oitavo critério mais relevante para o grupo Desenvolvedores, que consideram relevante que o SGBD possa atender aos requisitos da aplicação e permanecer estável durante sua execução, atendendo as necessidades de negócio definidas.

i) Recursos de Administração (C6). Nono critério melhor pontuado, analisa se o SGBD NoSQL pode fornecer recursos que possam facilitar a administração de dados, desta forma desenvolvedores podem considerar importante haver ferramentas que facilitem a realização de alterações no banco de dados. 
j) Capacidade de Investimento (C4). Décimo critério mais importante para os profissionais desenvolvedores, este critério está relacionado com melhorias e lançamentos de novos produtos e versões, sendo importante então para este grupo que os fornecedores de SGBDs NoSQL possam acompanhar as novidades do mercado e evoluir conforme as necessidades das aplicações.

\subsection{Análise conjunto do grupo DBAs e DAs}

A Tabela 8 apresenta o ranking de critérios de seleção de SGBDs NoSQL definido para o grupo DBAs e DAs. Os principais critérios de seleção de SGBDs NoSQL para este grupo são: desempenho, confiabilidade, disponibilidade, flexibilidade, capacidade de investimento, manutenabilidade, escalabilidade horizontal, funcionalidade, apoio da comunidade e licença de uso.

\begin{tabular}{|c|c|c|c|c|c|c|c|c|c|c|c|c|c|c|c|c|c|c|c|c|c|c|}
\hline \multirow{2}{*}{$\begin{array}{c}\text { Paine- } \\
\text { listas }\end{array}$} & \multicolumn{22}{|c|}{ Criterios de Seleção de SGBD NoSQL } \\
\hline & $\mathrm{C} 1$ & $\mathrm{C} 2$ & $\mathrm{C} 3$ & $\mathrm{C} 4$ & C5 & $\mathrm{C} 6$ & $\mathrm{C7}$ & $\mathrm{C} 8$ & $\mathrm{Cg}$ & C10 & C11 & $\mathrm{C} 12$ & $\mathrm{C} 13$ & C14 & $\mathrm{C} 15$ & $\mathrm{C} 16$ & $\mathrm{C} 17$ & $\mathrm{C} 18$ & $\mathrm{C} 19$ & $\mathrm{C} 20$ & $\mathrm{C} 21$ & $\mathrm{C} 22$ \\
\hline 1 & 2 & 2 & 2 & 3 & 4 & 4 & 4 & 3 & 5 & 4 & 4 & 5 & 3 & 2 & 4 & 1 & 2 & 3 & 3 & 3 & 4 & 3 \\
\hline 5 & 4,2 & 5,6 & 4,2 & 5,6 & 7 & 5,6 & 7 & 5,6 & 4,2 & 4,2 & 5,6 & 7 & 5,6 & 4,2 & 5,6 & 4,2 & 4,2 & 4,2 & 5,6 & 4,2 & 4,2 & 4,2 \\
\hline 12 & 5,6 & 2,8 & 2,8 & 7 & 7 & 1,4 & 5,6 & 5,6 & 7 & 4,2 & 4,2 & 5,6 & 4,2 & 4,2 & 0 & 1,4 & 0 & 4,2 & 0 & 4,2 & 5,6 & 7 \\
\hline 16 & 2,8 & 1,4 & 2,8 & 5,6 & 5,6 & 4,2 & 4,2 & 5,6 & 4,2 & 4,2 & 5,6 & 4,2 & 4,2 & 2,8 & 5,6 & 5,6 & 4,2 & 4,2 & 2,8 & 5,6 & 4,2 & 4,2 \\
\hline 18 & 3 & 5 & 3 & 3 & 5 & 3 & 4 & 4 & 3 & 2 & 3 & 4 & 5 & 2 & 3 & 0 & 4 & 4 & 5 & 4 & 4 & 3 \\
\hline 20 & 3 & 3 & 4 & 4 & 5 & 4 & 5 & 4 & 3 & 3 & 4 & 5 & 5 & 4 & 4 & 3 & 3 & 3 & 4 & 3 & 3 & 3 \\
\hline 22 & 4,8 & 6,4 & 3,2 & 6,4 & 8 & 6,4 & 6,4 & 8 & 3,2 & 4,8 & 6,4 & 4,8 & 6,4 & 3,2 & 6,4 & 6,4 & 4,8 & 4,8 & 6,4 & 6,4 & 6,4 & 6,4 \\
\hline 25 & 4 & 4 & 2 & 4 & 5 & 4 & 4 & 4 & 4 & 3 & 4 & 4 & 4 & 3 & 4 & 4 & 3 & 4 & 3 & 4 & 4 & 5 \\
\hline 27 & 2 & 2 & 3 & 4 & 5 & 3 & 4 & 4 & 5 & 3 & 4 & 3 & 4 & 4 & 4 & 3 & 4 & 4 & 4 & 3 & 4 & 4 \\
\hline 30 & 5,1 & 5,1 & 3,4 & 6,8 & 8,5 & 6,8 & 6,8 & 6,8 & 6,8 & 5,1 & 8,5 & 8,5 & 6,8 & 6,8 & 6,8 & 6,8 & 6,8 & 5,1 & 6,8 & 5,1 & 6,8 & 8,5 \\
\hline Posição & 18 & 17 & 22 & 5 & 1 & 13 & 3 & 4 & 10 & 16 & 6 & 2 & 8 & 19 & 11 & 21 & 20 & 15 & 14 & 12 & 9 & 7 \\
\hline & & & & & $\begin{array}{l}\mathrm{n}= \\
\mathrm{m}=\end{array}$ & $\begin{array}{l}22 \\
10 \\
\end{array}$ & & $\begin{array}{l}\bar{x}= \\
S=\end{array}$ & & $\begin{array}{r}115 \\
13337 \\
\end{array}$ & & $\begin{array}{l}w \\
x^{2} \\
\end{array}$ & $\begin{array}{l}= \\
=\end{array}$ & $\begin{array}{r}1,2 \\
268,7 \\
\end{array}$ & & & & & & & & \\
\hline
\end{tabular}

Legenda: As fórmulas de cálculo envolvidas, bem como o significado das variáveis utilizadas constam no Anexo A.

Tabela 8 - Respostas dos especialistas na $2^{\text {a }}$ Rodada - DBAs e DAs Fonte: Próprio autor

Verifica-se nos resultados do painel para o grupo DBAs e DAs um alto grau de concordância segundo as faixas sugeridas por Schmidt (1997). O coeficiente de concordância para o grupo de DBAs e DAs é de 1,280, sendo maior do que o do grupo Geral. Verificou-se que o grupo possui o maior coeficiente de concordância comparando-se com os outros grupos, possuindo coeficiente de concordância maior que o do grupo Desenvolvedores e do grupo 
Demais Profissionais de TI, mostrando assim que há um maior consenso de opiniões neste grupo quando comparado com a opinião dos demais.

Analisando os critérios de seleção de SGBDs NoSQL mais relevantes para o grupo de DBAs e DAs é plausível considerar que:

a) Desempenho (C5). É o critério mais relevante para seleção de SGBD NoSQL. Desta forma, para este grupo de especialistas, a principal proposta dos SGBDs NoSQL que é garantir desempenho às aplicações em ambiente de grande volume de dados também vai de acordo com a sua opinião no momento da escolha de um SGBD NoSQL, corroborando assim a principal proposta dos SGBDs NoSQL trazida neste trabalho. Este resultado mostra que sob o ponto de vista de profissionais ligados diretamente com a administração de banco de dados é essencial que as aplicações continuem com bom desempenho mesmo com aumento no volume de dados, sendo tolerável ter outros aspectos em segundo plano como confiabilidade e disponibilidade. Este foi o grupo responsável pela primeira colocação deste critério no ranking geral, uma vez que sua pontuação se distanciou muito dos demais critérios.

b) Confiabilidade (C12). É o segundo critério considerado mais relevante para o grupo de DBAs e DAs. Desta forma, além da avaliação de desempenho, este grupo também preza pela confiabilidade que o SGBD dispõe, ou seja, sua capacidade de manter seu nível de desempenho, ser tolerante a falhas e continuar funcionando em situações inesperadas.

c) Disponibilidade (C7). É o terceiro critério considerado mais relevante para o grupo. Assim, DBAs e DAs encaram que a garantia de alta disponibilidade justifica, juntamente com desempenho e confiabilidade, a escolha de um SGBD NoSQL, sendo requisitos fundamentais para aplicações Web que trafegam grande volume de dados e considerável quantidade de acessos, uma vez que a informação deve estar disponível com um tempo de resposta on-line.

d) Flexibilidade (C8). É o quarto critério melhor pontuado e para o grupo DBAs e DAs critérios de flexibilidade são importantes uma vez que facilita o trabalho de manutenção do modelo de dados, uma vez que permite alterações com menores impactos às aplicações, tornando mais simples a gestão de mudança.

e) Capacidade de Investimento (C4). Critério que ocupa a quarta posição do ranking, mostrando que o grupo DBAs e DAs considera importante a continuidade nas melhorias dos pacotes de SGBDs. Este é um dos critérios pouco atingido normalmente pelos SGBDs NoSQL devido principalmente à sua natureza Open Source. No entanto, DBAs e DAs julgam importante que o SGBD NoSQL possa oferecer alguma capacidade de investimento para futuras melhorias, uma vez que a realidade das aplicações $W e b$ e as necessidades de negócio 
mudam, o que torna desejável que o SGBD NoSQL possa ter capacidade de investimento para adaptar-se e atender às suas novas necessidades.

f) Manutenabilidade (C11). Este critério é o sexto classificado no ranking deste grupo, sendo importante, pois analisa se o SGBD permite que alterações sejam feitas no sistema sem causar grandes impactos à aplicação, facilitando assim a atividade de administração de dados, pois requer menor planejamento para alterações nas estruturas do banco de dados. Esta característica é bem atendida pelos SGBDs NoSQL devido a sua estrutura mais simplificada e a possibilidade de se trabalhar de forma distribuída.

g) Escalabilidade Horizontal (C22). Sétimo critério melhor classificado no grupo, este critério facilita a atividade do administrador de banco de dados, que quando necessário escalar a capacidade de processamento e armazenamento do banco, ao invés de trocar toda a infraestrutura do banco de dados por melhores máquinas apenas são adicionadas novas máquinas no cluster.

h) Funcionalidade (C13). O oitavo critério mais relevante para o grupo está relacionado com a funcionalidade do SGBD NoSQL. Assim administradores de banco de dados consideram relevante que o SGBD NoSQL possa atender aos requisitos da aplicação e permanecer estável durante sua execução, atendendo as necessidades de negócio definidas.

i) Apoio da Comunidade (C21). O nono critério melhor pontuado refere-se ao apoio da comunidade, que está relacionado com a facilidade de se encontrar informações, melhores práticas e fóruns de discussão de determinado SGBD NoSQL. Para administradores de dados o apoio da comunidade pode tornar mais fácil o processo de administração do banco de dados, especialmente em um conceito recente como NoSQL, devido a ampla disponibilização de informações em fóruns especializados.

j) Licença de Uso (C9). O décimo critério melhor pontuado pelos especialistas DBAs e DAs refere-se a licença de uso que o SGBD NoSQL apresenta, sendo importante assim a análise da licença para definir se está compatível com as necessidades do projeto de dados. Este é um critério de importância para este grupo, pois são os profissionais diretamente relacionados com a atividade de análise de licença durante um processo de seleção de SGBD.

\subsection{Análise conjunta do grupo Demais Profissionais de TI}

A Tabela 9 apresenta o ranking de critérios de seleção de SGBDs NoSQL definido para o grupo Demais Profissionais de TI. Os principais critérios de seleção de SGBDs NoSQL para este grupo são: confiabilidade, desempenho, disponibilidade, escalabilidade horizontal, 
funcionalidade, manutenabilidade, reputação, capacidade de investimento, flexibilidade e economia.

\begin{tabular}{|c|c|c|c|c|c|c|c|c|c|c|c|c|c|c|c|c|c|c|c|c|c|c|}
\hline \multirow{2}{*}{$\begin{array}{l}\text { Paine- } \\
\text { lista }\end{array}$} & \multicolumn{22}{|c|}{ Criterios de Seleção de SGBD NoSQL } \\
\hline & $\mathrm{C} 1$ & $\mathrm{C} 2$ & $\mathrm{C3}$ & $\mathrm{C} 4$ & $\mathrm{C5}$ & $\mathrm{C} 6$ & $\mathrm{C7}$ & $\mathrm{C} 8$ & $\mathrm{Cg}$ & $\mathrm{C} 10$ & C11 & $\mathrm{C} 12$ & $\mathrm{C} 13$ & $\mathrm{C} 14$ & $+\mathrm{C} 15$ & $\mathrm{C} 16$ & $\mathrm{C} 17$ & $\mathrm{C} 18$ & $\mathrm{C} 19$ & $\mathrm{C} 20$ & $\mathrm{C} 21$ & $\mathrm{C} 22$ \\
\hline 3 & 4,8 & 4,8 & 3,6 & 4,8 & 4,8 & 3,6 & 3,6 & 3,6 & 3,6 & 2,4 & 4,8 & 4,8 & 4,8 & 3,6 & 2,4 & 3,6 & 3,6 & 3,6 & 3,6 & 1,2 & 0 & 4,8 \\
\hline 6 & 4 & 3 & 3 & 4 & 4 & 3 & 5 & 3 & 3 & 1 & 4 & 5 & 3 & 1 & 5 & 3 & 2 & 2 & 2 & 3 & 3 & 4 \\
\hline 10 & 5,6 & 4,2 & 4,2 & 5,6 & 5,6 & 4,2 & 5,6 & 4,2 & 4,2 & 1,4 & 5,6 & 5,6 & 5,6 & 2,8 & 4,2 & 1,4 & 1,4 & 1,4 & 4,2 & 4,2 & 5,6 & 7 \\
\hline 14 & 6 & 6 & 4,5 & 4,5 & 7,5 & 6 & 6 & 6 & 4,5 & 4,5 & 6 & 7,5 & 6 & 6 & 4,5 & 4,5 & 4,5 & 4,5 & 4,5 & 4,5 & 6 & 7,5 \\
\hline 17 & 3 & 1 & 2 & 4 & 4 & 3 & 4 & 4 & 3 & 4 & 4 & 5 & 4 & 1 & 5 & 4 & 3 & 3 & 2 & 2 & 3 & 4 \\
\hline 29 & 6,8 & 6,8 & 5,1 & 6,8 & 8,5 & 5,1 & 8,5 & 6,8 & 5,1 & 5,1 & 6,8 & 8,5 & 8,5 & 5,1 & 5,1 & 6,8 & 6,8 & 5,1 & 5,1 & 6,8 & 8,5 & 6,8 \\
\hline 31 & 8,4 & 6,3 & 6,3 & 8,4 & 11 & 6,3 & 11 & 8,4 & 6,3 & 4,2 & 6,3 & 11 & 8,4 & 6,3 & 8,4 & 6,3 & 6,3 & 4,2 & 6,3 & 8,4 & 6,3 & 8,4 \\
\hline 32 & 5,1 & 5,1 & 3,4 & 5,1 & 8,5 & 6,8 & 6,8 & 6,8 & 6,8 & 5,1 & 8,5 & 8,5 & 6,8 & 6,8 & 6,8 & 6,8 & 6,8 & 5,1 & 6,8 & 6,8 & 6,8 & 6,8 \\
\hline Posicao & 7 & 13 & 20 & 8 & 2 & 12 & 3 & 9 & 15 & 22 & 6 & 1 & 5 & 19 & 10 & 16 & 18 & 21 & 17 & 14 & 11 & 4 \\
\hline & & & & & & $\begin{array}{l}n= \\
m=\end{array}$ & $\begin{array}{c}22 \\
8 \\
\end{array}$ & & $\begin{array}{l}\bar{x}= \\
S=\end{array}$ & & $\begin{array}{r}92, \\
0015 \text {, }\end{array}$ & & $\begin{array}{l}w= \\
x 2=\end{array}$ & $\begin{array}{l}= \\
=1\end{array}$ & $\begin{array}{r}1,0 \\
177,9 \\
\end{array}$ & & & & & & & \\
\hline
\end{tabular}

Legenda: As fórmulas de cálculo envolvidas, bem como o significado das variáveis utilizadas constam no Anexo A.

Tabela 9 - Respostas dos especialistas na $2^{\text {a }}$ Rodada- Demais Profissionais de TI Fonte: Próprio autor

Verifica-se nos resultados do painel para o grupo Demais Profissionais de TI um alto grau de concordância segundo as faixas sugeridas por Schmidt (1997), possuindo um grau de concordância de 1,059, sendo praticamente igual ao grau de concordância do grupo Geral e maior que o grau do grupo Desenvolvedores.

Analisando os critérios de seleção de SGBDs NoSQL mais relevantes para o grupo de Demais Profissionais de TI é plausível considerar que:

a) Confiabilidade (C12). Considerado o critério mais relevante para o grupo Demais Profissionais de TI, os gerentes, principais elementos que compõe este grupo, consideram que para a escolha de um SGBD NoSQL a confiabilidade deve ser o critério com maior peso a ser avaliado, mostrando na visão destes profissionais que o SGBD deve garantir o funcionamento das aplicações, mesmo que possa custar deixar em segundo plano outros critérios como Desempenho e Disponibilidade. Como o grupo analisado é composto principalmente por gerentes, entende-se que o mais importante é que os SGBDs NoSQL possam suportar as aplicações de forma confiável, possuindo mecanismos de recuperação de falhas para situações inesperadas, prezando assim pela capacidade da aplicação manter-se sempre no ar, mesmo em situações inesperadas. Mesmo com a proposta principal dos SGBDs NoSQL resolver problemas ligados principalmente com desempenho em ambientes de massivo volume de 
dados, especialistas ligados com a gestão de TI consideram que é mais importante na sua avaliação para escolha de um SGBD NoSQL o mesmo ser confiável a ter melhor desempenho.

Desempenho (C5). Segundo critério considerado mais relevante, ou seja, cumprindose as condições de confiabilidade, estes profissionais prezam pela capacidade de garantir as aplicações manter satisfatório nível de desempenho mesmo com o aumento no volume de dados.

Disponibilidade (C7). Ocupando a terceira posição do ranking, especialistas deste grupo acreditam que quando há requisitos de alta disponibilidade de suas aplicações é importante analisar a escolha de um SGBD NoSQL ao invés do tradicional modelo relacional.

Escalabilidade Horizontal (C22). Uma das preocupações da gestão também é reduzir custos operacionais e de infraestrutura, o que justifica a importância dada para a escalabilidade horizontal, que ocupou a quarta posição do ranking, uma vez que com o mesmo incorre-se em custos menores adicionando novas máquinas ao cluster ao invés de substituição de máquinas e recursos de hardware quando há a necessidade de escalar o banco de dados.

Funcionalidade (C13). Ocupando a quinta posição do ranking, este grupo também julga importante que um SGBD NoSQL seja capaz de se adequar e operar da forma como se espera para o atendimento das necessidades de negócio planejadas, satisfazendo critérios de funcionalidade.

Manutenabilidade (C11). Sexto critério mais bem colocado, este grupo considera importante a facilidade de manutenção, pois assim é possível diminuição dos recursos dispensados no planejamento de mudança e maior eficiência na evolução das aplicações.

Reputação (C1). Sendo o sétimo critério melhor pontuado pelo grupo Demais Profissionais de TI, esse critério é de fato importante para um grupo que não se relaciona diretamente com critérios técnicos, dando importância assim para a qualidade no atendimento e reputação no mercado de determinado fornecedor de SGBD NoSQL.

Capacidade de Investimento (C4). Ocupando a oitava posição do ranking, o grupo considera importante a continuidade nas melhorias dos pacotes de SGBDs. Este é um dos critérios pouco atingido normalmente pelos SGBDs NoSQL devido principalmente à sua natureza Open Source. No entanto, os membros do grupo Demais Profissionais de TI julgam importante que o SGBD NoSQL possa oferecer alguma capacidade de investimento para futuras melhorias, uma vez que a realidade das aplicações $W e b$ e as necessidades de negócio 
mudam, o que torna desejável que o SGBD NoSQL possa ter capacidade de investimento para adaptar-se e atender às suas novas necessidades.

Flexibilidade (C8). Ocupando a nona posição, o grupo considera que critérios de flexibilidade são importantes para a organização, uma vez que possibilita com maior facilidade a alteração e manutenção no banco de dados com menores custos e impactos para a aplicação.

Economia (C15). Critério que ocupa a décima posição do ranking, a economia é especialmente importante uma vez que gerentes, maioria dos membros deste grupo, preocupam-se com os gastos e resultados financeiros da organização, sendo importante redução dos custos na aquisição de um SGBD. Os SGBDs NoSQL normalmente não apresentam custo de licença e aquisição, no entanto podem oferecer maiores custos de treinamento e adaptação das aplicações por ser este um novo conceito de gerenciamento de dados ainda pouco utilizado no mercado.

Verificou-se por meio da análise dos resultados para o grupo Demais Profissionais de TI que alguns critérios que eram esperados terem maior importância dentro do contexto da organização tiveram baixo grau de importância. Por exemplo, o critério economia, que era esperado estar entre os principais para este grupo, que é composto em sua maioria por gerentes, ficou apenas em décimo lugar. Este resultado mostra que este grupo não considera aspectos relacionados com a organização como relevantes para a adoção de um SGBD NoSQL, contrariando o que era esperado, onde critérios técnicos relacionados especificamente com o produto como confiabilidade e desempenho tem maior importância para este grupo do que características da organização.

\subsection{Comparação dos resultados entre os grupos de especialistas e tipos de critérios}

Os critérios de Produto foram os critérios de maior importância definidos pelos especialistas, uma vez que representam quatro dos nove principais critérios identificados. Desta forma as características relacionadas diretamente com o SGBD NoSQL são as mais relevantes para sua escolha, podendo assim representar maior peso para a tomada de decisão. Os critérios de Qualidade tiveram três critérios entre os principais. Com relação aos aspectos do Fornecedor, foi identificado apenas um critério dentre os principais. Os critérios 
relacionados à Organização foram os menos importantes uma vez que nenhum deles está entre os nove mais importantes.

A análise do Quadro 11 mostra que o ranking obtido para cada um dos grupos é relativamente diferente do grupo Geral, com algumas mudanças nas posições, inclusive do critério de maior pontuação, no caso o Desempenho. No grupo Geral o critério com maior pontuação é o Desempenho, enquanto nos grupos Desenvolvedores e Demais Profissionais de TI o critério com maior pontuação foi a Confiabilidade. Para o grupo DBAs e DAs a pontuação obtida com o critério Desempenho foi bem maior do que a pontuação dada para este critério nos demais grupos, o que mostra claramente que a visão técnica de banco de dados é diferente das demais, onde a preocupação maior para a escolha de uma SGBD NoSQL tende a ser no tempo de resposta às consultas realizadas pelas aplicações Web. Por meio do Quadro 11 pode-se verificar as alterações de posições que ocorreram com a análise do resultado do Painel Delphi separada por grupo, onde são destacadas em negrito as nove primeiras posições do ranking do grupo Geral que compõe a lista dos principais critérios após a aplicação do corte da média da pontuação.

\begin{tabular}{|c|c|c|c|c|c|}
\hline \multirow{2}{*}{\multicolumn{2}{|c|}{\begin{tabular}{|c|} 
Critério X \\
Classificação por Grupo
\end{tabular}}} & \multicolumn{4}{|c|}{ Classificação dos Grupos } \\
\hline & & Geral & Desenvol- & DBAs e & $\begin{array}{l}\text { Demais } \\
\text { Profissionais de }\end{array}$ \\
\hline \multirow{4}{*}{ 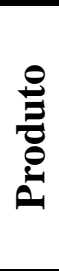 } & C5 - Desempenho & 1 & 2 & 1 & 2 \\
\hline & C7 - Disponibilidade & 3 & 4 & 3 & 3 \\
\hline & $\begin{array}{c}\text { C22 - Escalabilidade } \\
\text { Horizontal } \\
\end{array}$ & 4 & 3 & 8 & 4 \\
\hline & C8 - Flexibilidade & 7 & 6 & 4 & 9 \\
\hline \multirow{3}{*}{ 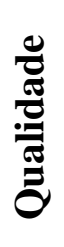 } & C12 - Confiabilidade & 2 & 1 & 2 & 1 \\
\hline & C11 - Manutenabilidade & 5 & 5 & 5 & 5 \\
\hline & C13 - Funcionalidade & 6 & 8 & 6 & 6 \\
\hline \multirow{2}{*}{ 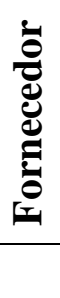 } & $\begin{array}{l}\text { C4 - Capacidade de } \\
\text { Investimento }\end{array}$ & 8 & 9 & 7 & 7 \\
\hline & C21 - Apoio da Comunidade & 9 & 7 & 9 & 11 \\
\hline
\end{tabular}

Quadro 11 - Comparativo Ranking Critérios de Seleção SGBD NoSQL 
O critério Apoio da Comunidade (C21) é o único que não foi enquadrado em nenhum grupo, pois não se encaixa em nenhuma das classificações adotadas para os demais.

Analisando o Quadro 11, verifica-se alguns resultados plausíveis como:

- O grupo DBAs e DAs foi o grupo que deu maior importância para os critérios relacionados com Fornecedores, o que era esperado uma vez que são esses profissionais que lidam diretamente com fornecedores de SGBDs. Este também foi o grupo que melhor pontuou o critério Desempenho (C5), o que era esperado uma vez que este grupo é especializado em resolver problemas de desempenho nos bancos de dados e convive com os problemas de desempenho de consultas das aplicações.

- O critério Reputação foi mais bem pontuado pelo grupo Demais Profissionais de TI. Quanto à reputação, este é um resultado esperado, pois os gerentes, maioria que compõe este grupo, normalmente levam em conta fatores não técnicos, como a reputação de determinado produto, privilegiando muitas vezes a escolha do produto líder de mercado, sem avaliação prévia mais apurada de requisitos técnicos do SGBD.

- O critério Desempenho foi o que obteve maior pontuação, conforme esperado no início da pesquisa, uma vez que os trabalhos revisados na literatura sobre o tema trazem como principal ganho com a adoção de SGBDs NoSQL um maior desempenho devido sua estrutura simplificada de modelagem de dados.

A análise dos dados também trouxe resultados que podem ser considerados como contribuições para o entendimento do processo de seleção de SGBD como:

- Esperava-se que critérios como Filosofia da Organização e Profissional de TI pudessem ser um obstáculo para a escolha de um SGBD NoSQL, no entanto requisitos relacionados à organização tiveram pouca relevância quando comparados aos demais, ou seja, a decisão para escolha de um SGBD NoSQL tem predominância técnica apesar da importância do contexto organizacional na adoção de qualquer nova tecnologia.

- Foi encontrado um novo critério não relacionado na literatura e que ficou na lista dos critérios mais relevantes para seleção de SGBDs NoSQL: Apoio da Comunidade (C21), desta forma, para a escolha de um SGBD NoSQL, especialistas consideram importante que o mesmo tenha bom suporte na 
comunidade, como existência de fóruns especializados no tema. O grupo Desenvolvedores foi o que melhor pontuou este critério, no entanto analisando apenas os gerentes do grupo Demais Profissionais de TI, este critério ficou na sétima posição, configurando entre os principais, mostrando assim um resultado inesperado de que gerentes consideram importante o apoio da comunidade para a seleção de um SGBD NoSQL. A importância atribuída a este critério se deve uma vez que o mesmo assume o papel do suporte, uma vez que os bancos NoSQL normalmente não possuem suporte oficial do fornecedor.

- O critério Flexibilidade (C8) teve melhor classificação para o grupo DBAs e DAs, ocupando a quarta posição neste grupo, sendo que nos demais grupos não configura entre os principais. Este foi um resultado não esperado, uma vez que critério de Flexibilidade normalmente impacta o grupo de Desenvolvedores, uma vez que SGBDs que apresentam problemas de flexibilidade podem impactar diretamente as aplicações, dificultando o processo de alteração no modelo de dados.

- Esperava-se que o grupo Demais Profissionais de TI, composto principalmente por gestores, fossem privilegiar critérios ligados a organização como Profissional de TI, Filosofia da Organização etc. No entanto este grupo manteve comportamento parecido com os demais, dando maior importância para critérios técnicos e relacionados especificamente ao SGBD, como Confiabilidade e Desempenho, contrariando assim a expectativa inicial para este grupo que era privilegiar aspectos organizacionais de TI para o processo de seleção de SGBDs NoSQL.

Verifica-se que os critérios Reputação (C1) e Licença de Uso (C9) tiveram as maiores variações de posição entre os grupos, onde o critério Licença de Uso aparece na lista dos dez primeiros apenas no grupo DBAs e DAs, o que mostra a sua maior importância neste grupo, uma vez que são esses profissionais que estão diretamente relacionados com a verificação de licenças de uso na adoção de um novo SGBD NoSQL e são os profissionais que fazem a análise de licenças para a contratação de um novo pacote SGBD. Já a reputação é uma característica normalmente desejada por gerentes.

Analisando os nove critérios melhores posicionados, verifica-se que eles pouco se alteram de um grupo para outro, apenas alternando as posições entre os grupos, o que reforça a hipótese do consenso da opinião geral do grupo com relação aos critérios considerados mais 
relevantes. O critério considerado de maior relevância no grupo Geral foi o critério de Desempenho, o que enfatiza o contexto do Big Data abordado neste trabalho, onde os SGBDs NoSQL possuem como principal objetivo atender a necessidade de desempenho diante de um volume crescente de dados que as aplicações Web geram. O critério Desempenho é frequentemente abordado no contexto de SGBDs NoSQL, onde algumas aplicações abrem mão de consistência para obtenção de desempenho.

Apesar de o critério Desempenho ter sido o mais bem pontuado no grupo Geral, este aparece como o de maior pontuação apenas no grupo DBAs e DAs, sendo o critério Confiabilidade o de maior pontuação para os grupos Demais Profissionais de TI e Desenvolvedores. Assim Demais Profissionais de TI e Desenvolvedores consideram a confiabilidade como critério mais importante na escolha de um SGBD NoSQL, ou seja, não estão dispostos de abrir mão da confiabilidade para obter desempenho. Este resultado reforça a ideia de que os especialistas com contato mais próximo das aplicações e requisitos de negócio tendem a dar maior importância à confiabilidade de um SGBD NoSQL. Já o grupo DBAs e DAs que não estão tão ligados com as necessidades de negócio das aplicações, tendem a pontuar mais o critério de desempenho quando analisam a escolha de um SGBD NoSQL, uma vez que a análise deste grupo tende a ter um critério mais técnico e prático em banco de dados que os demais.

A explicação para o grupo Geral ter como principal critério o desempenho mesmo apenas o grupo DBAs e DAs ter escolhido este critério como mais relevante é a distância na pontuação para o segundo critério mais pontuado. No grupo Demais Profissionais de TI a diferença na pontuação entre Confiabilidade e Desempenho foi de dois pontos e no grupo Desenvolvedores essa diferença foi de apenas 1,4 pontos. Já no grupo DBAs e DAs a diferença de pontuação entre Desempenho e Confiabilidade foi de 11,9 pontos, ou seja, sendo esta maior do que a diferença dos outros dois grupos somadas.

Verifica-se, por fim, que o critério Recursos Adicionais ocupa a posição menos relevante no ranking consolidado do grupo Geral e dos grupos Desenvolvedores e DBAs e DAs. Esta baixa importância na maioria dos grupos reflete que a presença de recursos adicionais é pouco relevante para se escolher um SGBD NoSQL, uma vez que cenários onde os SGBDs NoSQL são importantes, como ambientes Web, a presença de recursos adicionais como bases de teste e ferramentas de administração tem pouca importância quando comparado com outras necessidades como desempenho e disponibilidade por exemplo. A presença de recursos adicionais pode ser desejável, mas não determinante para a escolha de um SGBD NoSQL. 


\section{Conclusões}

O objetivo deste trabalho foi identificar e analisar os principais critérios que devem ser usados para avaliação de um SGBD NoSQL, com base na opinião de especialistas em SGBDs. Dentro desse contexto, pretendeu-se: (1) identificar na literatura os principais critérios de seleção de SGBDs; (2) identificar com especialistas, a partir dos critérios encontrados na literatura, os principais critérios para seleção de SGBDs NoSQL; e (3) ordenar os critérios de seleção de SGBDs NoSQL conforme a importância atribuída pelos especialistas.

Para atingir os objetivos propostos, efetuou-se uma pesquisa descritiva e qualitativa utilizando a técnica Delphi com a colaboração de 32 especialistas. Os resultados obtidos para cada objetivo específico estão apresentados nesta seção. Cabe destacar ainda que a presente pesquisa apresenta limitações. Entre elas, destacam-se:

- Limitações relacionadas ao método. O uso do painel Delphi não permite generalização dos resultados e pode ocorrer excesso de influência por parte de um ou vários painelistas. A seleção da amostra de respondentes e o tratamento dos resultados não tem significância estatística. Existe excessiva dependência dos resultados em relação à escolha dos especialistas, com possibilidade de introdução de viés pela escolha dos respondentes.

- Método de Pesquisa. Foi utilizada a forma de ranking para aplicação do Painel Delphi com grupo misto de especialistas, fugindo da abordagem tradicional da aplicação do método com um grupo de especialistas apenas no tema objeto de estudo. Nesta pesquisa utilizou-se também perfis que não são de especialistas técnicos em banco de dados, como gerentes, desenvolvedores e fornecedores de SGBDs. Essa abordagem difere do padrão descrito pela técnica. Porém os resultados da pesquisa mostraram que a opinião do diversos grupos não é muito diferente, e considera-los na pesquisa permitiu um resultado mais abrangente.

- Abrangência dos Resultados. Com base no perfil de especialistas os resultados se aplicam no contexto de organizações que atuam em ambientes Web.

Apesar das limitações apresentadas, os resultados obtidos são satisfatórios face aos objetivos propostos. Trata-se de uma pesquisa qualitativa, cujo objetivo é identificar os principais critérios para seleção de SGBDs NoSQL sem a pretensão de propor um modelo de 
avaliação. A seguir são apresentados com mais detalhes os objetivos que foram concluídos nesta pesquisa:

\section{a) Critérios para Seleção de SGBDs Descritos na Literatura}

Foram identificados 19 critérios para seleção de SGBDs descritos na literatura. Essa identificação foi feita por meio de uma revisão da literatura com emprego da técnica de revisão sistemática. Esses critérios foram agrupados em quatro categorias e estão resumidos a seguir:

- Características do Fornecedor. Reputação (C1), Suporte (C2), Recursos Adicionais Oferecidos (C3) e Capacidade de investimento (C4).

- Características do Produto. Desempenho (C5), Recursos de Administração (C6), Disponibilidade (C7), Flexibilidade (C8), Licença de uso (C9).

- Características de Qualidade. Usabilidade (C10), Manutenabilidade (C11), Confiabilidade (C12), Funcionalidade (C13) e Portabilidade (C14).

- Características da Organização. Econômico (C15), Inovação (C16), Perfil de risco (C17), Importância atribuída a TI (C18) e Profissional de TI (C19).

\section{b) Critérios de Seleção de SGBD NoSQL Identificados Empiricamente}

A partir dos 19 critérios identificados na literatura, foi aplicada a técnica Delphi e foram consolidados 22 critérios, com a adição de três critérios sugeridos pelos especialistas: SGBD Open Source (C20), Apoio da Comunidade (C21) e Escalabilidade horizontal (C22).

Os 22 critérios consolidados foram ordenados pelo grau de importância e foram obtidos nove principais critérios para seleção de SGBD NoSQL. Esses nove critérios em ordem de importância são: Desempenho (C5), Confiabilidade (C12), Disponibilidade (C7), Escalabilidade horizontal (C22), Manutenabilidade (C11), Funcionalidade (C13), Flexibilidade (C8), Capacidade de Investimento (C4) e Apoio da comunidade (C21).

Tais critérios podem ser utilizados nas organizações, na ordem de importância apresentada, para avaliar o uso de SGBDs NoSQL.

\section{c) Conclusões Acerca dos Critérios de Seleção de SGBDs NoSQL}

O Painel Delphi contribuiu para a consolidação, junto aos especialistas envolvidos, de 22 critérios que podem ser utilizados para avaliação e seleção de SGBDs NoSQL. Verificouse que a literatura possui pouco conteúdo explorando a questão do processo de seleção de SGBDs, uma vez que a revisão sistemática encontrou poucas referências neste aspecto. Desta 
forma não foi possível afirmar se de fato tais critérios encontrados na literatura poderiam ser aplicados para avaliação e seleção de SGBDs NoSQL. Assim o Painel Delphi pôde validar os critérios encontrados na literatura quanto o seu grau de importância para seleção e avaliação de SGBDs NoSQL e adicionar novos critérios relevantes encontrados pelos especialistas.

Analisando a sequência do ranking, é interessante notar que os critérios que ocupam as duas primeiras posições podem ser conflitantes, de certa forma, uma vez que alguns SGBDs NoSQL abrem mão de consistência e integridade, que conferem confiabilidade as aplicações, para a obtenção de desempenho. Este conflito pode trazer questionamentos e dúvidas acerca da aplicação dos critérios levantados na escolha de SGBDs NoSQL, no entanto é importante esclarecer que o critério confiabilidade pode assumir um conceito amplo e é importante reduzir o seu contexto para a aplicação no escopo deste estudo, que são organizações privadas, em ambiente Web. Neste contexto a confiabilidade confere às aplicações que continuem com o correto funcionamento em situações inesperadas e de erro e neste aspecto o critério de desempenho não conflita com o critério de confiabilidade, uma vez que existem SGBDs NoSQL que garantem o mesmo nível de desempenho em situações inesperadas ou eventuais problemas, garantindo também confiabilidade, como o SGBD Cassandra que suporta bem o processamento distribuído trabalhando com vários nós, assim caso haja indisponibilidade de um nó, outro assume automaticamente, permitindo a continuidade dos serviços e mantendo níveis de desempenho.

Os critérios apresentados estão associados principalmente às características de produto, ou seja, às características do SGBD em si, sendo o Desempenho (C5) principal critério escolhido, corroborado pelo trabalho de Leavitt (2010) que destaca o desempenho como principal característica dos SGBDs NoSQL. Conclui-se que os especialistas consideram como principais critérios para seleção de SGBDs NoSQL as características técnicas do SGBD.

Alguns critérios de Qualidade também foram elencados entre as principais posições do ranking. Os critérios relacionados com as características da Organização e do Fornecedor tiveram menores pontuações e ocuparam poucas posições no ranking, o que demonstra que na opinião dos especialistas, o contexto da organização, sua filosofia, política de treinamento, bem como as características dos fornecedores como suporte e disponibilidade tem pouca importância na escolha de um SGBD NoSQL, contrariando o que era esperado antes da realização do Painel Delphi. 
Foi encontrada uma nova dimensão entre os principais critérios para avaliação de SGBDs NoSQL que é o Apoio da Comunidade, ressaltada principalmente pelos grupos técnicos Desenvolvedores e DBAs e DAs.

\subsection{Pesquisas Futuras}

A abrangência do tema Big Data e o massivo volume de dados exigido nas aplicações Web possibilitam o desenvolvimento de diversos estudos na área de Sistema de Informação. Nesse contexto, recomenda-se a elaboração de novas pesquisas, a partir dos resultados deste trabalho. Entre as várias alternativas de pesquisa, destacam-se:

- Papel da comunidade. Nesta pesquisa pôde ser observado que o apoio da comunidade é importante para a escolha de um SGBD NoSQL, pois pode facilitar o processo de implantação de uma nova tecnologia com a disponibilização de informações compartilhadas entre os profissionais. Este resultado abre a possibilidade de futuras pesquisas com uma análise mais aprofundada do papel que a comunidade pode exercer na seleção e gerenciamento de banco de dados e sua importância para adoção de novas tecnologias.

- Pesquisa quantitativa com amostra aleatória de empresas que permita generalizar os resultados. Uma das limitações deste trabalho é a impossibilidade de se realizar generalizações dos resultados, devido às particularidades da técnica empregada e uso de amostra reduzida. Assim este trabalho pode servir como base para realização de pesquisas quantitativas que possibilitem a generalização dos resultados.

- Estudo de caso. Sugere-se a realização de um estudo de caso a partir dos critérios mais importantes identificados nesta pesquisa que possibilite um entendimento com maior profundidade destes critérios no processo de seleção de SGBDs NoSQL.

Os critérios levantados neste estudo podem ser utilizados como um guia inicial com o objetivo de auxiliar as organizações que se encontram em um cenário onde a implantação de SGBDs NoSQL pode ser aplicável. 


\subsection{Considerações Finais}

A cada dia, e com maior intensidade nos últimos anos, o problema do Big Data vem marcando presença crescente no contexto das aplicações Web onde o crescente volume, variedade e velocidade de informações tem-se tornado uma preocupação para os líderes das organizações. Se no passado o excessivo volume de dados representava um custo importante para as organizações, atualmente, com custos de armazenamento decrescentes, outras questões têm surgido: como determinar a relevância entre os grandes volumes de dados, como processar de forma eficiente estes dados e como criar valor a partir dos mesmos.

Além disso, as organizações enfrentam outros problemas como a variedade de dados e suas variadas fontes, e a velocidade com que eles estão sendo produzidos e precisam ser tratados para atender a demanda. É um grande desafio vincular, correlacionar, limpar e transformar os dados de um sistema. Neste contexto do Big Data, surgem os SGBDs NoSQL com o objetivo de prover uma modelagem de dados simplificada, possibilitando ganhos de desempenho, maior grau de escalabilidade, flexibilidade e disponibilidade.

Por outro lado, os SGBDs NoSQL não são uma novidade simples de ser adotada, mas é possível reconhecer cenários mais adequados para sua adoção. Dentro desse contexto, esta pesquisa contribuiu para identificar os critérios mais importantes para seleção de SGBDs NoSQL, explicitando para as organizações candidatas à adoção de SGBD NoSQL o que elas precisam analisar dentro do seu contexto organizacional. Um elenco de critérios foi compilado e ordenado neste estudo e pode servir de guia para organizações que atuam em um ambiente onde é interessante a adoção de um SGBD NoSQL.

Um aspecto não esperado encontrado neste trabalho foi a identificação de uma nova dimensão em processos de seleção de SGBDs, o Apoio da Comunidade. Como falado anteriormente, este critério foi incluído pelos especialistas na segunda rodada do Painel Delphi e ficou entre os principais critérios do ranking sendo que normalmente este critério não é considerado em processos de seleção, mostrando assim a identificação de uma nova variável a ser considerada em processos de seleção de SGBDs NoSQL.

Deve-se, entretanto, tratar com parcimônia os resultados obtidos neste estudo, dadas as limitações da pesquisa e do fato do conceito NoSQL ser muito recente. 


\section{Referências}

BATINI, C.; CAPPIELlO, C.; FRANCALANCI, C.; MAURINO, A. Methodologies for data quality assessment and improvement. ACM Computing Surveys, v. 41, n. 3, p. 1-52, 2009. Disponível em: <http://portal.acm.org/citation.cfm?doid=1541880.1541883>. Acesso em: 24/5/2013.

BELCHIOR, A. D. Um modelo fuzzy para avaliação da qualidade de software. Rio de Janeiro, 1997. Tese (Doutorado em Engenharia de Sistemas e de Computação) - Programa de Pós-Graduação de Engenharia da Universidade Federal do Rio de Janeiro, COPPE.

BERG, B. L.; LUNE, H. Qualitative research methods for the social sciences. 3a ed. Pearson Boston, 2004.

CERVO, A. L. A. P. A. B. Metodologia científica. $5^{\text {a }}$ ed. São Paulo: Prentice Hall, 2006.

CHANG, F.; DEAN, J.; GHEMAWAT, S. Bigtable: A distributed storage system for structured data. ACM Transactions on Database Systems. Disponível em: <http://dl.acm.org/citation.cfm?id=1365816>. Acesso em: 8/6/2013.

CODD, E. F. Extending the database relational model to capture more meaning. ACM Transactions on Database Systems, v. 4, p. 397-434, 1979. Disponível em: <http://portal.acm.org/citation.cfm?doid=320107.320109>.

CRESWELL, J. W. Projeto de Pesquisa métodos qualitativo, quantitativo e misto. 2a ed. Porto Alegre, 2007.

DATE, J. C. Introdução a Sistemas de Banco de Dados. 7a ed. Education, Pearson, 2004.

DAVIDSON, E. Evaluating database management systems. In Proceedings of the June 7-10, national computer conference (AFIPS '82). ACM, New York, NY, USA, 1982.

DEAN, J.; GHEMAWAT, S. MapReduce: simplified data processing on large clusters. Communications of the ACM, p. 1-13, 2008. Disponível em: <http://dl.acm.org/citation.cfm?id=1327492>. Acesso em: 8/6/2013.

DEWITT, D. AND GRAY, J. Parallel database systems: The future of high performance database systems. Commun. ACM 35. 1992.

DICKSON, G. W.; NECHIS, M. Key information system issues for the 1980's. MIS Quartely, v. 8, n. 3, p. 135-159, 1984.

ELMASRI, R.; NAVATHE, S. B. Sistemas de Banco de Dados. São Paulo - SP: Pearson Education do Brasil, 2005. 
FRIEDMAN, M. A Comparison of Alternative Tests of Significance for the Problem of m Rankings. The Annals of Mathematical Statistics, v. 11, n. 1, p. 86-92, 1940. Disponível em: <http://www.jstor.org/stable/2235971>.

GARTNER. Hype Cycle for Big Data, 2012. Gartner Inc. Disponível em: <http://www.gartner.com/technology/research/methodologies/hype-cycle.jsp>. Acesso em 05/08/2013.

GHAEMI, R., FARD, A. M., TABATABAEE, H., \& SADEGHIZADEH, M.. Evoluntionary query for heterogenous distributed database systems. World Academy of Science, Engineering and Technology, p. 43-49. 2008.

GHEMAWAT, S.; GOBIOFF, H.; LEUNG, S. The Google file system. SIGOPS Oper. Syst. Rev. 37, p. 29-43, 2003. Disponível em: <http://doi.acm.org/10.1145/1165389.945450>.

HALLOWELL, M. R.; GAMBATESE, J. A. Qualitative Research: Application of the Delphi Method to CEM Research. Journal of Construction Engineering and Management, p. 99-107, 2010.

IBRAHIM, A.; AYYUB, B. M. Multi-criteria ranking of components according to their priority for inspection. Fuzzy Sets and Systems, v. 48, n. 1, p. 1-14, 1992. Disponível em: <http://linkinghub.elsevier.com/retrieve/pii/0165011492902472>.

INMON, W. H. Building the Data Warehouse. Fourth ed. John Wiley \& Sons, Inc., New York, NY, USA. 2005.

JOHNSON, N. L.; KOTZ, S.; BALAKRISHNA, N. Continuous Univariate Distributions. 2a ed. New York, NY, USA: Wiley-Interscience Publication, 1970.

KAYO, E. K.; SECURATO, J. R. Método Delphi: fundamentos, críticas e vieses. Cadernos de Pesquisa em Administração, v. 1, p. 51-61, 1997.

KIMBALL, RALPH; ROSS, MARGY. The Data Warehouse Toolkit: guia completo para modelagem dimensional. $2^{\text {a }}$ ed. Rio de Janeiro: Campus, 2002.

KENDALL, M. G.; SMITH, B. B. The problem of m rankings. Annals of Mathematical Statistics, p. 275-287, 1939.

KOSCIANSKI, A.; SOARES, M. Qualidade de software: aprenda as metodologias e técnicas mais modernas para o desenvolvimento de software. $2^{\mathrm{a}}$ ed. São Paulo - SP, 2007.

KOSCIANSKI, A.; VILLAS-BOAS, A.; ASANOME, C.; et al. Guia para utilização das normas sobre avaliaçao de qualidade de produto de software, v. 5, 1999.

LEAVITT, N. Will NoSQL Databases Live Up to Their Promise? IEEE Computer, v. 43, n. 2, p. 12-14, 2010. Disponível em: <http://ieeexplore.ieee.org/lpdocs/epic03/wrapper.htm?arnumber=5410700>.

LLYAS, M. P.; VIJAYAKUMAR, R. A Proxy Based Dynamic Data Management using Hierarchical Database for Location Based Services. In Proceedings of the International 
Conference and Workshop on Emerging Trends in Technology (ICWET '10). ACM, New York, NY, USA, 75-80. Disponível em <http://doi.acm.org/10.1145/1741906.1741920>, 2010.

LÓSCIO, B. F.; OLIVEIRA, H. R.; PONTES, J. C. S. NoSQL no desenvolvimento de aplicaçoes Web colaborativas. VIII Simpósio Brasileiro de Sistemas Colaborativos, 2011.

MARCONI, M. DE A.; LAKATOS, E. M. Fundamentos de metodologia científica. $6^{\text {a }}$ ed. São Paulo: Atlas, 2007.

MARTINO, J. P. Technological forecasting for decision making. McGraw-Hill Engineering and Technology Management Series. 3rd ed, 1993.

MIN, H. Selection of Software: The Analytic Hierarchy Process. International Journal of Physical Distribution \& Logistics Management, p. 42-52, 1992.

NOAMAN, A. Y. Distributed data warehouse architecture and design. Winnipeg, Canada, 2000. Tese (Doutorado em Filosofia em Ciências da Computação) - The University of Manitoba (Canada).

POKORNY, J. NoSQL databases. A step to database scalability in web environment. In Proceedings of the 13th International Conference on Information Integration and Webbased Applications and Services (iiWAS '11). ACM, New York, NY, USA, 278-283, 2011. DOI=10.1145/2095536.2095583 http://doi.acm.org/10.1145/2095536.2095583.

O`NEIL, P.; D. Q. Improved query performance with variant indexes. ACM SIGMOD Record, v. 26, n. 2, p. 38-49, 1997.

Oracle Key-Value Pairs, 2011. Disponível em: <http://www.oracle.com/technetwork/products/nosqldb/overview/key-value-497224.html>. Acesso em: 10/10/2012.

PMBOK. A Guide to the Project Management Body of Knowledge (PMBOK Guides). Project Management Institute. 2004.

PRESSMAN, R. A. Software engineering: a practitioner's approach. 5th ed. New York: Thomas Casson, 2001.

RAHIEN, A. That No SQL Thing: Column (Family) Database,2010. Disponível em: $<$ http://ayende.com/blog/4500/that-no-sql-thing-column-family-databases $>$. Acesso em $14 / 01 / 2013$.

RAMAKRISHNAN, R.; GEHRKE, J. Sistemas de gerenciamento de banco de dados. $3^{\mathrm{a}}$ ed. McGraw-Hill Interamericana do Brasil Ltda, 2003.

REDMOND, E.; WILSON, J. R. Seven Databases in Seven Weeks A Guide to Modern Databases and the NoSQL Movement. Dallas: Copyright (c) 2012 Pragmatic Programmers, LLC., 2012. 
ROCHA, A. R. C. DA; MALDONADO, J. C.; WEBER, K. C. Qualidade de Software Teoria e Pratica. Pearson Education do Brasil/Makron Books Ltda., v. 1, 2001.

SADALAGE, P. J.; FOWLER, M.; RIVER, U. S. NoSQL distilled: a brief guide to the emerging world of polyglot persistence. Pearson ed. 2013.

SAKR, S.; LIU, A.; BATISTA, D. M.; ALOMARI, M. A Survey of Large Scale Data Management Approaches in Cloud Environments. IEEE Communications Surveys \& Tutorials, v. 13, n. 3, p. 311-336, 2011. Disponível em: <http://ieeexplore.ieee.org/lpdocs/epic03/wrapper.htm?arnumber=5742778>.

SCHMIDT, R. C. Managing Delphi Surveys Using Nonparametric Statistical Techniques. Decision Sciences, v. 28, n. 3, p. 763-774, 1997. Disponível em: <http://doi.wiley.com/10.1111/j.1540-5915.1997.tb01330.x>.

STONEBRAKER, M. Stonebraker on NoSQL and enterprises. Communications of the ACM, v. $54, \quad$ n. $8, \quad$ p. $10, \quad 2011 . \quad$ Disponível em: <http://portal.acm.org/citation.cfm?doid=1978542.1978546>. Acesso em: 8/9/2011.

STRONG, D. M.; LEE, Y. W.; WANG, R. Y. Data Quality in Context. Commun. ACM 40, , 103-110. 1997.

STYLIANOU, A. C.; KUMAR, R. L. An integrative framework for IS quality management. Commun. ACM, v. 43, n. 9, p. 99-104, 2000. Disponível em: <http://doi.acm.org/10.1145/348941.349009>.

TAYLOR, P.; LEE, D.; LIANG, S. H. L. International Journal of Geographical Geopot: a Cloud-based geolocation data service for mobile applications. International Journal of Geographical Information Science, p. 37-41, 2011.

TERENCE, J.; WRIGHT, C.; GIOVINAZZO, R. A. DELPHI Uma ferramenta de apoio ao planejamento prospectivo. Caderno de Pesquisas em Administração (USP), São Paulo, v. 1, n. 0, p. 54-65, 2000.

TIWARI, S. Professional NoSQL. Indianapolis: John Wiley \& Sons, Inc., 2011.

TODAY, I.; PIKE, O. M. NoSQL and Document-Oriented Databases, 2010.

TUDORICA, B. G.; BUCUR, C. A comparison between several NoSQL databases with comments and notes. Roedunet International Conference (RoEduNet), 2011 10th , p. 1,5, 23$25,2011$.

VIJAYKUMAR, S. Implementation of NOSQL for robotics," Emerging Trends in Robotics and Communication Technologies (INTERACT), International Conference on , vol, no., pp.195,200, 3-5, 2010.

WHITE, C. A technical Architecture for Data Warehousing. InfoDB Journal, 1995. 
XIANG, P.; HOU, R.; ZHOU, Z. Cache and consistency in NOSQL. 2010 3rd International Conference on Computer Science and Information Technology, p. 117-120, 2010. IEEE. Disponível em: <http://ieeexplore.ieee.org/lpdocs/epic03/wrapper.htm?arnumber=5563525>.

YE, Z.; LI, S. A request skew aware heterogeneous distributed storage system based on Cassandra. Computer and Management (CAMAN), 2011 International Conference on , vol, no., p.1,5, 19-21, 2011. 


\section{APÊNDICE}

APÊNDICE A - Questionário Painel Delphi

APÊNDICE B - Questionário para mapeamento de perfil de especialistas

APÊNDICE C - Carta convite para participação da primeira rodada do Painel Delphi

APÊNDICE D - Carta lembrete para participação do Painel Delphi

APÊNDICE E - Carta convite para participação da segunda rodada do Painel Delphi e informativo do resultado da primeira rodada 


\section{APÊNDICE A}

USP - Universidade de São Paulo

EACH - Escola de Artes Ciências e Humanidades

PPGSI - Programa de Pós-graduação em Sistemas de Informação

Pesquisa "Critérios de Seleção de Sistemas de Gerenciamento de Banco de Dados Não Relacionais em Organizações Privadas"

Assinale com "X" o grau de importância que você atribui para os critérios abaixo relacionados no processo de seleção de SGBDs NoSQL, ou seja, a importância que você atribui para cada critério para se escolher um banco de dados não relacional. (escolha apenas um grau de importância para cada item)

\begin{tabular}{|c|c|c|c|c|c|c|}
\hline Características do Fornecedor & Nenhuma & $\begin{array}{l}\text { Muito } \\
\text { pouca }\end{array}$ & Pouca & Moderada & Muita & Total \\
\hline $\begin{array}{l}\text { C1 Reputação (A característica de reputação está relacionada com a boa reputação do } \\
\text { fornecedor para responder aos pedidos de informação, lidar com os problemas relatados } \\
\text { com o SGBD e fornecer apoio técnico). }\end{array}$ & $\square$ & $\square$ & $\square$ & $\square$ & $\square$ & $\square$ \\
\hline $\begin{array}{l}\text { C2 Suporte (Comunicação de problemas / Notificação de problemas / mecanismos de } \\
\text { alarmes / Suporte para instalação). }\end{array}$ & $\square$ & $\square$ & $\square$ & $\square$ & $\square$ & $\square$ \\
\hline $\begin{array}{l}\text { C3 Recursos adicionais oferecidos (Base de dados de teste / treinamento oferecido / } \\
\text { disponibilidade de serviços de venda (disponibilidade de ajuda dos fornecedores sobre o } \\
\text { SGBD)). }\end{array}$ & $\square$ & $\square$ & $\square$ & $\square$ & $\square$ & $\square$ \\
\hline C4 Capacidade de investimento (Previsão de melhorias futuras). & $\square$ & $\square$ & $\square$ & $\square$ & $\square$ & $\square$ \\
\hline \multicolumn{7}{|l|}{ Características do Produto } \\
\hline $\begin{array}{l}\text { C5 Desempenho (Otimização de consultas / execução nativa ou modo compatibilidade / } \\
\text { capacidade de múltiplas bases / comportamento temporal / utilização de recursos). }\end{array}$ & $\square$ & $\square$ & $\square$ & $\square$ & $\square$ & $\square$ \\
\hline $\begin{array}{l}\text { C6 Recursos de Administração (Dicionário de Dados /Ferramentas de administração de } \\
\text { dados / manuais técnicos). }\end{array}$ & $\square$ & $\square$ & $\square$ & $\square$ & $\square$ & $\square$ \\
\hline $\begin{array}{l}\text { C7 Disponibilidade (Disponibilidade da base de dados enquanto são realizadas funções de } \\
\text { administração de dados / Processamento concorrente). }\end{array}$ & $\square$ & $\square$ & $\square$ & $\square$ & $\square$ & $\square$ \\
\hline
\end{tabular}


Nenhuma Muito Pouca Moderada Muita Total

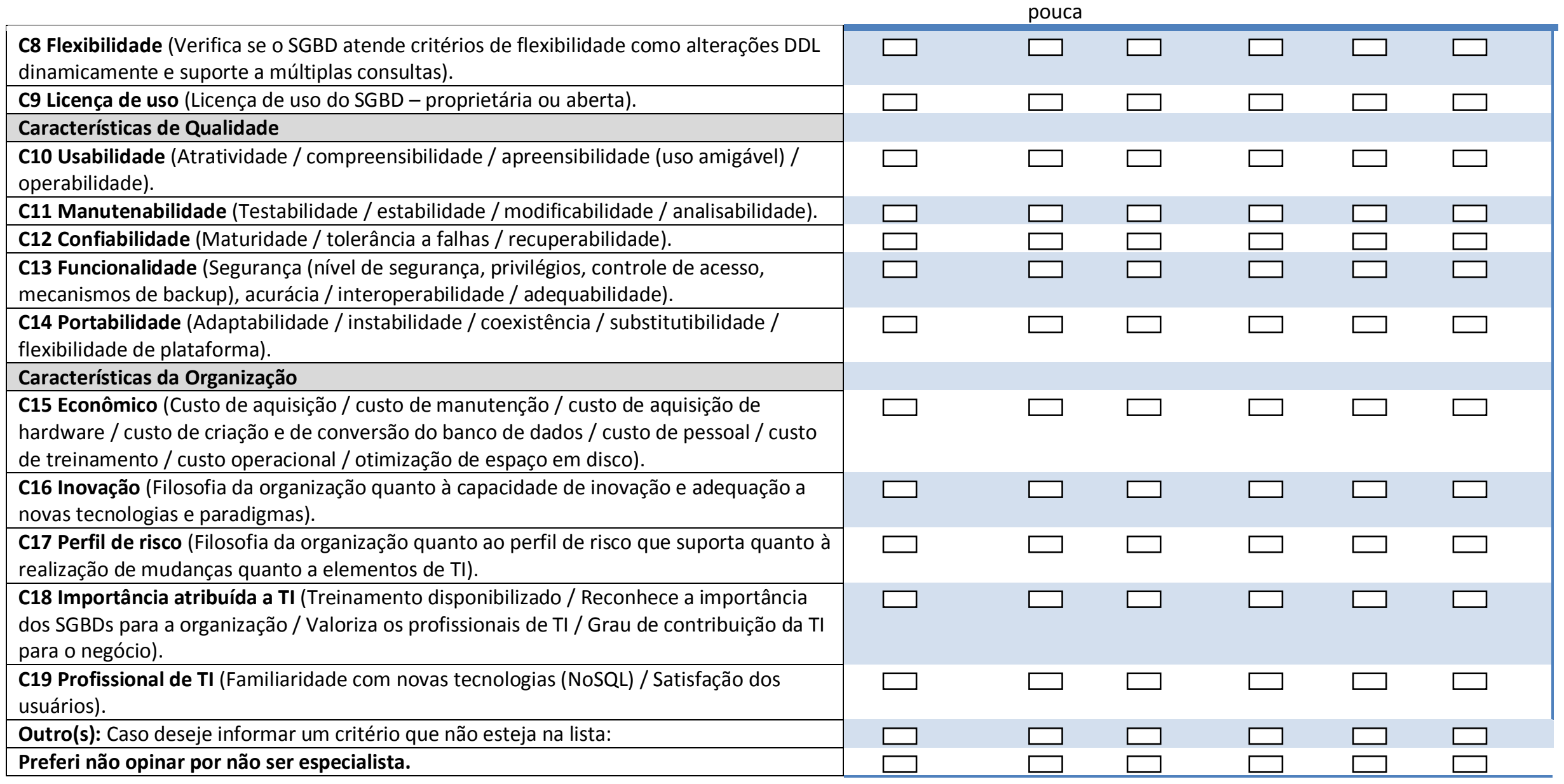




\section{APÊNDICE B}

\section{Questionário para mapeamento de perfil de especialistas}

1. Nome do entrevistado

2.a Quantos anos de experiência na área de TI?
a) menos 1 ano
b) 1 a 3 anos
c) 3 a 5 anos
d) 5 a 10 anos
e) mais de 10 anos

2.b Qual sua experiência com banco de dados
a) nenhuma
b) conhecimento SGBDs relacionais
c) conhecimento SGBD relacionais e NoSQL
d) já participei de projetos ou banco de dados
e) domínio e atuação na área de banco de dados

3. Já participou de algum processo de seleção de SGBD para o desenvolvimento de um novo sistema?
a) $\operatorname{sim}$ b) não

4.a Qual sua formação acadêmica
a) curso técnico
b) superior
c) pós-graduação
d) mestrado
e) doutorado / pós doc

4.b Dentre a(s) formação(es) escolhida(s) acima, indique apenas as que estão relacionadas com a área de Sistemas / Computação / TI
a) curso técnico
b) superior
c) pós-graduação
d) mestrado
e) doutorado / pós doc 
Caso for desenvolvedor, responda as próximas duas questões:

5. Já desenvolveu aplicações suportadas por SGBDs NoSQL?

a) $\operatorname{sim}$ b) não

6. Se sim, indique o grau de domínio que possui no desenvolvimento de aplicações suportadas por SGBDs NoSQL:
a) Nenhum
b) Muito pouco
c) Pouco
d) Moderado
e) Muito
f) Total 


\section{APÊNDICE C}

UNIVERSIDADE DE SÃO PAULO

Escola de Artes, Ciências e Humanidades

Prezado,

Sou mestrando da Escola de Artes, Ciência e Humanidades da USP, e Administrador de Banco de Dados e estou desenvolvendo uma pesquisa referente à minha dissertação:

\section{Critérios de Seleção de Sistemas de Gerenciamento de Banco de Dados Não Relacionais em Organizações Privadas}

a qual propõe um procedimento de avaliação para seleção de SGBDs NoSQL.

Conforme contato pessoal, telefônico ou por e-mail, solicito a sua importante participação neste Painel de Especialistas em Banco de Dados, respondendo ao questionário de uma pesquisa Delphi.

A pesquisa Delphi é feita em várias rodadas procurando-se obter o consenso do Painel de Especialistas.

- Nesta primeira rodada você está sendo solicitado a definir o grau de importância que você atribui a 19 critérios considerados a partir da revisão da literatura e que deverão ser utilizados na avaliação para seleção de SGBD NoSQL.

- Caso ache necessário, você pode incluir algum critério que não esteja relacionado na lista e definir o seu grau de importância.

- Na próxima rodada você será apresentado ao resultado desta primeira e será solicitado a informar a sua aceitação ou rejeição ao resultado, justificando o motivo. Apenas quem respondeu o questionário da primeira rodada participará desta segunda.

- Em uma eventual terceira rodada, apenas os critérios que não foram totalmente aceitos serão novamente colocados em discussão. Pode ocorrer que aqueles que não tenham tido aceitação plena sejam excluídos, não havendo, portanto a necessidade dessa terceira rodada.

O questionário encontra-se em: http://www.surveymonkey.com/s/NGN25TR

Ao iniciar o questionário você será solicitado a informar o seu nome. Essa informação é enviada ao e-mail independente, e será preservado o anonimato das respostas que é um dos princípios básicos do painel Delphi. 


\title{
APÊNDICE D
}

\author{
UNIVERSIDADE DE SÃO PAULO
}

Escola de Artes, Ciências e Humanidades

Prezado,

Observei que até o momento não recebi resposta sobre a primeira fase do Painel Delphi referente à dissertação:

\section{Critérios de Seleção de Sistemas de Gerenciamento de Banco de Dados Não Relacionais em Organizações Privadas}

A qual se encontra em: http://www.surveymonkey.com/s/NGN25TR

A sua participação é muito importante e não leva mais que 10 minutos. O questionário ficará disponível até o dia 15/01.

Obrigado

Alexandre M. de Souza 


\title{
APÊNDICE E
}

\author{
UNIVERSIDADE DE SÃO PAULO
}

Escola de Artes, Ciências e Humanidades

\section{Prezado colaborador}

Inicialmente agradeço a sua paciência na resposta à primeira rodada da pesquisa Delphi destinada a definir os principais critérios de seleção de SGBD NoSQL.

Conforme informado anteriormente, a Técnica Delphi consiste em diversas rodadas. Chegamos à segunda delas. Lembre-se, por favor, que essa técnica procura obter o consenso de opiniões. Peço-lhe, então, um pouco mais de paciência.

Agora o processo ocorre da seguinte maneira: face ao resultado da primeira rodada é solicitado aos participantes optar se deseja manter a resposta dada na primeira rodada ou se pretende mudar sua opinião. É importante ressaltar que não é obrigatória a mudança na resposta.

Foi feito um relatório completo que resume o resultado obtido com a primeira rodada do painel e está disponível no link abaixo e ao lado está aberta uma caixa para nova resposta. Lembrando que é permitido manter a resposta anterior. Ao final foram incluídos mais dois critérios que são sugestões da rodada anterior. Peço que marque, tal como foi feito na primeira rodada, o grau de importância que atribui para estes critérios no contexto de SGBD NoSQL: 


\begin{tabular}{|c|c|c|c|c|c|c|c|c|c|c|}
\hline Critério & Nenhuma & $\begin{array}{l}\text { Muito } \\
\text { pouca }\end{array}$ & Pouca & Moderada & Muita & Total & Pontuação & Classificação & $\begin{array}{l}\text { Resposta } \\
\text { Anterior }\end{array}$ & $\begin{array}{c}\text { Nova } \\
\text { Resposta }\end{array}$ \\
\hline C12 Confiabilidade & 0,0 & 0,0 & 3,1 & 6,3 & 34,4 & $\begin{array}{r}203 \\
4\end{array}$ & 0,0 & 0,0 & & \\
\hline C7 Disponibilidade & 0,0 & 0,0 & 3,1 & 3,1 & 50,0 & $\begin{array}{r}198, \\
8\end{array}$ & 0,0 & 0,0 & & \\
\hline C5 Desempenho & 0,0 & 0,0 & 3,1 & 3,1 & 40,6 & $\begin{array}{r}0 \\
196, \\
5\end{array}$ & 0,0 & 0,0 & & \\
\hline C8 Flexibilidade & 0,0 & 0,0 & 9,4 & 15,6 & 56,3 & $\begin{array}{r}173, \\
7\end{array}$ & 0,0 & 0,0 & & \\
\hline $\begin{array}{l}\text { C11 } \\
\text { Manutenabilidade }\end{array}$ & 0,0 & 0,0 & 9,4 & 18,8 & 53,1 & $\begin{array}{r}172, \\
4\end{array}$ & 0,0 & 0,0 & & \\
\hline C13 Funcionalidade & 0,0 & 3,1 & 12,5 & 18,8 & 46,9 & $\begin{array}{r}166, \\
4\end{array}$ & 0,0 & 3,1 & & \\
\hline $\begin{array}{l}\text { C4 Capacidade de } \\
\text { investimento }\end{array}$ & 0,0 & 0,0 & 0,0 & 43,8 & 46,9 & $\begin{array}{r}162, \\
9\end{array}$ & 0,0 & 0,0 & & \\
\hline C15 Econômico & 3,2 & 3,2 & 9,7 & 29,0 & 29,0 & $\begin{array}{r}157, \\
1\end{array}$ & 3,2 & 3,2 & & \\
\hline C1 Reputação & 0,0 & 0,0 & 15,6 & 40,6 & 34,4 & $\begin{array}{r}156, \\
5\end{array}$ & 0,0 & 0,0 & & \\
\hline C9 Licença de uso & 0,0 & 3,2 & 19,4 & 35,5 & 22,6 & $\begin{array}{r}152, \\
0\end{array}$ & 0,0 & 3,2 & & \\
\hline $\begin{array}{l}\text { C6 Recursos de } \\
\text { Administração }\end{array}$ & 0,0 & 12,5 & 3,1 & 37,5 & 37,5 & $\begin{array}{r}150, \\
6 \\
\end{array}$ & 0,0 & 12,5 & & \\
\hline $\begin{array}{l}\text { C19 Profissional de } \\
\text { TI }\end{array}$ & 3,3 & 0,0 & 20,0 & 30,0 & 30,0 & $\begin{array}{r}143, \\
9\end{array}$ & 3,3 & 0,0 & & \\
\hline C2 Suporte & 0,0 & 6,5 & 22,6 & 29,0 & 32,3 & $\begin{array}{r}142, \\
3\end{array}$ & 0,0 & 6,5 & & \\
\hline C17 Perfil de risco & 3,1 & 3,1 & 12,5 & 43,8 & 34,4 & $\begin{array}{r}141, \\
9\end{array}$ & 3,1 & 3,1 & & \\
\hline $\begin{array}{l}\text { C18 Importância } \\
\text { atribuída a TI }\end{array}$ & 3,2 & 6,5 & 19,4 & 32,3 & 25,8 & $\begin{array}{r}138, \\
7\end{array}$ & 3,2 & 6,5 & & \\
\hline C16 Inovação & 3,1 & 12,5 & 9,4 & 34,4 & 34,4 & $\begin{array}{r}138, \\
0\end{array}$ & 3,1 & 12,5 & & \\
\hline C10 Usabilidade & 0,0 & 6,3 & 25,0 & 40,6 & 18,8 & $\begin{array}{r}137, \\
0\end{array}$ & 0,0 & 6,3 & & \\
\hline C14 Portabilidade & 0,0 & 12,5 & 21,9 & 31,3 & 28,1 & $\begin{array}{r}130, \\
8\end{array}$ & 0,0 & 12,5 & & \\
\hline $\begin{array}{l}\text { C3 Recursos } \\
\text { adicionais oferecidos }\end{array}$ & 3,1 & 6,3 & 31,3 & 46,9 & 9,4 & $\begin{array}{r}119, \\
0\end{array}$ & 3,1 & 6,3 & & \\
\hline \multicolumn{11}{|l|}{$\begin{array}{l}\text { C20 SGBD Open } \\
\text { Source* }\end{array}$} \\
\hline \multicolumn{11}{|l|}{$\begin{array}{l}\text { C21 Apoio da } \\
\text { Comunidade* }\end{array}$} \\
\hline $\begin{array}{l}\text { C22 Escalabilidade } \\
\text { horizontal* }\end{array}$ & & & & & & & & & & \\
\hline
\end{tabular}

\section{*Novos Critérios}

Atenciosamente,

Alexandre Morais de Souza 


\section{ANEXOS}

ANEXO A - Fórmulas e variáveis para os cálculos realizados no Painel Delphi 


\section{ANEXO A}

\begin{tabular}{lll}
\hline & \multicolumn{1}{c}{ Variável / Definição } & \multicolumn{1}{c}{ Fórmula } \\
\hline \hline$R_{k}$ & $\begin{array}{l}\text { Soma dos ranks de um elemento } k \text { em jlistas ordenadas } \\
\text { elaboradas num tema de um painel; indica a posição do } \\
\text { elemento na lista ordenada coletiva }\end{array}$ & $R_{k}=\sum_{j} r a n k_{k j}$ \\
\hline$n$ & Quantidade de elementos em uma lista ordenada & \\
\hline$m$ & $\begin{array}{l}\text { Quantidade de listas individuais ordenadas elaboradas } \\
\text { num tema de um painel }\end{array}$ \\
\hline $\bar{x}$ & $\begin{array}{l}\text { Média da soma dos ranks do total de elementos de um } \\
\text { conjunto de listas ordenadas elaboradas num tema de } \\
\text { um painel }\end{array}$ & $\bar{x}=m(n+1) / 2$ \\
\hline$X_{k}$ & $\begin{array}{l}\text { Diferença entre a soma dos ranks de um elemento } k \text { e a } \\
\text { média }\end{array}$ & $X_{k}=R_{k}-\bar{x}$ \\
\hline$Y_{k}$ & $\begin{array}{l}\text { Quadrado da diferença entre a soma dos ranks de um } \\
\text { elemento } k \text { e a média }\end{array}$ & $Y_{k}=X_{k}{ }^{2}$ \\
\hline$S$ & $\begin{array}{l}\text { Soma dos quadrados das diferenças entre a soma dos } \\
\text { ranks de um elemento } k \text { e a média }\end{array}$ & $S=\sum_{k} Y_{k}$ \\
\hline$W$ & $\begin{array}{l}\text { Coeficiente de concordância } \\
\text { phiara avaliar a significância de } W\end{array}$ & $W=S /\left(\left(n^{3}-n\right) m^{2} / 12-m \sum_{j}\right)$ \\
\hline$\chi^{2}$ & $\begin{array}{l}\text { Chi-quadrado, com }(n-1) \text { graus de liberdade, utilizado } \\
\text { para }\end{array}$ & $\chi^{2}=m(n-1) W$ \\
\hline
\end{tabular}

